This item was submitted to Loughborough's Research Repository by the author.

Items in Figshare are protected by copyright, with all rights reserved, unless otherwise indicated.

\title{
Human resource management, complementarity and organisational performance
}

\section{PLEASE CITE THE PUBLISHED VERSION}

https://www.bam.ac.uk/civicrm/event/info?id=3638

\section{PUBLISHER}

British Academy of Management

VERSION

AM (Accepted Manuscript)

LICENCE

CC BY-NC-ND 4.0

\section{REPOSITORY RECORD}

Ali, Manhal, Reza Salehnejad, and Peter Kawalek. 2020. "Human Resource Management, Complementarity and Organisational Performance". Loughborough University. https://hdl.handle.net/2134/12576665.v1. 


\title{
Human Resource Management, Complementarity and Organisational Performance
}

\author{
Manhal Ali ${ }^{* 1}$, Reza Salehnejad ${ }^{\dagger 2}$, and Peter Kawalek $\ddagger 3$ \\ ${ }^{1}$ Leeds University Business School, University of Leeds, Leeds, UK \\ ${ }^{2}$ Alliance Manchester Business School, University of Manchester, Manchester, UK \\ ${ }^{3}$ School of Business and Economics, Loughborough University, Loughborough, UK
}

June 2020

\begin{abstract}
A feature of public sector organisations is the presence of substantial variations in productivity. What drives organisational productivity and its persistence? Using a rich panel on NHS hospitals in England, we trace the variation in productivity back to differences in clusters of complementary management practices. We introduce the indeterminacy effect of management practices, provide systematic evidence on the non-linearity effect and the complementarity effect of the practices, and identify several practically significant clusters of management practices involving incentives, workplace flexibility, job training, team quality and job design. The complementary character of management practices explains why low performing organisations remain low performing over time.
\end{abstract}

Keywords: Public sector organisations, Healthcare, Human Resource Management, NHS, Complementarity, Cluster analysis, Correlated Random Effects, Productivity, Quality Adjustment

JEL codes: I1, M5, M20, D22, C1, L2

\footnotetext{
*Corresponding author: M.M.Ali@leeds.ac.uk

$\dagger$ reza.salehnejad@manchester.ac.uk

†P.Kawalek@lboro.ac.uk
} 


\section{Introduction}

A quotidian feature of public healthcare organisations is the presence of substantial variations in both productivity and patient outcomes (Branch et al., 2012). In a major study of US hospitals, Chandra et al. (2016) found material differences in both productivity (Total Factor Productivity, TFP) and heart attack survival rates. Moreover, these are related: a patient treated at a $90^{\text {th }}$ percentile productivity hospital is expected to survive more than 1.55 times longer than one treated similarly at a $10^{\text {th }}$ percentile hospital. In the UK, Castelli et al. (2015) and Aragon et al. (2017) found material productivity variation between English NHS acute hospital organisations (also known as hospital trusts). 90 $0^{\text {th }}$ productivity percentile hospitals are 1.54 times more productive than those in the $10^{\text {th }}$ percentile. Figure 1 plots the data they construct. Furthermore, productivity dispersion persists over time. Regressing these productivity measures on their one-year lags yields autoregressive coefficients 0.86 and 0.93 respectively: productive hospitals tend to remain so.
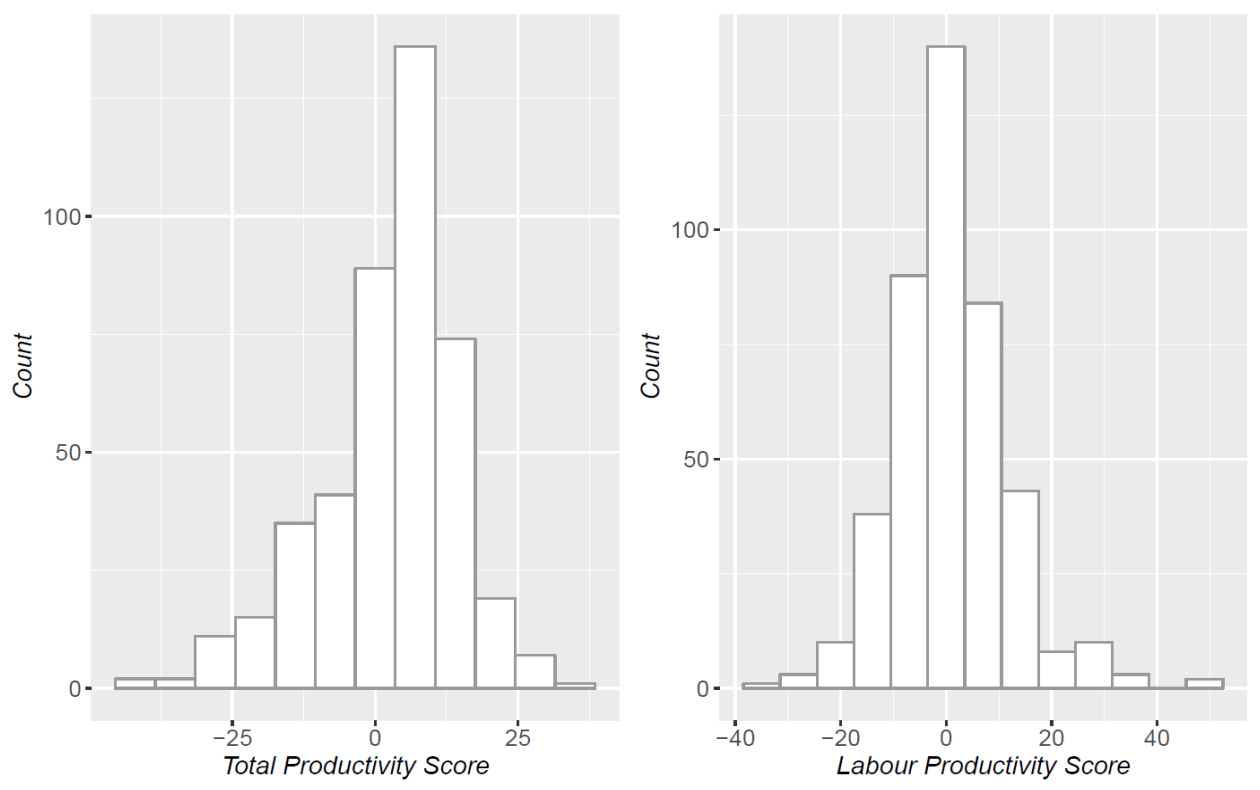

Figure 1: Variations in Productivity (Total and Labour) across NHS Trusts 2010/11 to 2012/13

Healthcare systems worldwide are under severe pressure from ageing populations, rising costs of medical technologies, increasing expectations and tight budgets. Given the evidence of enormous variations in efficiency levels among public health organisations, there appear to be large opportunities to mitigate these pressures using current resources. Any effort at improving performance demands understanding of why some hospitals perform better. This paper investigates drivers of the performance heterogeneity by focusing on clusters of management practices. 
The literature offers a rich list of explanations for the heterogeneity in performance. A series of papers refers to internal drivers. Rafferty et al. (2007) and Needleman et al. (2011) find a positive relationship between human capital (e.g. nurse staffing) and healthcare quality. Menachemi et al. (2008), Miller and Tucker (2011), McCullough et al. (2013) and Dranove et al. (2014) identify a positive relationship between health information technology and outcomes. Gaynor et al. (2005), O'Brien et al. (2008) and Hentschker and Mennicken (2014) document a positive relationship between hospital volume and quality of care, and productivity.

Another body of literature examines the role of external factors. A key result is that competition, provided prices are regulated, has a positive impact on healthcare productivity (Bijlsma et al., 2013; Bloom et al., 2015; Chandra et al., 2015; Propper, 2012). Other researchers have studied the impacts of government policies (Gaynor et al., 2012), public reporting of performance (Gupta, 2017) and provision of information (Katz, 2013).

A fundamental insight from the empirical literature is that variations in physical assets, human capital and technologies across hospitals only partially account for the productivity dispersion (Bradley et al., 2012, 2010; Hoeks et al., 2010; Roland and Rosen, 2011). "Finer" measures of human capital and technology would still leave the dispersion largely unexplained (Bender et al., 2016; Cummins and Violante, 2002; Galindo-Rueda and Haskel, 2005; Sakellaris and Wilson, 2004). Critically, the impact of factors such as human capital and technology on performance depends on complementary managerial practices and organisational features (Bresnahan et al., 2002).

These findings have led attention towards management practices and organizational factors (Janke et al., 2018). Bloom et al. (2014), McConnell et al. (2014), Rumbold et al. (2015) and Bloom et al. (2015) find that the quality of management practices and hospital performance are highly correlated, suggesting a possible role of management practices. The evidence is that, as it is the organization of resources and management routines that ultimately link hospital inputs to outputs, then as the organizational characteristics of a hospital change, so does the production function (May, 1947).

This study will build on this emerging literature that argues for the impact of management practices. We distinguish between Operation Management (OM) and Human Resource Management (HRM) practices (Siebers et al., 2008). OM practices include information and communication technology, process control, Just-in-Time and lean practice methods. HRM practices relate to functions such as recruitment, training, performance appraisal, opportunities to develop, flexible work schemes, social securities and labour welfare. Bartel (2004) finds that more innovative HRM practices lead to higher performance in the banking sector. Ichniowski and 
Shaw (1999) provide evidence on the impact of innovative HRM systems in the steel industry. Black and Lynch (2004) argue that workplace innovations such as employee involvement and profit sharing played a pivotal role in the surge in productivity in the 1990s. West et al. (2002, 2006) and Vermeeren et al. (2014) document a strong association between HRM practices and performance in healthcare. Our aim is to extend the study of the role of HRM practices to the public sector, where labour accounts for the major costs of production. Our first hypothesis runs as:

HRM Hypothesis: Human resource management matters. Typical practices such as training and development, appraisal, team work, engagement, flexible working practices and employee.

The theory, however, emphasises the importance of complementarities. Management practices complement each other and their total impact is larger than the sum of their individual impacts when they are utilized in conjunction (Holmstrom and Milgrom, 1994). Teams are more effective in organisations where they are complemented by group incentives, training, effective communication and work-place flexibility (Brynjolfsson and Milgrom, 2013; Milgrom and Roberts, 1995). Organizations that complement management practices with enhanced compensation policies experience higher productivity (Ichniowski et al., 1997). It is clusters of complementary management practices that shape performance, not individual practices. An otherwise optimal management practice may alone have no impact. There are significant complementarities between managerial and organizational practices (West et al., 2006). There are also complementarities between management practices and other production inputs such as human capital (Milgrom and Roberts, 1990) and firm characteristics (e.g., decentralization) (Bloom et al., 2012). Alternative alignments of management practices and hospital characteristics give rise to different productivity levels. Our second and more central hypothesis runs as:

Complementarity Hypothesis: Variations in clusters of management practices are partly responsible for the productivity dispersion. The total impact of management practices in organisations where they are implemented as a package are likely to be larger.

The above analysis suggests that when some members of a complementary set of practices are absent, the incomplete cluster may have little or no impact. Further, the quality or strength of a complementary practice may require to reach a threshold to have any impact (Meagher and Strachan, 2013). Weak management practices may have no noticeable impact. These intuitions point to the non-linear effect of management practices: 
Non-linearity Hypothesis: Management practices require to reach certain thresholds to have any impact on performance. Otherwise, they may have no noticeable effect.

We construct a panel on drivers of hospital productivity for the years 2010/11 to 2012/13. We borrow the data on the total factor and labour productivity measures from Aragon et al. (2015). We use a measure of patient satisfaction with hospital services to construct quality adjusted productivity measures. We draw on the NHS Staff Survey to construct measures of HRM practices. The panel helps shed light on specific channels through which management practices shape productivity. As a methological innovation, we first employ machine learning clustering techniques to identify clusters of HRM practices and next test the significance of the clusters using econometrics techniques. We take some steps to address endogeneity issues and the robustness of the results.

We make several contributions. We introduce and provide evidence on the non-linearity effect, provide systemic evidence on the complementarity effect, document the effect of clusters of management practices, and identify several practically significant clusters of management practices. We provide evidence that workplace flexibility improves productivity only with proper incentives. Workforce training gives rise to higher productivity only when it is complemented with adequate incentives. Only when jobs are well designed, teams are well structured and proper incentives are simultaneously in place, staff enjoys higher productivity. Our results on the cluster effect of HRM practices suggest that the focus of policy should be on clusters of best practices, not individual practices. The results explain why it is challenging to imitate good management practices, showing that good practices come in forms of clusters and that adopting individual practices will be ineffective. While our data come form the healthcare sector, the empirical validity of the findings extend to the public sector at large (Brown, 2004; Gould-Williams, 2003). For brevity, we only report the key findings in the text, and delegate extra expositions and full results to an online supplementary file.

\section{Productivity Measures, Data and Descriptive Statistics}

Productivity is defined as the ratio of outputs to inputs. The productivity of a single hospital can be measured as:

$$
\text { Productivity of hospital trust } h=\frac{\text { Outputs }_{h}}{\text { Inputs }_{h}}
$$

In the NHS, Castelli et al. (2015), Aragon et al. (2015), Jones and Charlesworth (2013) and Dunleavey and Carrera (2010) measure productivity as the ratio of total output produced to total 
input expenditure incurred to produce the output. Hospital output includes all healthcare goods and services that are delivered. Hospital inputs include labour, capital and intermediate production factors (e.g., drugs) (Aragon et al., 2015). If the inputs used in measuring productivity only consist of labour, the measure is known as labour productivity. If the inputs encompass all of a hospital's inputs, the measure is called total factor productivity (TFP). Our productivity data come from Aragon et al. (2015), who build cost-adjusted labour and total factor productivity measures for all NHS hospitals in England, using Hospital Episode Statistics (HES) from NHS Digital and Reference Cost (RC) database. The productivity measures are obtained by standardising each hospital's TFP and labour productivity score using the national averages to provide a relative-percentage interpretation. If a hospitals' $h$ productivity score is 10.5 , this implies that the hospital is $10.5 \%$ more productive compared to the national average. The online supplementary file fully describes the construction of the measures.

Measuring hospital performance requires a quality-adjusted productivity measure. We follow Dunleavey and Carrera (2010) in using patient satisfaction as our quality indicator to adjust the productivity measures. Using patient experience attenuates the case-mix adjustment bias affecting mortality and readmission rates. We take the data for patient experience from the NHS Adult Inpatient and Outpatient Surveys. Inpatient patient experience scores are summarized on a scale of $0-100$ and calculated as average of five domains: access and waiting, quality of care, information and choice, building closer relationships, cleanliness and comfort. Patient experience of outpatient services is scored between $0-100$ and is measured as an average of five questions across the care pathway: pre-visit, during the visit and the post-visit-period. Both scores are weighted by age and gender to avoid case-mix adjustment bias. We arrange the satisfaction scores in an ascending order and divide them into five equally spaced intervals. A quality weighting factor for each of these intervals is created and are assigned to each hospital $h$ depending on their satisfaction score. The weighting factor ranges from 0.2 to 1 in increments of 0.2 , where 0.2 represents lowest possible weight and 1 represents maximum. We multiply the quality adjustment factors with the cost-weighted output for each hospital and divide it by its total inputs. The final measure is standardised to obtain relative productivity scores. The online appendix explains the construction of the weighted measures in detail. The online appendix also considers adjusting the productivity measures using Hospital Standardised Mortality Ratio.

Data on HRM practices are from NHS Staff Surveys (NSS) for the years 2010 to 2012. We select $10 \mathrm{HRM}$ practices from the survey, including several variables that reflect senior management practices and leadership quality. They are decentralization of decision making 
(Decisions), suggesting ideas for improving services (Ideas), effective communication between senior management and staff (Communication), and senior managers acting on staff feedback (Feedback). The responses on survey questions for these variables are Likert type measured on a five point scale from strongly disagree to strongly agree. We construct the metrics by taking their Positive Response Rate (PRR) i.e. the percentage of respondents who agree or strongly agree. The four practices constitute the key elements of Appelbaum et al. (2000) highperformance work system and measure staff's perceptions of the HRM environment. We add several other HRM variables:

Team Quality measures team effectiveness. The index is constructed by taking the average of PRR of three questions: team members often discuss team effectiveness, communicate closely with each other and have a set of shared objectives. Flexible measures the percentage of respondents who are using flexible working options. Training measures the percentage of respondents who had on-the-job training. The data for 2012 are estimated using the average of values for 2010 and 2011. Intention to Leave measures the extent to which staff are considering leaving their organisation. We take the variable as an indirect measure of the adequacy of incentives. Data for 2012 are mean imputed. Job-Satisfaction reflects the extent to which employees are satisfied with the recognition they receive for good work and the extent to which their work is valued. Job-Design measures the extent to which jobs have clear goals, provide clear feedback on performance and give staff the opportunity to participate in decision making. The data for 2012 are estimated using a simple mean imputation method from 2008 to 2011.

Table 1 shows the correlation test results for HRM variables. Consistent with the complementary hypothesis, the variables are highly correlated. Hospitals that adopt one HRM practice are likely to adopt other practices.

Table 2 shows that HRM practices have experienced changes in their mean scores during the period. Figure S1 in the online supplementary file reveals considerable variation among the HRM variables. The majority of variation are due to between-variation as opposed to within variation (online table S3).

We control for Teaching status, Foundation Trust (FT) status and size measured by number of beds. FT hospitals are not-for-profit public organizations that exercise greater managerial autonomy from direct government control. We also control for skill-mix by including the proportion of medical, nursing and support staff to total staff. Different patient groups may demand different care requirements. Recognizing this, we include percentage of female patients and admissions in various age groups. We control for the proportion of patients ad- 
Table 1: Correlations of HRM Practices

\begin{tabular}{|c|c|c|c|c|c|c|c|c|c|}
\hline & Decisions & Ideas & Communication & Feedback & Team Quality & Flexible & Training & Job-Satisfaction & Intention to leave \\
\hline \multicolumn{10}{|l|}{ Decisions } \\
\hline Ideas & $0.62^{* * * *}$ & & & & & & & & \\
\hline Communication & $0.87^{* * * *}$ & $0.46^{* * * *}$ & & & & & & & \\
\hline Feedback & $0.74^{* * * *}$ & $0.61^{* * * *}$ & $0.55^{* * * *}$ & & & & & & \\
\hline Team Quality & $0.34^{* * * *}$ & $0.41^{* * * *}$ & $0.30^{* * * *}$ & $0.34^{* * * *}$ & & & & & \\
\hline Flexible & $0.16^{* * * *}$ & 0.07 & $0.29^{* * * *}$ & -0.08 & $0.14^{* *}$ & & & & \\
\hline Training & $0.14^{* *}$ & $0.29^{* * * *}$ & $0.14^{* *}$ & $0.16^{* *}$ & $0.18^{* * * *}$ & $0.19^{* * * *}$ & & & \\
\hline Job-Satisfaction & $0.73^{* * * *}$ & $0.46^{* * * *}$ & $0.80^{* * * *}$ & $0.48^{* * * *}$ & $0.30^{* * * *}$ & $0.46^{* * * *}$ & $0.30^{* * * *}$ & & \\
\hline Intention to leave & $-0.32^{* * * *}$ & $-0.45^{* * * *}$ & $-0.28^{* * * *}$ & $-0.33^{* * * *}$ & $-0.17^{* * * *}$ & $-0.38^{* * * *}$ & $-0.42^{* * * *}$ & $-0.54^{* * * *}$ & \\
\hline Job-Design & $0.65^{* * * *}$ & $0.64^{* * * *}$ & $0.51^{* * * *}$ & $0.70^{* * * *}$ & $0.46^{* * * *}$ & 0.06 & $0.23^{* * * *}$ & $0.61^{* * * *}$ & $-0.47^{* * * * *}$ \\
\hline
\end{tabular}

mitted as emergencies. Regional differences are accounted for by controlling for the number of GPs per 100,000 resident population, Market Forces Factor (MFF) and a dummy variable for London. Table A.1 defines the variables and gives the data sources, and online table S4 provides the summary statistics.

\section{Exploring Complementarities}

Economic theory predicts complementarities among management practices. It suggests "workplace practices tend to cluster more than random chance would predict." (Brynjolfsson and Milgrom, 2013). Despite progress, the theory is still silent on which particular clusters of practices are most critical for performance, and empirical findings are diverse. Appelbaum et al. (2000) find the cluster of incentive pay, employment security, merit-based promotions and reduced status distinctions as critical. Ichniowski et al. (1997) documents the complementary role of incentive pay and employment security. Bloom and Van Reenen (2007) offer evidence on the importance of incentive pay, employment security, merit-based promotions and performance review. A reason that may partly explain the diverse results is the lack of a method for systematically identifying complementary practices. We use machine learning clustering techniques to identify clusters of HRM practices. As the analysis is exploratory, the data are pooled together across the periods. 


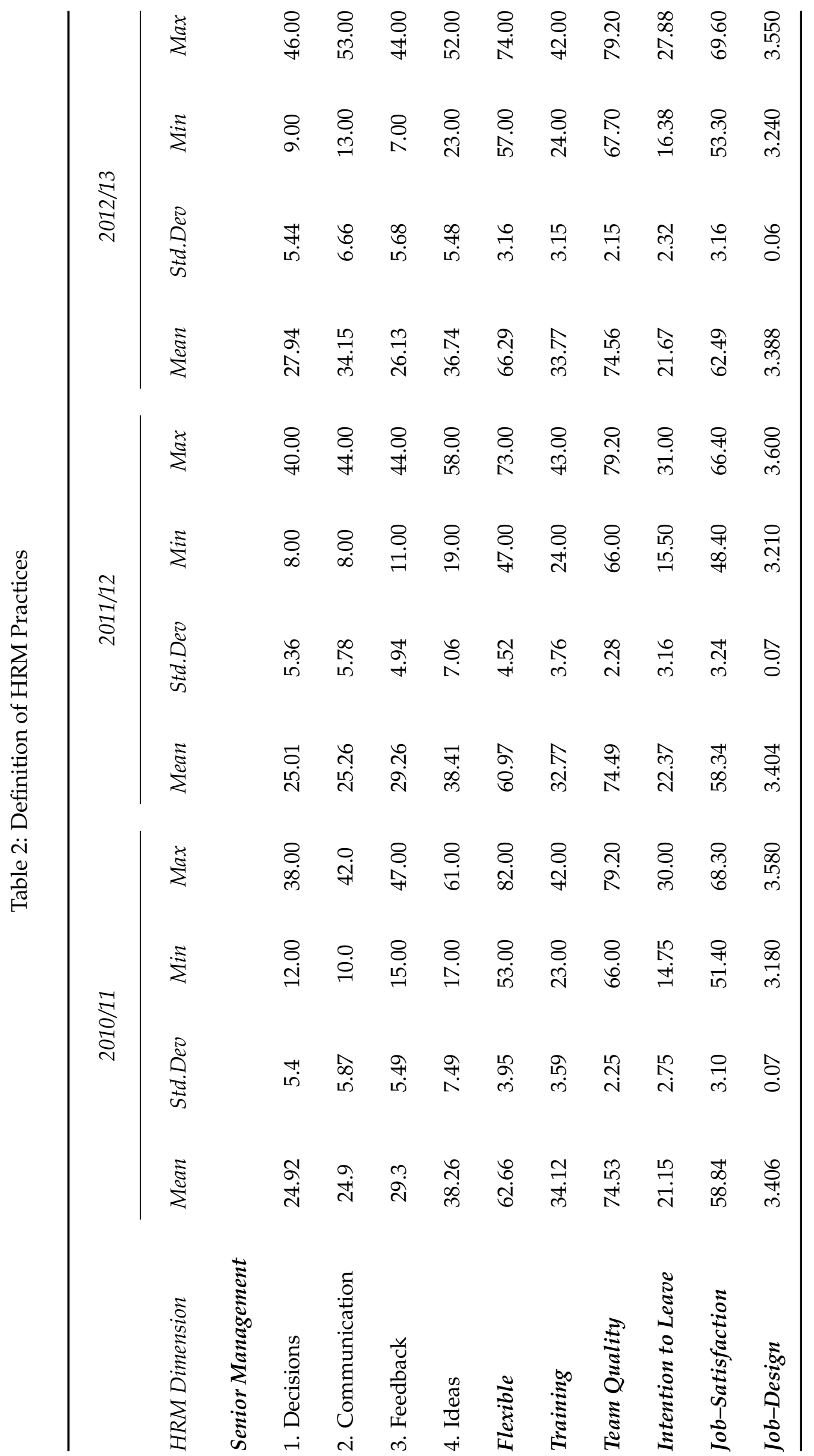




\subsection{Clustering Analysis}

Clustering techniques organize observations into groups such that there is high-intra group similarity but low-inter group similarity. For start, we use K-means clustering (weighted Knearest neighbours), which groups the observations into a pre-specified number of clusters and helps discern dominant clusters graphically (James et al., 2013). Setting the number of clusters at 3 offers well-defined clusters of the observations. Figure 2 shows the clusters for the HRM variables and total factor productivity.

Some interesting patterns emerge. High productivity (red cluster) and low productivity (blue cluster) hospitals both could belong to cases where Ideas, Decisions, Feedback, Team quality and Job design mostly lie above their median.The two clusters are reasonably sharply separated by Intention-to-leave. The high productivity cluster represents hospitals where Intention-to-leave mainly lies below its median. Also, high productivity hospitals are mainly those with a flexible working environment whereas low productivity observations belong to cases where workplace flexibility is below the median. Similar facts are found for labour productivity in online supplementary figure S2.

Nearest-neighbours clustering provides a qualitative representation. To test the significance of the clusters, one requires separating the clusters numerically. We turn to hierarchical clustering, which builds a hierarchy of clusters that differ in terms of closeness. The result is a tree structure, called dendrogram, that can be summarised at various levels of complexity (James et al., 2013). We summarise the results into 10 clusters so that each contains adequate observations. Table A.2 (and online supplementary Table L3) report the clusters.

Consistent with $\mathrm{K}$-means clustering, several clear complementary patterns emerges. High productivity hospitals belong to clusters where senior management practices, Job satisfaction, Team quality, Job design and workplace flexibility take values above their medians but Intention-to-leave takes a value below its median. This suggests senior management practices, flexibility in workplace, Team quality and Training are complementary. Hospitals with lowest total factor productivity belong to clusters where senior management variables mainly lie above their medians, Flexible and Training lie below their median but Intention-to-leave lies above its median (exceptions in clusters with few observations). An interpretation of this result is that senior management practices will fail to have any positive impact unless other complementary practices such as adequate incentives or workplace flexibility and training are in place. A missing complementary practice may render a whole set of management practices ineffective. We use econometric techniques to test the significance of these clusters. 


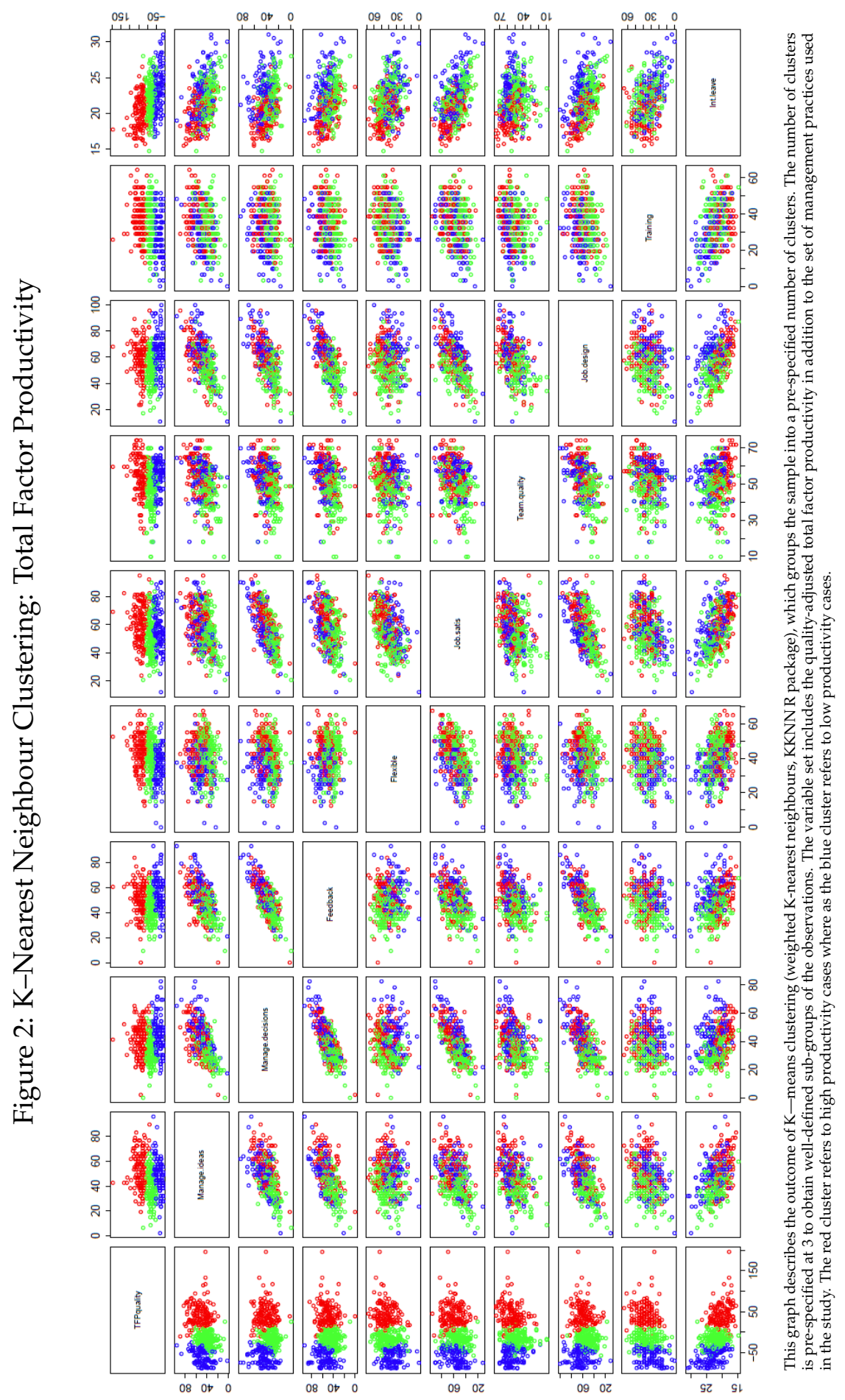




\section{Correlated Random Effects}

There are two common panel regression estimators: Fixed Effects (FE) and Random Effects (RE). Both recognise the possibility of unobserved hospital heterogeneity effects, captured by $c_{i}:$

$$
y_{i t}=\mathbf{x}_{i t} \boldsymbol{\beta}+c_{i}+u_{i t} ; t=1,2, \ldots, T
$$

where $u_{i t}$ represents a random component that is independent of $\mathbf{x}_{i t}$. Random Effects treats unmeasured characteristics $c_{i}$ as a component of the independent error term $u_{i t}$ (i.e., $\operatorname{Cov}\left(\mathbf{x}_{i t}, c_{i}\right)=$ $0, t=1,2, \ldots, T)$. Fixed effects dispenses with the assumption that $c_{i}$ is uncorrelated with the explanatory variables $\mathbf{x}_{i t}$. The technique adopts a 'within estimation' specification using time demeaning to remove unobserved heterogeneity $c_{i}$.

Fixed effects requires considerable 'within-unit' variation over time. Otherwise, the estimator will generate large standard errors. Our variables are persistent over time, making the FE estimator inefficient. Instead, we turn to Correlated Random Effects (CRE) technique, which is comparable to the FE estimator (Wooldridge, 2013).

Consider equation (2). In CRE, we model correlation between $c_{i}$ and $\mathbf{x}_{i t}$. Since $c_{i}$ is constant over time, it can be correlated with the average level of the $\mathbf{x}_{i t}$. Let $\overline{\mathbf{x}}_{i}=T^{-1} \sum_{t=1}^{T} \mathbf{x}_{i t}$ be time averages. It is plausible to assume the simple linear relationship

$$
c_{i}=\alpha+\lambda \overline{\mathbf{x}}_{i}+r_{i}
$$

where $r_{i}$ is, by assumption, uncorrelated with each $x_{i t}$. Substituting (3) into (2) gives:

$$
y_{i t}=\alpha+\beta_{i} \mathbf{x}_{i t}+\lambda \overline{\mathbf{x}}_{i}+r_{i}+u_{i t}
$$

The equation has a composite error term $r_{i}+u_{i t}$, consisting of a time-invariant unobservable $r_{i}$ and the idiosyncratic shocks, $u_{i t}$. Since $u_{i t}$ is, by assumption, uncorrelated with $\mathbf{x}_{i t}$, for all $s$ and $t, u_{i t}$ is uncorrelated with $\overline{\mathbf{x}}_{i}$. Equation (4) can be estimated using random effects estimation. The addition of $\overline{\mathbf{x}}_{i}$ controls for the correlation between $c_{i}$ and the sequence $\left\{\mathbf{x}_{i t}: t=1,2, \ldots, T\right\}$. Wooldridge $\left(2013\right.$, Ch. 14.3) shows that $\hat{\beta}_{C R E}=\hat{\beta}_{F E}$, where $\hat{\beta}_{F E}$ stands for FE estimates. As in Goerke and Pannenberg (2011), we assume that $c_{i}$ may only be correlated with certain variables, $\mathbf{x}_{i t}$, and only introduce the within-hospital means of variables of interest in the regressions. 


\section{Empirical Analysis}

We set ourselves the task that the effect of individual management practices is indeterminate (indeterminacy effect). For a practice to have noticeable impact, the intensity / quality of management practices should reach a threshold (non-linearity effect) and the practice should be a member of a complementary cluster (complementary effect). This section turns to econometric analysis to provide evidence of these effects. We start by showing that individual practices may have no effect. Once we account for non-linearities and complementarities, management practices substantially affect performance. The next section identifies some practically significant clusters of HRM practices that drive performance. The online appendix investigates the robustness of our results.

\subsection{The Indeterminacy Effect}

Our first hypothesis relates to the indeterminacy of the effect of individual management practices. Our basic model to test the effect takes the form:

$$
y_{i t}=\alpha+\beta_{i} \mathbf{x}_{i t}+\gamma_{i} \mathbf{m}_{i t-1}+\lambda_{i} \overline{\mathbf{m}}_{i}+u_{i t}
$$

where $\mathbf{m}_{i t}$ stands for a vector of HRM practices and $\overline{\mathbf{m}}_{i}$ for their within-hospital means. The coefficients of the lagged HRM variables $\gamma_{i}$ represent FE estimates whereas the coefficients of the averages $\lambda_{i}$ represent RE estimates. The errors are adjusted for heteroskedasticity and year dummies are included to reduce omitted variable bias. To avoid multicollinearity, we estimate separate models using subsets of uncorrelated HRM practices.

Table A.3 reports our preliminary results for the TFP measure. Each column includes a set of not highly correlated management variables. Column 1 includes Ideas, Flexible and Training. The FE coefficient of Ideas fails to be significant but its RE coefficient, 0.796 , is significant at $1 \%$. Better management of ideas in the workplace positively correlates with higher total factor productivity. The FE coefficient of Flexible is significant at $1 \%$ and negative, suggesting that within-hospital increases in workplace flexibility lower productivity. The RE coefficient is positive and significant. Workplace flexibility and higher productivity are positively correlated. The FE coefficient of Training is significant and negative whereas its RE coefficient is insignificant and positive. The remaining columns replace Ideas with Decisions, Communication and Feedback. The statistical pattern remains the same. Only the RE coefficients of the practices are significant except for Feedback. The FE coefficients of Flexible and Training remain negative. The year dummies indicate significant year fixed effects. 
Online Table L1 reports the results for labour productivity. The FE coefficients of senior management variables appear as significant at 10\%, except for Communication. An 1-unit increase in variables Ideas and Decision is associated with $0.212 \%$ and $0.321 \%$ increase in labour productivity. The FE coefficients of Flexible and Training are significant with a negative sign. While these results offer some evidence on possible impact of management practices, they are far from being conclusive. The FE estimates are either insignificant or have the wrong sign. Evidently, there are multiple possible explanations for these findings. They can be due mismeasurement, small sample size and noise in the data. Consistent with the theory, though, the results may well indicate the indeterminacy of the effect of individual practices. Management practices begin to have meaningful impact only when their quality / strength reach a required threshold and are in the presence of complementary practices.

\subsection{The Non-linearity Effect}

Meagher and Strachan (2013) investigate non-linearities in the impact of management practices on firm performance using a Gaussian process and a continuous piece-wise linear approach with probabilistically smoothed endogenous breaks. The analysis reveals significant evidence of a U-shaped relationship, with the biggest returns to management occurring when practices are at their highest levels. Here, we adopt a simpler approach. We test the effect by comparing impacts of HRM practices in sub-samples wherein the strength of the practices differ. We calculate the median of the within-hospital means of the senior management variables and test the coefficient of each variable in the sub-sample where the within-unit mean of the variable is equal to or exceeds its median. Table A.4 reports the results for the TFP measure. For the sake of space we include only the coefficients of variables of interest. The full set of results are reported in table S5.

The FE coefficient of Ideas is 0.434 , significant at $1 \%$, the FE coefficient of Decisions is 0.459 , significant at $5 \%$, and the FE coefficient of Feedback is 0.440 , significant at $10 \%$. These estimates are substantially different than the results for the full sample in Table A.3, suggesting that the strength of HRM practices matters. The negative FE coefficient of Training is no longer significant. The coefficient of Flexible continues to be negative and significant at $10 \%$. Online supplementary table, L2, reports similar results for labour productivity. We find no evidence of serial correlation in the panel results using Breusch-Godfrey test. These results provide evidence on the indeterminacy effect that the intensity of management practices should reach a certain threshold to have any impact. An immediate implication of the non-linearity effect is that the introduction of individual practices alone are not enough. The quality and intensity of 
the practices matter too.

\subsection{The Complementarity Effect}

The non-linearly effect shows the importance of thresholds. The direction of the impact of management practices primarily depends on the presence of other practices - the complementarity effect. The literature provides several ways of testing complementarities. An approach is to examine the statistical significance of an HRM practice in sub-samples where other complementary practices exceed a certain threshold.The exploratory analysis pointed to the complementarity of senior management practices. To test this,we construct an indicator variable that takes value one when the within-hospital mean of Ideas exceeds its median and zero otherwise, and test the fixed effects coefficients of the other HRM variables in the sub-sample where the indicator variable takes value one. Table A.5 reports the partial results whereas the full set of results are reported in table S6. The first three columns belong to total factor productivity whereas the remaining columns belong to labour productivity. In the TFP columns, the FE coefficients of the lagged Decisions, 0.708, Communications, 0.420, and Feedback, 0.541, are all significant at $1 \%$.

When ideas are managed effectively, a within-hospital change in other senior management variables will have a positive impact on productivity. None of these FE coefficients are significant in the sub-sample where the indicator variable takes zero. The FE coefficient of workplace flexibility appears as significant at $1 \%$ across the three columns. The variable's random effects coefficient is no longer significant. Training loses significance too. This is either because Training varies little within the sub-sample or because better managed hospitals already enjoy a highly trained workforce. We find similar results in columns 4 through 6 for labour productivity. Repeating the analysis for other HRM practices in the cluster, such as, Feedback yields similar results. In hospitals where an HRM practice, e.g., Ideas, exceeds a threshold, enhancing other complementary practices increases productivity. Management practices show strong complementarity effects.

A more effective approach to testing complementarity is to interact management variables with each other (Ichniowski et al., 1997). In one form, this can be achieved by constructing an indicator variable that captures various levels (e.g., quartile) of a management variable, and interact it with other practices. That is to test a model of the form:

$$
y_{i t}=\alpha+\beta_{i} \mathbf{x}_{i t}+\gamma_{i} m_{i t-1}+\eta_{i} \times I \times m_{i t-1}+\lambda_{i} \bar{m}_{i}+u_{i t}
$$

where $\mathbf{x}_{i t}$ stand for control variables, $m_{i t}$ stands for the HRM variable, I refers to the indicator 
variable. $\eta_{i}$ reflects the marginal effect of the HRM variable in the sub-sample where the indicator takes value one. The total FE coefficient of $m_{i t}$ is given by $\gamma_{i}+\eta_{i}$.

The clustering analysis suggests high productivity hospitals belong to clusters where intention-to-leave, our indirect measure of incentive adequacy, is low but workplace flexibility is sufficiently strong. To test this, we calculate the within-group mean of Intention-to-leave for each hospital, and estimate the four quartiles of the distribution of the within-group mean to construct four dummy variables, each taking value 1 for a hospital if its within-group mean falls in the quartile and otherwise zero. We interact the indicator with Flexible to investigate how incentives interact with workplace flexibility to impact productivity. That is, we test a model of the form:

$$
y_{i t}=\alpha+\beta_{i} \mathbf{x}_{i t}+\gamma_{i} f l_{i t-1}+\eta_{i} \times I \times f l_{i t-1}+\lambda_{i} \bar{f}_{i}+u_{i t}
$$

where $f l_{i t}$ stands for Flexible and $I$ refers to the Intention-to-leave dummy variable.

Table A.6 presents the key results (full results reported in table S7). Column 1 reports the results for the case where the within-group mean of Intention-to-leave falls in the lowest quartile. Column 2 reports the results for the case where the within-group-mean of the variable falls in the second quartile, and so forth. Returning to the first column, the FE coefficient of the lagged variable Flexible is negative $(-0.399)$ and significant at $1 \%$. The coefficient of the interaction term, 0.443 , is positive and significant at $1 \%$. This means the overall FE estimate of Flexible for hospitals where the intention to leave is low is $-0.399+0.443=0.044$. One unit increase in workplace flexibility will increase productivity by 0.044 unit. In column 4 , where the within-group mean of Intention-to-leave is equal or above the third quartile, both FE coefficients of Flexible $(-0.296)$ and the interaction term $(-0.307)$ are negative and significant at $5 \%$. Overall, the coefficient of Flexible in the upper quartile is $-0296-0.307=-0.603$. Assuming Intention-to-leave captures incentives, when incentives are poor, an increase in workplace flexibility can lower productivity. With adequate incentives, increasing workplace flexibility may increase productivity. Supplementary table L4 for labour productivity further strengthens the insights.

Similarly, the impact of workforce training depends on whether proper incentives are in place. Table A.7 reports the results for total factor productivity (online table S7). In the sub-sample where the within-hospital mean of Intention-to-leave falls in the lowest quartile, the total FE coefficient of Training is $-0.265+0.524=0.259$, implying a positive impact. In trusts where the within-hospital mean of Intention-to-leave lies in the upper quartile, the total FE coefficient for Training is $-0.043-0.415=-0.458$, indicating a negative impact. The 
FE coefficients fail to be significant in the second and third quartiles. With weak incentives, workforce training may bring little improvement. Whether a management practice positively or negatively impacts productivity depends on other practices. Supplementary table L5 for labour productivity offers further support.

The complementary hypothesis also implies synergies between HRM practices and production inputs. Human capital inputs are more productive in effectively managed hospitals. Or, the proportion of emergency patients has a lesser negative impact in well-managed hospitals. We test these conjectures by constructing a composite measure, Management, for senior management variables using principal component analysis. We use the composite measure to define an indicator that takes value one when the within-hospital mean of the composite management index exceeds its median and otherwise zero. We interact the variable with the proportion of medical staff, the nurses and emergency patients. The first three columns in Table A.8 report the partial results (full results reported in supplementary table S8). The interaction coefficients represent FE estimates. The interaction coefficient for medical staff, 1.613, is significant at $1 \%$. In hospitals where the within-group mean of the management index exceeds the median, the total effect of medical staff is $-0.948+1.61=0.662$. In the presence of relevant management practices, the variable medical staff has a positive impact on total factor productivity. A similar interpretation applies to nurses and the proportion of emergency patients. The negative effect of the proportion of emergency patients is lower in hospitals with better management practices. The FE coefficients for labour productivity in the table follow a similar pattern. Production inputs are more effective with complementary management practices.

Further evidence on the complementarity of HRM practices can be seen by jointly interacting Job Satisfaction, Team Quality and Job Design with factors of production. We construct an indicator variable that takes value one when the within-hospital means of these variables exceed their medians and otherwise zero. The variable is interacted with proportions of medical staff, nurses and emergency patients. The last three columns in Table A.8 report the results. The interaction terms are significant. In hospitals where the within-hospital means of the HRM variables exceed their medians, human capital variables contribute to productivity more strongly. These results require that the within-hospital mean of the three variables jointly exceeds the median of the variables' within-group averages. It is the cluster of human resources that can impact productivity (Ichniowski et al., 1997). Supplementary table L6 provides similar results for labour productivity.

Similar findings are obtained when we adjust the cost-adjusted productivity scores using Hospital Standardized Mortality Ratio (HSMR) (section 5 in the supplementary file). The 
findings are robust to the inclusion of other controls such as London to capture regional differences. Our data are observational; intention-to-leave may capture factors beyond incentives; and there are challenges in testing complementarity. While these call for caution, the results are consistent with our most plausible theoretical assumptions. Implementing HRM practices in isolation may not produce the desired effects and it may be counter-productive for an organization (Ichniowski et al., 1997; Vermeeren et al., 2014). It is the cluster of HRM practices that matters for performance.

As well as pointing out the systemic character of public management, the findings suggest the intricacy of arranging management practices. To identify clusters that mechanistically contribute to productivity requires further technical research, including qualitative research of how the new management practices are brought into effect. Yet insights gained from such investigation have significant potential. Management might gain knowledge of which practices work with which in order to achieve the desired outcomes of effective public management.

\section{Conclusion}

A facet of public sector organisations is considerable variation in productivity. This presents substantial scope for improvements. We investigate the role of HRM practices in public organisations using data on the NHS acute hospital trusts. NHS trusts are large public organisations, some with more than 4,500 employees. We make several contributions. We introduce and provide evidence on the non-linearity effect, provide systemic evidence on the complementarity effect, document the effects of clusters of management practices and identify several practically significant clusters.

Our analysis suggests that the effects of individual HRM practices are indeterminate. The direction of the effect of a practice is determined within a cluster. Workplace flexibility improves performance only if the organisation effectively manages ideas, communications and employee feedback and implements an adequate incentive system. If any of these elements is missing, e.g., if incentives are inadequate, workplace flexibility can lower productivity. In a poorly aligned cluster of HRM practices, workplace flexibility can weaken organizational attachment, give rise to staff absenteeism and turnover and worsen job attitudes. A similar insight applies to the effect of training in public organisations. Without adequate incentives, workforce training may have little impact. Our analysis also reveals the joint importance of team quality, job design and proper incentives. It is the joint presence of these factors along with high quality senior managerial practices that yield higher human capital productivity. Once some of these factors are missing, human capital productivity is likely to fall. The com- 
plementary character of management practices highlights the importance of internal organisational design and the leadership role in putting an optimal cluster of practices in place. Organisational change necessitates a holistic shift from one cluster of practices to another. Adopting clusters of optimal management practices can noticeably increase productivity using current resources.

It is difficult to establish causality using survey data in an observational setting. Hospitals that acquire better reputation might be able to draw better managerial talents into their team, which may change the work environment. Such latent common causes can give rise to correlation among individual management practices. Controlling for additional drivers partially deals with endogeneity. Our results are, however, in line with the theoretical reasoning given earlier and are consistent with an emerging body of experimental findings (Bloom et al., 2013; Bruhn et al., 2018; Giorcelli, 2016). Further progress calls for appropriate instrumental variables.

Any policy use of our results necessitates understanding why HRM practices differ across organisations. We aim to investigate management heterogeneity in our future research, furthering the research in Bloom et al. (2015). It would be interesting to replicate our study for other public organisations. 


\section{References}

Appelbaum, E., Bailey, T., Berg, P., and Kalleberg, A. L. (2000). Manufacturing Advantage: Why High-Performance Work Systems Pay Off. Cornell University Press.

Aragon, M. J. A., Castelli, A., and Gaughan, J. (2017). Hospital Trusts Productivity in the English NHS: Uncovering Possible Drivers of Productivity Variations. PLoS ONE, 12(8):e0182253.

Aragon, M. J. A., Castelli, A., Gaughan, J., et al. (2015). Hospital Trusts Productivity in the English NHS: Uncovering Possible Drivers of Productivity Variations. CHE Research Paper 117. University of York.

Bartel, A. P. (2004). Human Resource Management and Organizational Performance: Evidence from Retail Banking. Industrial \& Labor Relations Review, 57(2):181-203.

Bender, S., Bloom, N., Card, D., Van Reenen, J., and Wolter, S. (2016). Management Practices, Workforce Selection and Productivity. NBER Working Paper No. 22101.

Bijlsma, M. J., Koning, P. W., and Shestalova, V. (2013). The Effect of Competition on Process and Outcome Quality of Hospital Care in the Netherlands. De Economist, 161(2):121-155.

Black, S. E. and Lynch, L. M. (2004). What's Driving the New Economy?: The Benefits of Workplace Innovation. The Economic Journal, 114(493):F97-F116.

Bloom, N., Eifert, B., Mahajan, A., McKenzie, D., and Roberts, J. (2013). Does Management Matter? Evidence from India. The Quarterly Journal of Economics, 128(1):1-51.

Bloom, N., Propper, C., Seiler, S., and Van Reenen, J. (2015). The Impact of Competition on Management Quality: Evidence from Public Hospitals. The Review of Economic Studies, 82(2):457-489.

Bloom, N., Sadun, R., and Van Reenen, J. (2012). Americans Do IT Better: US Multinationals and the Productivity Miracle. The American Economic Review, 102(1):167-201.

Bloom, N., Sadun, R., and Van Reenen, J. (2014). Does Management Matter in Healthcare? Stanford Mimeo.

Bloom, N. and Van Reenen, J. (2007). Measuring and Explaining Management Practices Across Firms and Countries. The Quarterly Journal of Economics, 122(4):1351-1408. 
Bradley, E. H., Curry, L. A., Spatz, E. S., Herrin, J., Cherlin, E. J., Curtis, J. P., Thompson, J. W., Ting, H. H., Wang, Y., and Krumholz, H. M. (2012). Hospital strategies for reducing risk-standardized mortality rates in acute myocardial infarction. Annals of Internal Medicine, 156(9):618-626.

Bradley, E. H., Herrin, J., Curry, L., Cherlin, E. J., Wang, Y., Webster, T. R., Drye, E. E., Normand, S.-L. T., and Krumholz, H. M. (2010). Variation in hospital mortality rates for patients with acute myocardial infarction. The American Journal of Cardiology, 106(8):1108-1112.

Branch, G. F., Hanushek, E. A., and Rivkin, S. G. (2012). Estimating the Effect of Leaders on Public Sector Productivity: The Case of School Principals. NBER Working Paper No. 17803.

Bresnahan, T. F., Brynjolfsson, E., and Hitt, L. M. (2002). Information Technology, Workplace Organization, and the Demand for Skilled Labor: Firm-Level Evidence. The Quarterly Journal of Economics, 117(1):339-376.

Brown, K. (2004). Human Resource Management in the Public Sector. Public Management Review, 6(3):303-309.

Bruhn, M., Karlan, D., and Schoar, A. (2018). The Impact of Consulting Services on Small and Medium Enterprises: Evidence from a Randomized Trial in Mexico. Journal of Political Economy, 126(2):635-687.

Brynjolfsson, E. and Milgrom, P. (2013). Complementarity In Organization. In Gibbons, R. and Roberts, J., editors, The Handbook of Organizational Economics. Princeton University Press.

Castelli, A., Street, A., Verzulli, R., and Ward, P. (2015). Examining Variations in Hospital Productivity in the English NHS. The European Journal of Health Economics, 16(3):243-254.

Chandra, A., Finkelstein, A., Sacarny, A., and Syverson, C. (2015). Healthcare Exceptionalism? Performance and Allocation in the US Healthcare Sector. NBER Working Paper No. 21603.

Chandra, A., Finkelstein, A., Sacarny, A., and Syverson, C. (2016). Productivity Dispersion in Medicine and Manufacturing. The American Economic Review, 106(5):99-103.

Cummins, J. G. and Violante, G. L. (2002). Investment-Specific Technical Change in the United States (1947-2000): Measurement and Macroeconomic Consequences. Review of Economic Dynamics, 5(2):243-284.

Dranove, D., Forman, C., Goldfarb, A., and Greenstein, S. (2014). The Trillion Dollar Conundrum: Complementarities and Health Information Technology. American Economic Journal: Economic Policy, 6(4):239-270. 
Dunleavey, P. and Carrera, L. N. (2010). Why Does Productivity Vary Across NHS Hospital Trusts in England? Untangling How Management Competence and the Use of ICTs Shape Hospitals' Performance. Political Studies Association Conference, Edinburgh.

Galindo-Rueda, F. and Haskel, J. (2005). Skills, Workforce Characteristics and Firm-Level Productivity: Evidence from the Matched ABI/Employer Skills Survey. IZA Discussion Paper No. 1542.

Gaynor, M., Laudicella, M., and Propper, C. (2012). Can Governments Do it Better? Merger Mania and Hospital Outcomes in the English NHS. Journal of Health Economics, 31(3):528543.

Gaynor, M., Seider, H., and Vogt, W. B. (2005). The Volume-Outcome Effect, Scale Economies, and Learning-by-Doing. American Economic Review, 95(2):243-247.

Giorcelli, M. (2016). The long-term effects of management and technology transfer: Evidence from the us productivity program. Stanford Institute for Economic Policy Research, Discussion Paper, (16-010).

Goerke, L. and Pannenberg, M. (2011). Trade Union Membership and Dismissals. Labour Economics, 18(6):810-821.

Gould-Williams, J. (2003). The Importance of HR Practices and Workplace Trust in Achieving Superior Performance: A Study of Public-sector Organizations. International Journal of Human Resource Management, 14(1):28-54.

Gupta, A. (2017). Impacts of Performance Pay for Hospitals: The Readmissions Reduction Program. Becker Friedman Institute for Research in Economics Working Paper No. 2017-07.

Hentschker, C. and Mennicken, R. (2014). The volume-outcome relationship and minimum volume standards-empirical evidence for Germany. Health Economics, 24(6):644-658.

Hoeks, S., Scholte op Reimer, W., Lingsma, H., van Gestel, Y., van Urk, H., Bax, J., Simoons, M., and Poldermans, D. (2010). Process of care partly explains the variation in mortality between hospitals after peripheral vascular surgery. European Journal of Vascular and Endovascular Surgery, 40(2):147-154.

Holmstrom, B. and Milgrom, P. (1994). The firm as an incentive system. The American Economic Review, 84(4):972-991. 
Ichniowski, C. and Shaw, K. (1999). The Effects of Human Resource Management Systems on Economic Performance: An International Comparison of US and Japanese plants. Management Science, 45(5):704-721.

Ichniowski, C., Shaw, K., and Prennushi, G. (1997). The Effects of Human Resource Management Practices on Productivity: A Study of Steel Finishing Lines. The American Economic Review, 87(3):291-313.

James, G., Witten, D., Hastie, T., and Tibshirani, R. (2013). An Introduction to Statistical Learning. Springer.

Janke, K., Propper, C., and Sadun, R. (2018). The Impact of CEOs in the Public Sector: Evidence from the English NHS. Harvard Business School Working Paper 18-075.

Jones, N. and Charlesworth, A. (2013). The Anatomy of Health Spending 2011/12. London: Nuffield Trust.

Katz, M. L. (2013). Provider competition and healthcare quality: More bang for the buck? International Journal of Industrial Organization, 31(5):612-625.

May, K. (1947). Technological change and aggregation. Econometrica, Journal of the Econometric Society, pages 51-63.

McConnell, K. J., Chang, A. M., Maddox, T. M., Wholey, D. R., and Lindrooth, R. C. (2014). An Exploration of Management Practices in Hospitals. Healthcare, 2(2):121-129.

McCullough, J. S., Parente, S., and Town, R. (2013). Health information technology and patient outcomes: The role of organizational and informational complementarities. NBER Working Paper No. 18684.

Meagher, K. and Strachan, R. (2013). Evidence on the non-linear impact of management. Australian National University mimeo.

Menachemi, N., Chukmaitov, A., Saunders, C., and Brooks, R. G. (2008). Hospital Quality of Care: Does Information Technology Matter? The relationship between Information Technology Adoption and Quality of Care. Health Care Management Review, 33(1):51-59.

Milgrom, P. and Roberts, J. (1990). The Economics of Modern Manufacturing: Technology, Strategy, and Organization. The American Economic Review, 80(3):511-528.

Milgrom, P. and Roberts, J. (1995). Complementarities and Fit Strategy, Structure, and Organizational Change in Manufacturing. Journal of Accounting and Economics, 19(2):179-208. 
Miller, A. R. and Tucker, C. E. (2011). Can health care information technology save babies? Journal of Political Economy, 119(2):289-324.

Needleman, J., Buerhaus, P., Pankratz, V. S., Leibson, C. L., Stevens, S. R., and Harris, M. (2011). Nurse Staffing and Inpatient Hospital Mortality. New England Journal of Medicine, 364(11):1037-1045.

O'Brien, S. M., DeLong, E. R., and Peterson, E. D. (2008). Impact of case volume on hospital performance assessment. Archives of Internal Medicine, 168(12):1277-1284.

Propper, C. (2012). Competition, Incentives and the English NHS. Health Economics, 21(1):3340.

Rafferty, A. M., Clarke, S. P., Coles, J., Ball, J., James, P., McKee, M., and Aiken, L. H. (2007). Outcomes of variation in hospital nurse staffing in english hospitals: cross-sectional analysis of survey data and discharge records. International Journal of Nursing Studies, 44(2):175-182.

Roland, M. and Rosen, R. (2011). English nhs embarks on controversial and risky market-style reforms in health care. New England Journal of Medicine, 364(14):1360-1366.

Rumbold, B. E., Smith, J. A., Hurst, J., Charlesworth, A., and Clarke, A. (2015). Improving Productive Efficiency in Hospitals: Findings From a Review of the International Evidence. Health Economics, Policy and Law, 10(01):21-43.

Sakellaris, P. and Wilson, D. J. (2004). Quantifying Embodied Technological Change. Review of Economic Dynamics, 7(1):1-26.

Siebers, P.-O., Aickelin, U., Battisti, G., Celia, H., Clegg, C., Fu, X., De Hoyos Navarro, R. E., Iona, A., Petrescu, A. I., and Peixoto, A. (2008). Enhancing Productivity: The Role of Management Practices. Advanced Institute of Management Research Paper No. 65.

Vermeeren, B., Steijn, B., Tummers, L., Lankhaar, M., Poerstamper, R.-J., and Van Beek, S. (2014). HRM and its Effect on Employee, Organizational and Financial Outcomes in Health Care Organizations. Human Resources for Health, 12(1):35.

West, M. A., Borrill, C., Dawson, J., Scully, J., Carter, M., Anelay, S., Patterson, M., and Waring, J. (2002). The link Between the Management of Employees and Patient Mortality in Acute Hospitals. International Journal of Human Resource Management, 13(8):1299-1310.

West, M. A., Guthrie, J. P., Dawson, J. F., Borrill, C. S., and Carter, M. (2006). Reducing Patient Mortality in Hospitals: The Role of Human Resource Management. Journal of Organizational Behavior, 27(7):983-1002. 
Wooldridge, J. M. (2013). Introductory Econometrics: A Modern Approach. South Western, 5th edition. 


\section{Appendix Tables}

Table A.1: Data Definitions and Sources

\begin{tabular}{l}
\hline \hline Data \\
\hline Teaching \\
Foundation Trust \\
Hospital Beds \\
Market Forces Factor (MFF) \\
GP \\
Patients aged 0-14 (\%) \\
Patients aged 15-44 (\%) \\
Patients aged 45-59 (\%) \\
Patients aged over 60 (\%) \\
Proportion of Emergency patients (\%) \\
Proportion of female patients (\%) \\
Medical Staff (\%) \\
Nursing Staff (\%) \\
Total Staff (\%) \\
Management: Decisions
\end{tabular}

Management: Feedback

Management: Ideas

Management: Communication

Flexible Working Practice

Training

Team Quality

Intention to Leave (\%)

Continued on next page. .
Definition

Equal to 1 if hospital is Teaching trust and 0 otherwise http://www . nrls.npsa.nhs.uk/

Equal to 1 if hospital has FT status and 0 otherwise (Monitor) Average number of available beds (NHS England)

MFF * 100 (Dept. of Health)

General Practitioners per 100,000 population (NHSD)

Proportion of patients (FCE) under 14 years of age (NHSD)

Proportion of patients (FCE) between 15 and 44 years of age (NHSD)

Proportion of patients (FCE) between 45 and 59 years of age (NHSD)

Proportion of patients (FCE) aged over 60 years of age (NHSD)

(Emergency admissions / Total admissions) * 100 (NHSD)

(Female admissions / Total admissions) $* 100$ (NHSD)

(Medical workforce / Total Staff) $* 100$

(Nursing workforce / Total Staff) * 100

Total clinical \& non-clinical staff

$\%$ who answered agree and strongly agree to 'Senior managers here try to involve staff in important decisions'. Standardized to 0-100 scale (NSS)

$\%$ who answered agree and strongly agree to 'Senior managers act on staff feedback'. Standardized to 0-100 scale.(NSS)

$\%$ who answered agree and strongly agree to 'Senior Managers encourage staff to suggest new ideas for improving services'. The data for 2012 was not available and thus it was estimated by mean imputation. Standardized to $0-100$ scale (NSS)

$\%$ who answered agree and strongly agree to 'Communication between senior management and staff is effective'. Standardized to 0-100 scale (NSS)

$\%$ using flexible working options. Data for 2012 was mean imputed using the scores from 2008-2012 (Key summary score from NSS) (NSS)

Percentage of respondents who had any supervised on-the-job training (NSS)

Effective Team Working (NSS)

The extent to which staff are considering leaving their organisation, and looking for a new job either within or outside of the NHS (NSS) 
Table A.1: Data Definitions and Sources

\begin{tabular}{ll}
\hline \hline Data & Definition \\
\hline Job-Satisfaction & Average positive response rates of 7 measures of staff job- \\
& satisfaction (NSS) \\
Job-Design & Quality of job-design (NSS) \\
\hline \hline
\end{tabular}




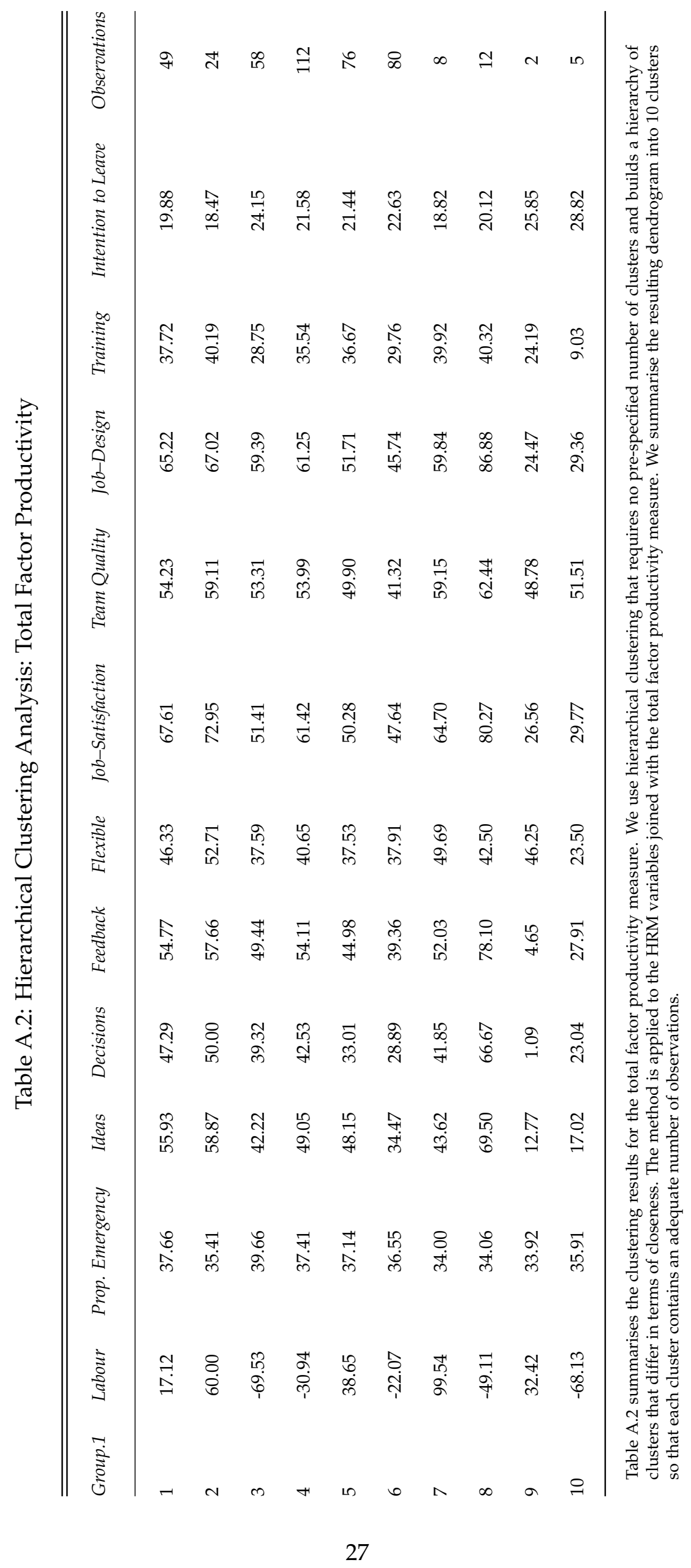


Table A.3: Base Model: Total Factor Productivity

\begin{tabular}{|c|c|c|c|c|}
\hline & (1) & (2) & (3) & (4) \\
\hline Intercept & $-118.3(176.4)$ & $-114.1(174.0)$ & $-102.0(174.9)$ & $-158.5(176.2)$ \\
\hline \multicolumn{5}{|l|}{ Structural } \\
\hline Teaching Trust & $-5.168(8.034)$ & $-0.357(8.137)$ & $0.299(8.038)$ & $1.813(8.240)$ \\
\hline Foundation Trust & $4.721(4.912)$ & 7.791 (4.977) & $6.769(4.918)$ & $7.117(5.106)$ \\
\hline Hospital Beds & $0.011(0.010)$ & $0.005(0.010)$ & $0.003(0.010)$ & $0.002(0.010)$ \\
\hline \multicolumn{5}{|l|}{ Regional } \\
\hline MFF & $-2.523(0.571)^{* * *}$ & $-2.878(0.586)^{* * *}$ & $-2.917(0.592)^{* * *}$ & $-2.592(0.619)^{* * *}$ \\
\hline GP per 100,000 & $2.388(0.534)^{* * *}$ & $2.327(0.569)^{* * *}$ & $2.396(0.569)^{* * *}$ & $2.432(0.580)^{* * *}$ \\
\hline \multicolumn{5}{|l|}{ Patient } \\
\hline Prop. Emergency & $-1.155(0.478)^{* *}$ & $-1.117(0.455)^{* *}$ & $-1.150(0.446)^{* *}$ & $-1.127(0.458)^{* *}$ \\
\hline Prop. Female & $0.462(1.213)$ & $0.730(1.212)$ & $0.675(1.226)$ & $0.786(1.234)$ \\
\hline Patients aged 0-14 & $2.606(1.046)^{* *}$ & $2.949(1.135)^{* * *}$ & $2.860(1.131)^{* *}$ & $3.010(1.106)^{* * *}$ \\
\hline Patients aged 45-59 & $2.737(1.874)$ & $2.394(1.941)$ & $1.973(1.931)$ & $2.337(1.881)$ \\
\hline Patients aged over 60 & $2.264(0.694)^{* * *}$ & $2.721(0.745)^{* * *}$ & $2.702(0.759)^{* * *}$ & $2.806(0.741)^{* * *}$ \\
\hline \multicolumn{5}{|l|}{ Skill-Mix } \\
\hline Prop. Medical & $-0.333(0.799)$ & $-0.052(0.841)$ & $-0.028(0.848)$ & $-0.014(0.848)$ \\
\hline Prop. Nurse & $0.049(0.553)$ & $0.199(0.558)$ & $0.271(0.550)$ & $0.193(0.566)$ \\
\hline \multicolumn{5}{|l|}{$H R M$} \\
\hline Idea & $0.189(0.120)$ & & & \\
\hline Decisions & & $0.270(0.172)$ & & \\
\hline Communication & & & $0.123(0.166)$ & \\
\hline Feedback & & & & $0.328(0.164)^{* *}$ \\
\hline Flexible & $-0.362(0.139)^{* * *}$ & $-0.385(0.144)^{* * *}$ & $-0.362(0.142)^{* *}$ & $-0.378(0.142)^{* * *}$ \\
\hline Training & $-0.205(0.119)^{*}$ & $-0.209(0.120)^{*}$ & $-0.191(0.123)$ & $-0.226(0.122)^{*}$ \\
\hline \multicolumn{5}{|l|}{ Average } \\
\hline Idea & $0.796(0.242)^{* * *}$ & & & \\
\hline Decisions & & $0.767(0.349)^{* *}$ & & \\
\hline Communication & & & $0.778(0.322)^{* *}$ & \\
\hline Feedback & & & & $0.423(0.350)$ \\
\hline Flexible & $0.706(0.358)^{* *}$ & $0.681(0.344)^{* *}$ & $0.663(0.333)^{* *}$ & $0.748(0.346)^{* *}$ \\
\hline Training & $0.289(0.260)$ & $0.391(0.298)$ & $0.363(0.313)$ & $0.437(0.317)$ \\
\hline \multicolumn{5}{|l|}{ Year Dummies } \\
\hline $2011 / 12$ & $-10.28(3.706)^{* * *}$ & $-9.939(3.582)^{* * *}$ & $-9.276(3.595)^{* *}$ & $-10.25(3.566)^{* * *}$ \\
\hline $2012 / 13$ & $-12.89(4.813)^{* * *}$ & $-12.92(4.742)^{* * *}$ & $-11.98(4.739)^{* *}$ & $-13.09(4.612)^{* * *}$ \\
\hline$R^{2}$ & 0.338 & 0.326 & 0.321 & 0.309 \\
\hline Adj. $R^{2}$ & 0.321 & 0.310 & 0.305 & 0.293 \\
\hline$N$ & 421 & 421 & 421 & 421 \\
\hline
\end{tabular}


Table A.4: Total Factor Productivity: Above Individual HRM Medians

\begin{tabular}{|c|c|c|c|c|}
\hline & (1) & (2) & (3) & (4) \\
\hline \multicolumn{5}{|l|}{ HRM } \\
\hline Ideas & $0.434(0.159)^{* * *}$ & & & \\
\hline Decisions & & $0.459(0.213)^{* *}$ & & \\
\hline Communication & & & $0.183(0.219)$ & \\
\hline Feedback & & & & $0.440(0.247)^{*}$ \\
\hline Flexible & $-0.622(0.187)^{* * *}$ & $-0.415(0.206)^{* *}$ & $-0.380(0.220)^{*}$ & $-0.325(0.187)^{*}$ \\
\hline Training & $0.013(0.177)$ & $-0.012(0.199)$ & $-0.002(0.192)$ & $-0.162(0.182)$ \\
\hline \multicolumn{5}{|l|}{ Average } \\
\hline Ideas & $0.801(0.503)$ & & & \\
\hline Decisions & & $1.221(0.563)^{* *}$ & & \\
\hline Communication & & & $1.422(0.540)^{* * *}$ & \\
\hline Feedback & & & & $1.036(0.688)$ \\
\hline Flexible & $0.455(0.428)$ & $1.021(0.551)^{*}$ & $1.359(0.495)^{* * *}$ & $1.060(0.581)^{*}$ \\
\hline Training & $0.304(0.371)$ & $0.188(0.411)$ & $-0.268(0.384)$ & $0.073(0.430)$ \\
\hline$R^{2}$ & 0.407 & 0.390 & 0.417 & 0.349 \\
\hline $\operatorname{Adj} . R^{2}$ & 0.369 & 0.352 & 0.377 & 0.314 \\
\hline$N$ & 224 & 218 & 217 & 209 \\
\hline
\end{tabular}

Table A.4 reports the TFP results for trusts where the within-hospital means of the senior management variables exceed their medians. Column 1 through 4 each includes a set of not highly correlated management variables. Management variables are lagged by one year. The coefficients of the original-form variables report FE estimates and the coefficients of the within-group means report RE estimates.

The columns include time dummies and other controls. Robust standard errors are in parentheses. ${ }^{* * *} p<0.01,{ }^{* *} p<0.05,{ }^{*} p<0.1$.

Table A.5: Simple Complementarity Results

\begin{tabular}{|c|c|c|c|c|c|c|}
\hline & (1) & (2) & (3) & (4) & (5) & (6) \\
\hline \multicolumn{7}{|l|}{ HRM } \\
\hline Decisions & $0.708(0.221)^{* * *}$ & & & $0.718(0.221)^{* * *}$ & & \\
\hline Communication & & $0.420(0.180)^{* *}$ & & & $0.360(0.180)^{* *}$ & \\
\hline Feedback & & & $0.541(0.196)^{* * *}$ & & & $0.499(0.205)^{* *}$ \\
\hline Flexible & $-0.746(0.198)^{* * *}$ & $-0.668(0.199)^{* * *}$ & $-0.693(0.192)^{* * *}$ & $-0.608(0.198)^{* * *}$ & $-0.519(0.199)^{* * *}$ & $-0.546(0.207)^{* * *}$ \\
\hline Training & $-0.032(0.184)$ & $-0.002(0.187)$ & $-0.024(0.189)$ & $-0.082(0.184)$ & $-0.039(0.187)$ & $-0.066(0.191)$ \\
\hline \multicolumn{7}{|l|}{ Average } \\
\hline Decisions & $0.211(0.440)$ & & & $0.056(0.440)$ & & \\
\hline Communication & & $0.307(0.441)$ & & & $0.301(0.441)$ & \\
\hline Feedback & & & $-0.103(0.486)$ & & & $-0.180(0.519)$ \\
\hline Flexible & $0.349(0.454)$ & $0.298(0.451)$ & $0.413(0.466)$ & $0.436(0.454)$ & $0.361(0.451)$ & $0.489(0.473)$ \\
\hline Training & $0.461(0.398)$ & $0.423(0.414)$ & $0.469(0.428)$ & $0.610(0.398)$ & $0.560(0.414)$ & $0.621(0.419)$ \\
\hline$R^{2}$ & 0.393 & 0.372 & 0.329 & 0.359 & 0.336 & 0.329 \\
\hline $\operatorname{Adj} . R^{2}$ & 0.357 & 0.337 & 0.298 & 0.325 & 0.305 & 0.298 \\
\hline$N$ & 224 & 224 & 224 & 224 & 224 & 224 \\
\hline
\end{tabular}


Table A.6: Total Factor Productivity: Incentives \& Workplace Flexibility

\begin{tabular}{lcccc}
\hline \hline & $(1)$ & $(2)$ & $(3)$ & $(4)$ \\
\hline HRM Variables E Interactions & & & & \\
Flexible & $-0.399(0.144)^{* * *}$ & $-0.349(0.146)^{* *}$ & $-0.294(0.144)^{* *}$ & $-0.296(0.140)^{* *}$ \\
Avg. Flexible & $0.643(0.328)^{*}$ & $0.924(0.375)^{* *}$ & $0.873(0.364)^{* *}$ & $0.775(0.366)^{* *}$ \\
milFlex & $0.443(0.112)^{* * *}$ & $-0.001(0.095)$ & $-0.131(0.095)$ & $-0.307(0.086)^{* * *}$ \\
\hline
\end{tabular}

Table A.6 segments the data according to the four quartiles of the within-group mean of Intention-to-Leave to investigate the interaction between incentives and workplace flexibility. Column 1 reports the results for hospitals where within-group mean of Intention-toleave falls in the first quartile. Column 2 through 4 are for the remaining quartiles. The dependent variable is total factor productivity.

The interaction term is miFlex. The coefficient of the original-form reports the FE estimate and the coefficient of the within-group mean reports the RE estimate. All the models include year dummies. Robust standard errors are given in parentheses. ${ }^{* * *} p<0.01$, ${ }^{* *} p<0.05,{ }^{*} p<0.1$.

Table A.7: Total Factor Productivity: Incentives \& Workforce Training

\begin{tabular}{|c|c|c|c|c|}
\hline & (1) & $(2)$ & (3) & $(4)$ \\
\hline \multicolumn{5}{|c|}{ HRM Variables \& Interactions } \\
\hline Training & $-0.265(0.128)^{* *}$ & $-0.117(0.136)$ & $-0.136(0.126)$ & $-0.043(0.136)$ \\
\hline Avg. Training & $0.389(0.291)$ & $0.606(0.282)^{* *}$ & $0.627(0.288)^{* *}$ & $0.468(0.281)^{*}$ \\
\hline milTrain & $0.524(0.145)^{* * *}$ & $-0.125(0.125)$ & $-0.069(0.143)$ & $-0.415(0.109)^{* * *}$ \\
\hline$R^{2}$ & 0.318 & 0.280 & 0.275 & 0.294 \\
\hline Adj. $R^{2}$ & 0.304 & 0.268 & 0.263 & 0.282 \\
\hline$N$ & 421 & 421 & 421 & 421 \\
\hline \multicolumn{5}{|c|}{$\begin{array}{l}\text { Table A.7 segments the data using the within-group mean of the Intention-to-leave variable to investigate the interaction } \\
\text { between incentives and workforce training. Column } 1 \text { reports hospitals where within-group mean of Intention-to-leave } \\
\text { is in the first quartile. Column } 2 \text { through } 4 \text { belong to the remaining quartiles. The dependent variable is total factor } \\
\text { productivity. The interaction term is miTrain. Training appears in each column twice: once in its original form and once as } \\
\text { a within-hospital mean. The coefficient of the original-form reports the FE estimate and the coefficient of the within-group } \\
\text { mean reports the RE estimate. All models include year dummies. Robust standard errors are in parentheses. }{ }^{* * *} p<0.01 \text {, } \\
{ }^{* *} p<0.05,{ }^{*} p<0.1 \text {. }\end{array}$} \\
\hline
\end{tabular}


Table A.8: Interaction Models: Human Capital Measures

\begin{tabular}{|c|c|c|c|c|c|c|}
\hline & (1) & (2) & (3) & (4) & (5) & (6) \\
\hline Prop. Emergency & $-0.371(0.638)$ & $-0.382(0.624)$ & $-0.788(0.629)$ & $-0.283(0.642)$ & $-0.264(0.625)$ & $-0.517(0.620)$ \\
\hline \multicolumn{7}{|l|}{ Skill-Mix (lagged) } \\
\hline Prop. Medical & $-0.948(1.326)$ & $0.095(1.313)$ & $0.162(1.277)$ & $-0.164(1.185)$ & $0.134(1.170)$ & $0.121(1.210)$ \\
\hline Prop. Nurse & $0.096(0.557)$ & $-0.155(0.573)$ & $0.133(0.556)$ & $0.137(0.531)$ & $-0.038(0.534)$ & $0.116(0.534)$ \\
\hline \multicolumn{7}{|l|}{ Averages } \\
\hline Prop. Medical & $-0.460(2.282)$ & $-0.578(2.275)$ & $-0.708(2.277)$ & $-0.720(2.192)$ & $-0.583(2.176)$ & $-0.574(2.193)$ \\
\hline Prop. Nurse & $0.337(1.200)$ & $0.265(1.223)$ & $0.223(1.208)$ & $-.239(1.203)$ & $-.334(1.222)$ & $-0.350(1.215)$ \\
\hline Prop. Emergency & $-1.008(0.754)$ & $-1.050(0.747)$ & $-0.924(0.758)$ & $-.774(0.761)$ & $-.786(0.747)$ & $-.710(0.765)$ \\
\hline \multicolumn{7}{|l|}{ Interactions } \\
\hline dMPropmed & $1.613(0.467)^{* * *}$ & & & $1.334(0.581)^{* *}$ & & \\
\hline dMPropnurse & & $0.641(0.172)^{* * *}$ & & & $0.609(0.215)^{* * *}$ & \\
\hline dMEmer & & & $0.520(0.150)^{* * *}$ & & & $0.518(0.206)^{* *}$ \\
\hline$R^{2}$ & 0.298 & 0.303 & 0.303 & 0.285 & 0.291 & 0.294 \\
\hline $\operatorname{Adj} . R^{2}$ & 0.285 & 0.290 & 0.289 & 0.272 & 0.278 & 0.281 \\
\hline$N$ & 417 & 417 & 417 & 417 & 417 & 417 \\
\hline $\begin{array}{l}\text { Table A. } 8 \text { tests } \mathrm{tl} \\
\text { managed organis } \\
\text { zero otherwise. } \\
\text { Columns } 1 \text { throu, } \\
4 \text { through } 6 \text { belor } \\
\text { RE estimates. All } \\
{ }^{*} p<0.1 .\end{array}$ & $\begin{array}{l}\text { Iman capital inputs } \\
\text { s. We create two ind } \\
\text { cond takes one whe } \\
\text { eport the results for } \\
\text { the second indicator. } \\
\text { els include year dum }\end{array}$ & $\begin{array}{l}\text { more productive ar } \\
\text { rs. The first takes } \\
\text { within-hospital } n \\
\text { n we interact the fir } \\
\text { coefficients of the } \\
\text { s. Robust standard }\end{array}$ & $\begin{array}{l}\text { ariables such as pro } \\
\text { when the within-hos } \\
\text { s of Job satisfaction, } \\
\text { dicator with the me } \\
\text { ginal-form variable } r \\
\text { rs are in parentheses }\end{array}$ & $\begin{array}{l}\text { rtion of emergency } \\
\text { al mean of the con } \\
\text { am quality and Jol } \\
\text { res of human capit } \\
\text { ort FE estimates an } \\
\text { he dependent varic }\end{array}$ & $\begin{array}{l}\text { ients has lower adve } \\
\text { te management inde } \\
\text { ign exceed their med } \\
\text { d proportion of emer } \\
\text { coefficients of the } \\
\text { s total factor product }\end{array}$ & $\begin{array}{l}\text { mpact in effectively } \\
\text { eeds its median and } \\
\text { and otherwise zero } \\
\text { y patients. Column } \\
\text {-group mean repor } \\
\text { *** } p<0.01,{ }^{* *} p<0.05\end{array}$ \\
\hline
\end{tabular}




\section{Supplementary File}

This document contains supplementary materials to support the analysis in the main text. The document is intended for on-line publication. Section 1 follows Aragon et al. (2015) to explain how the quality-adjusted productivity measures are constructed. Section 2 reports supplementary figures. Section 3 reports full tables of results which were given incompletely in the text for the sake of brevity. Section 4 reports labour productivity results, mirroring the results in the text for total factor productivity. Section 5 reports the robustness results discussed in the paper.

\section{Productivity Measure}

The methodology to construct quality adjusted hospital productivity is based on the approach taken by Dunleavey and Carrera (2010). To construct weights, the satisfaction scores across the hospitals for each year are arranged in an ascending order, and are then divided into five equally spaced intervals. A quality weighting factor for each of these intervals is created and are assigned to each hospital $h$ depending on their respective satisfaction score. The weighting factor ranges from 0.2 to 1 in increments of 0.2 , where 0.2 represents lowest possible weight and 1 represents maximum. Tables S1 and S2 provide these intervals and their respective quality adjustment weights for inpatient and outpatient satisfaction scores respectively. Quality adjustment weight for inpatient satisfaction score is denoted by $q_{h}^{\operatorname{Inp}}$, whereas its outpatient counterpart is denoted by $q_{h}^{\text {Out }}$. If a hospital $h$ 's inpatient and outpatient satisfaction score lies in the interval $72<q \leq 76.1$ and $80.1<q \leq 84.2$, then its respective quality adjustment weights would be assigned the following values: $q_{h}^{\text {Inp }}=0.4, q_{h}^{\text {Out }}=0.8$. The final weight, $q_{h}$, is composed of these two individual weights i.e. $q_{h}=\left\{q_{h}^{\text {Inp }}, q_{h}^{\text {Out }}\right\}$.

The two weights based on their respective inpatient and outpatient scores are then multiplied by the cost weighted output, and then divided by total input expenditure of each hospital $h$. These two data are obtained from Aragon et al. (2015). The ratio is then standardised to arrive at the final score for quality adjusted productivity. Tables S1 and S2 are based on data for the year 2012/13. Similar tables and quality adjusted hospital productivity using the same 
Table S1: Inpatient Satisfaction Score Adjustment: 2012/13

\begin{tabular}{c|c}
\hline Inpatient Satisfaction Score Interval $\left(q^{\text {Inp }}\right)$ & Adjustment Weight $\left(q_{h}^{\text {Inp }}\right)$ \\
\hline$q \leq 72$ & 0.2 \\
$72<q \leq 76.1$ & 0.4 \\
$76.1<q \leq 80.1$ & 0.6 \\
$80.1<q \leq 84.2$ & 0.8 \\
$q>84.2$ & 1 \\
\hline
\end{tabular}

This table provides the quality adjustment weights to each of the 5 equally spaced inpatient satisfaction score intervals. Satisfaction scores below or equal to 72 is assigned the lowest weight (0.2), and scores above or equal to 84.2 is assigned the highest weight

methodology have also been created for the other two years i.e. 2010/11 and 2011/12. These tables are not reported for the sake of brevity.

Table S2: Outpatient Satisfaction Score Adjustment: 2012/13

\begin{tabular}{c|c}
\hline Outpatient Satisfaction Score Interval $\left(q^{\text {Out }}\right)$ & Adjustment Weight $\left(q_{h}^{\text {Out }}\right)$ \\
\hline$q \leq 76.7$ & 0.2 \\
$76.7<q \leq 79.6$ & 0.4 \\
$79.6<q \leq 82.6$ & 0.6 \\
$82.6<q \leq 85.5$ & 0.8 \\
$q>85.5$ & 1 \\
\hline
\end{tabular}

This table provides the quality adjustment weights to each of the 5 equally spaced outpatient satisfaction score intervals. Satisfaction scores below or equal to 76.7 is assigned the lowest weight (0.2), and scores above or equal to 85.5 is assigned the highest weight

This methodology to construct quality adjusted hospital productivity is also very similar to approaches taken by Aragon et al. (2015) and Castelli et al. (2015). The only major difference concerns the methodology to construct and use quality adjustment weights. The quality adjustment factor, $q_{h}$, under Aragon et al. (2015) and Castelli et al. (2015), is constructed by standardising each hospital's quality indicator by the national average i.e. quality measure for all hospitals. Furthermore, the quality data is designed to reflect the quality-adjusted life years, and is obtained from accessing detailed patient-level data from Hospital Episode Statistics and ONS mortality database.

Aragon et al. (2015) define the measure of output for hospital productivity as follows:

$$
X_{h}=\sum_{j=1}^{J} x_{j h} \bar{c}_{j}
$$


where $x_{j h}$ represents output category $j$ with $j=1,2, \ldots, J$ for hospital $h . \bar{c}_{j}$ is the cost weight and is defined as $\bar{c}_{j}=c_{j} / \hat{c}$ where $c_{j}$ represents the national average cost for patients allocated to output $j$ and $\hat{c}$ is the national average cost across all patients. The main difference between the productivity measure employed in this paper and the one used in Aragon et al. (2015) is that allowance is made for quality adjustment for each hospital. $q_{h}$ is the quality adjustment factor for hospital $h$, where $q_{h}=\left\{q_{h}^{\text {Inp }}, q_{h}^{\text {Out }}\right\} . q_{h}$ or its two components, $q_{h}^{\text {Inp }}$ and $q_{h}^{\text {Out }}$ is multiplied to cost-weighted output in equation (1) to obtain quality-weighted hospital output for each hospital $h$ :

$$
X_{h}^{Q}=\sum_{j=1}^{J} x_{j h} \bar{c}_{j} q_{h}
$$

If there are multiple quality indicators, then we simply weight the hospital by as many quality adjustment factors. The output measure is based on Healthcare Resource Groups (HRG). HRGs is used to classify patients into different patient groups to take into account their diverse healthcare needs and treatments. Hospital output in equation (1) or (2) take into account all healthcare services produced by NHS hospitals. These include not only inpatient and outpatient but also accident \& emergency, diagnostics, maternity, mental amongst others. Measure of total inputs is given by equation (3)

$$
Z_{h}^{T F}=Z_{h}^{L}+E_{h}^{M}+E_{h}^{K}=Z_{h}^{D L}+E_{h}^{A}+E_{h}^{M}+E_{h}^{K}
$$

where

$$
Z_{h}^{L}=Z_{h}^{D L}+E_{h}^{A}
$$

is the total labour expenditure consisting of direct labour and agency staff expenditure where

$$
Z_{h}^{D L}=\sum_{n=1}^{N} z_{n h} \omega_{n}
$$

$z_{n h}$ is the volume of input type $n$ for example medical or nursing staff for $n=1 \ldots N$ and $\omega_{n}$ is the national average wage for input type $n . E_{h}^{A}$ is total expenditure on agency staff where $E_{h}^{M}$ and $E_{h}^{K}$ represent total expenditure for intermediate inputs and capital. Combining equations (2) and (4) yields labour productivity ratio:

$$
P_{h}^{L}=\frac{X_{h}^{Q}}{Z_{h}^{L}}=\frac{\sum_{j=1}^{J} x_{j h} \bar{c}_{j} q_{h}}{\sum_{n=1}^{N} z_{n h} \omega_{n}+E_{h}^{A}}
$$

and combining equations (2) and (3) gives TFP ratio for each hospital:

$$
P_{h}^{T F}=\frac{X_{h}^{Q}}{Z_{h}^{T F}}=\frac{\sum_{j=1}^{J} x_{j h} \bar{c}_{j} q_{h}}{\sum_{n=1}^{N} z_{n h} \omega_{n}+E_{h}^{A}+E_{h}^{M}+E_{h}^{K}}
$$

For the purposes interpretation and comparison across hospitals, TFP and labour productivity 
ratios are standardized using national average and multiplied by 100 :

$$
\begin{aligned}
P_{h}^{S, L} & =\left\{\left[\left(\frac{X_{h}^{Q}}{Z_{h}^{L}}\right) / \frac{1}{H} \sum_{h} \frac{X_{h}^{Q}}{Z_{h}^{L}}\right]-1\right\} \times 100 \\
P_{h}^{S, T F} & =\left\{\left[\left(\frac{X_{h}^{Q}}{Z_{h}^{T F}}\right) / \frac{1}{H} \sum_{h} \frac{X_{h}^{Q}}{Z_{h}^{T F}}\right]-1\right\} \times 100
\end{aligned}
$$

Equations (8) and (9) provides a relative interpretation of productivity. For example, if a hospital's standardized labour productivity index or score is 10 then this implies that labour productivity in that hospital is $10 \%$ higher than national average. 


\section{Supplementary Figures}

Figure S1: Distribution of 10 HRM Practices
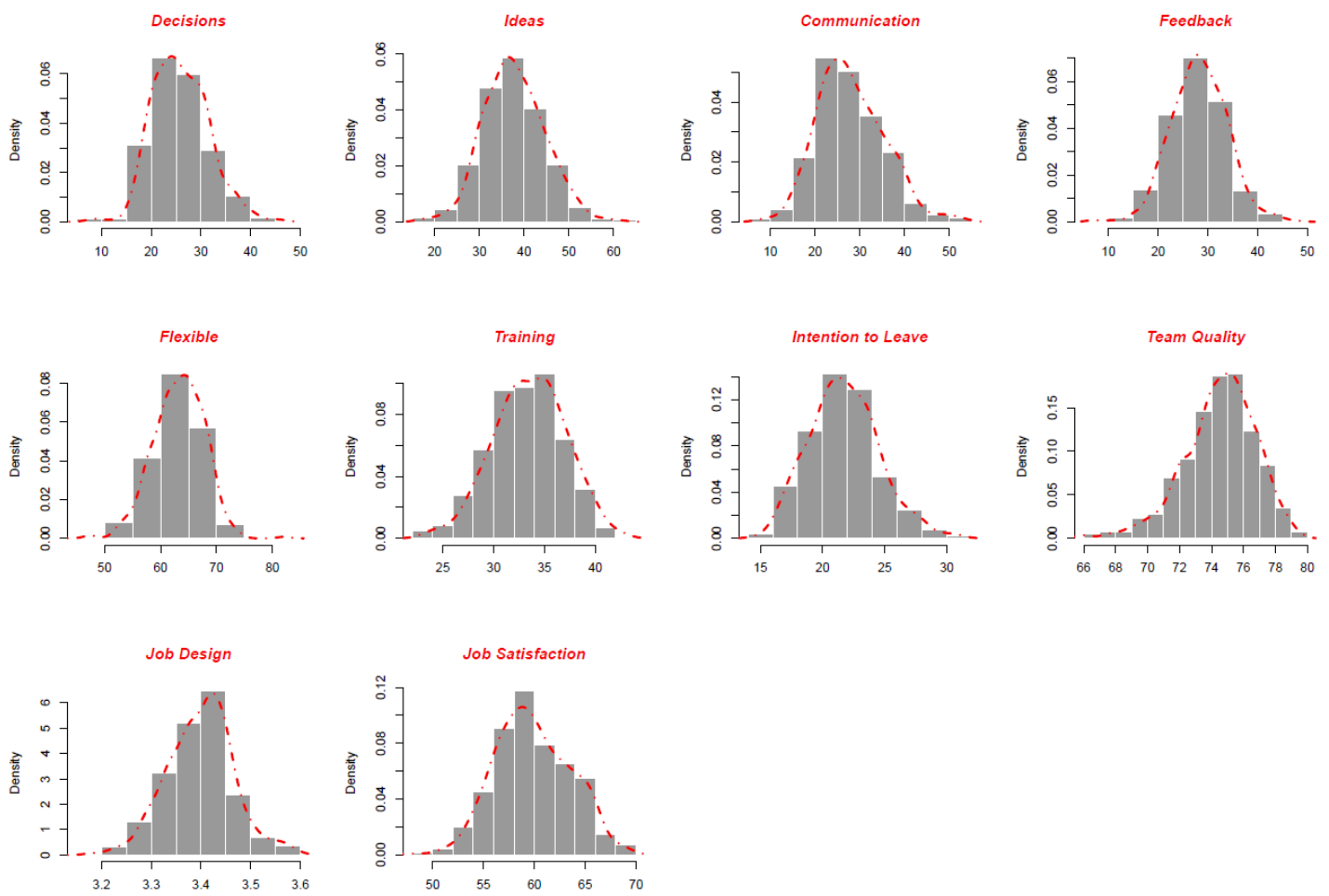

This diagram provides the distribution of the 10 human resource management practices. IT shows that there exists considerable variations in the use of these practices across the NHS hospitals. 


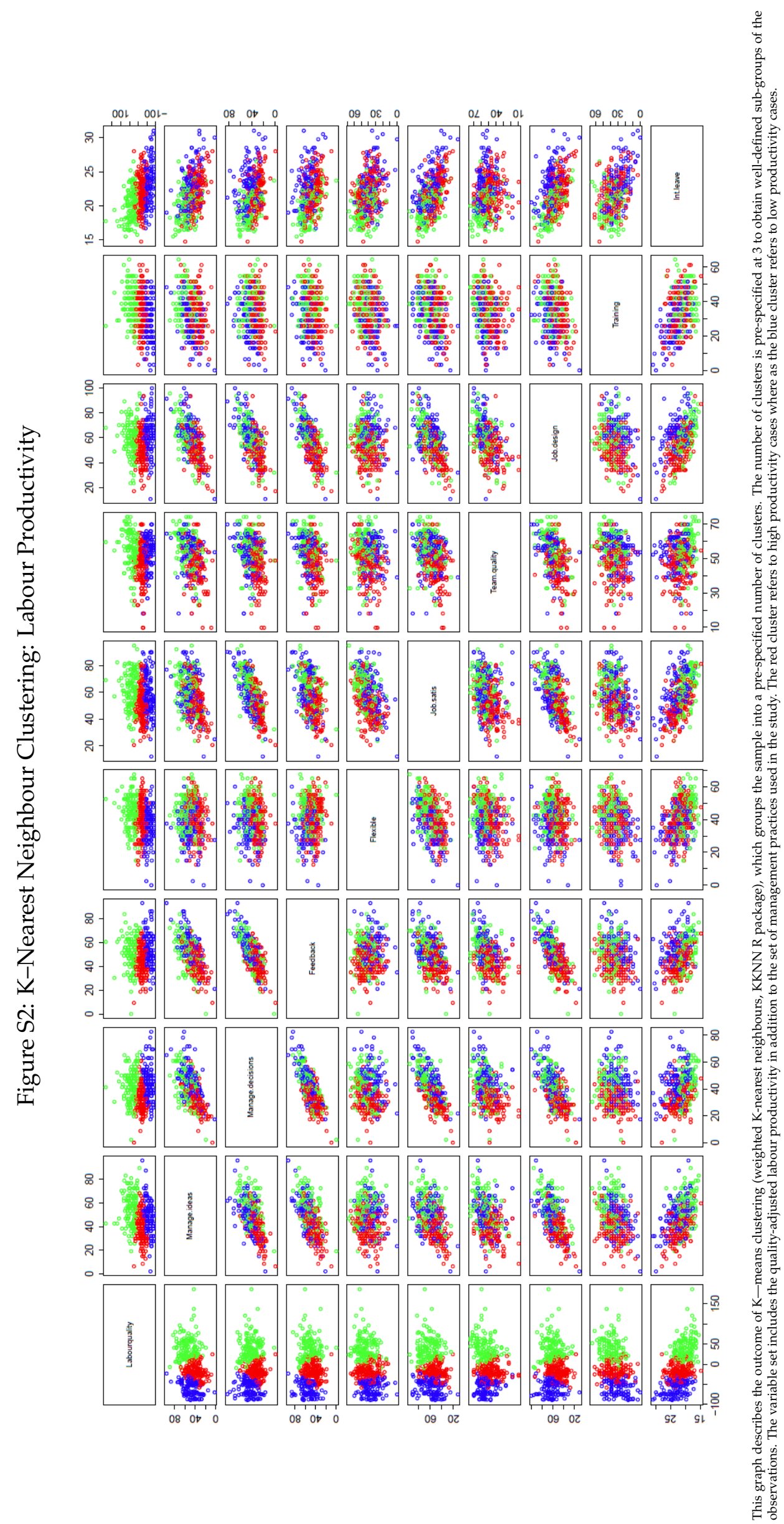




\section{Supplementary Tables}

Table S3: Between and Within Variation Statistics: HRM Practices

\begin{tabular}{lcccc}
\hline HRM Practices & Between Std.Dev & Within Std.Dev & Min (Within) & Max (Within) \\
\hline Senior Management & & & & \\
Decisions & 4.76 & 2.87 & 17.94 & 35.23 \\
Communication & 5.49 & 5.02 & 17.72 & 44.72 \\
Feedback & 4.74 & 2.92 & 20.25 & 35.25 \\
Ideas & 6.12 & 3.00 & 30.48 & 48.82 \\
Flexible & 3.42 & 2.94 & 51.94 & 74.94 \\
Training & 3.22 & 1.54 & 28.55 & 38.55 \\
Team Quality & 2.27 & 0.00 & 74.53 & 74.53 \\
Intention to Leave & 2.51 & 1.30 & 16.46 & 27.21 \\
Job-Satisfaction & 2.72 & 2.45 & 53.00 & 67.37 \\
Job-Design & 0.06 & 0.03 & 3.32 & 3.50 \\
\hline
\end{tabular}

Table S3 presents the within and the between variation of the 10 human resource management practices. It provides within (i.e. at hospital level) variation summary statistics for HRM practices measured using standard deviation alongside within minimum and maximum values. The table also provides between variations as a comparison to the within counterpart. The within-variation tells us how does an individual hospital vary at any particular time point from its individual mean. It is calculated by taking the mean of the standard deviations for hospitals in the sample data. 
Table S4: Summary Statistics for Other Hospital and Patient led Factors

\begin{tabular}{|c|c|c|c|c|c|c|c|}
\hline \multirow[b]{2}{*}{ Variables } & \multirow[b]{2}{*}{ Definition } & \multicolumn{2}{|c|}{ 2010/11 } & \multicolumn{2}{|c|}{$2011 / 12$} & \multicolumn{2}{|c|}{$2012 / 13$} \\
\hline & & Mean & Std.Dev & Mean & Std.Dev & Mean & Std.Dev \\
\hline \multicolumn{8}{|l|}{ Structural } \\
\hline Teaching Status & $\begin{array}{l}\text { Equal to } 1 \text { if hospital is Teaching } \\
\text { and } 0 \text { otherwise }\end{array}$ & 0.21 & 0.41 & 0.21 & 0.41 & 0.22 & 0.41 \\
\hline Foundation Trust & $\begin{array}{l}\text { Equal to } 1 \text { if hospital has FT status } \\
\text { and } 0 \text { otherwise }\end{array}$ & 0.51 & 0.50 & 0.54 & 0.50 & 0.57 & 0.5 \\
\hline Beds & Average number of available beds & 742.87 & 328.84 & 739.13 & 338.77 & 750.96 & 342.00 \\
\hline \multicolumn{8}{|l|}{ Regional } \\
\hline London & $\begin{array}{l}\text { Equal to } 1 \text { if hospital located in } \\
\text { London and } 0 \text { otherwise }\end{array}$ & 0.17 & 0.37 & 0.17 & 0.37 & 0.15 & 0.36 \\
\hline MMF (\%) & $\mathrm{MFF}^{*} 100$ & 108.62 & 7.30 & 108.48 & 7.09 & 108.24 & 6.91 \\
\hline GP & $\begin{array}{l}\text { Number of GPs per } 100,000 \text { resi- } \\
\text { dent population }\end{array}$ & 68.35 & 3.79 & 63.38 & 3.95 & 67.32 & 3.77 \\
\hline \multicolumn{8}{|l|}{ Patient-Led } \\
\hline Prop Emergency (\%) & $\begin{array}{l}\text { (Emergency admissions / Total ad- } \\
\text { missions) }{ }^{*} 100\end{array}$ & 37.57 & 5.77 & 36.93 & 5.49 & 37.41 & 5.52 \\
\hline Prop Female (\%) & $\begin{array}{l}\text { (Female admissions / Total admis- } \\
\text { sions })^{*} 100\end{array}$ & 56.92 & 2.82 & 56.67 & 2.79 & 56.53 & 2.65 \\
\hline Patients aged 0-14 (\%) & $\begin{array}{l}\text { Proportion of patients }(\mathrm{FCE}) \text { under } \\
14 \text { years of age }\end{array}$ & 11.24 & 3.64 & 11.10 & 3.74 & 11.10 & 3.65 \\
\hline Patients aged $15-44(\%)$ & $\begin{array}{l}\text { Proportion of patients (FCE) be- } \\
\text { tween } 15 \text { and } 44 \text { years of age }\end{array}$ & 27.42 & 5.07 & 26.61 & 4.91 & 25.73 & 4.60 \\
\hline Patients aged $45-59(\%)$ & $\begin{array}{l}\text { Proportion of patients (FCE) be- } \\
\text { tween } 45 \text { and } 59 \text { years of age }\end{array}$ & 15.48 & 1.75 & 15.62 & 1.82 & 15.69 & 1.80 \\
\hline Patients aged over $60(\%)$ & $\begin{array}{l}\text { Proportion of patients (FCE) aged } \\
\text { over } 60 \text { years of age }\end{array}$ & 45.54 & 7.23 & 46.26 & 7.30 & 47.02 & 6.98 \\
\hline \multicolumn{8}{|l|}{ Skill-Mix } \\
\hline Prop Medical (\%) & $\begin{array}{l}\text { (Medical workforce / Medical }+ \\
\text { non-medical workforce) } * 100\end{array}$ & 11.14 & 1.97 & 11.76 & 2.24 & 11.61 & 2.56 \\
\hline Prop Nurse (\%) & $\begin{array}{l}\text { (Nursing workforce / Medical + } \\
\text { non-medical workforce) } * 100\end{array}$ & 32.57 & 3.89 & 30.96 & 2.82 & 31.16 & 2.81 \\
\hline
\end{tabular}

Table S4 provides brief variable definitions for the control variables, and their corresponding summary statistics, mean and standard deviation. 
Table S5: Total Factor Productivity: Above Individual HRM Medians

\begin{tabular}{|c|c|c|c|c|}
\hline & (1) & (2) & (3) & (4) \\
\hline Intercept & $-105.6(222.9)$ & $-406.6(227.6)^{*}$ & $-242.7(218.1)$ & $-432.3(261.1)^{*}$ \\
\hline \multicolumn{5}{|l|}{ Structural } \\
\hline Teaching Trust & $-0.298(11.21)$ & $-4.020(11.35)$ & $-2.468(10.66)$ & $-5.019(12.14)$ \\
\hline Foundation Trust & $4.415(6.474)$ & $3.480(7.312)$ & $3.752(7.086)$ & $2.316(7.046)$ \\
\hline Hospital Beds & $-0.006(0.013)$ & $0.023(0.023)$ & $0.034(0.020)^{*}$ & $0.034(0.023)$ \\
\hline \multicolumn{5}{|l|}{ Regional } \\
\hline MFF & $-2.577(0.976)^{* * *}$ & $-1.988(0.900)^{* *}$ & $-2.425(0.726)^{* * *}$ & $-1.725(0.946)^{*}$ \\
\hline GP per 100,000 & $2.196(0.705)^{* * *}$ & $2.325(0.836)^{* * *}$ & $2.486(0.879)^{* * *}$ & $2.941(0.967)^{* * *}$ \\
\hline \multicolumn{5}{|l|}{ Patient } \\
\hline Prop. Emergency & $-1.378(0.463)^{* * *}$ & $-0.725(0.638)$ & $-0.528(0.574)$ & $-0.760(0.653)$ \\
\hline Prop. Female & $1.203(1.629)$ & $1.685(1.355)$ & $0.492(1.406)$ & $1.006(1.548)$ \\
\hline Patients aged 0-14 & $2.724(1.429)^{*}$ & $4.086(1.505)^{* * *}$ & $2.671(1.410)^{*}$ & $4.530(1.554)^{* * *}$ \\
\hline Patients aged 45-59 & $1.526(2.237)$ & $4.166(2.314)^{*}$ & $1.320(2.412)$ & $3.143(2.402)$ \\
\hline Patients aged over 60 & $2.350(0.843)^{* * *}$ & $3.695(0.890)^{* * *}$ & $2.928(0.850)^{* * * *}$ & $3.566(0.965)^{* * *}$ \\
\hline \multicolumn{5}{|l|}{ Skill-Mix } \\
\hline Prop. Medical & $-0.926(1.314)$ & $-0.172(1.082)$ & $-0.084(1.016)$ & $-0.772(0.995)$ \\
\hline Prop. Nurse & $0.252(0.718)$ & $-0.100(0.782)$ & $0.276(0.750)$ & $0.076(0.782)$ \\
\hline \multicolumn{5}{|l|}{$H R M$} \\
\hline Ideas & $0.434(0.159)^{* * *}$ & & & \\
\hline Decisions & & $0.459(0.213)^{* *}$ & & \\
\hline Communication & & & $0.183(0.219)$ & \\
\hline Feedback & & & & $0.440(0.247)^{*}$ \\
\hline Flexible & $-0.622(0.187)^{* * *}$ & $-0.415(0.206)^{* *}$ & $-0.380(0.220)^{*}$ & $-0.325(0.187)^{*}$ \\
\hline Training & $0.013(0.177)$ & $-0.012(0.199)$ & $-0.002(0.192)$ & $-0.162(0.182)$ \\
\hline \multicolumn{5}{|l|}{ Average } \\
\hline Ideas & $0.801(0.503)$ & & & \\
\hline Decisions & & $1.221(0.563)^{* *}$ & & \\
\hline Communication & & & $1.422(0.540)^{* * *}$ & \\
\hline Feedback & & & & $1.036(0.688)$ \\
\hline Flexible & $0.455(0.428)$ & $1.021(0.551)^{*}$ & $1.359(0.495)^{* * *}$ & $1.060(0.581)^{*}$ \\
\hline Training & $0.304(0.371)$ & $0.188(0.411)$ & $-0.268(0.384)$ & $0.073(0.430)$ \\
\hline$R^{2}$ & 0.407 & 0.390 & 0.417 & 0.349 \\
\hline Adj. $R^{2}$ & 0.369 & 0.352 & 0.377 & 0.314 \\
\hline$N$ & 224 & 218 & 217 & 209 \\
\hline
\end{tabular}


Table S6: Simple Complementarity Results

\begin{tabular}{|c|c|c|c|c|c|c|}
\hline & (1) & (2) & (3) & (4) & (5) & (6) \\
\hline Intercept & $-56.73(229.9)$ & $-17.81(242.3)$ & $-69.49(243.8)$ & $0.793(229.93)$ & $37.37(242.31)$ & $-1.278(236.8)$ \\
\hline \multicolumn{7}{|l|}{ Structural } \\
\hline Teaching Trust & $6.376(10.84)$ & $4.771(11.12)$ & $5.145(11.60)$ & $5.005(10.84)$ & $3.596(11.12)$ & $3.921(12.38)$ \\
\hline Foundation Trust & $5.845(6.669)$ & $5.007(6.570)$ & $5.025(6.853)$ & $7.593(6.669)$ & $6.834(6.570)$ & $6.790(6.790)$ \\
\hline Hospital Beds & $-0.011(0.013)$ & $-0.012(0.013)$ & $-0.012(0.013)$ & $-0.005(0.013)$ & $-0.006(0.013)$ & $-0.006(0.014)$ \\
\hline \multicolumn{7}{|l|}{ Regional } \\
\hline MFF & $-3.148(1.066)^{* * *}$ & $-3.249(1.114)^{* * *}$ & $-2.770(1.165)^{* *}$ & $-3.086(1.066)^{* * *}$ & $-3.200(1.114)^{* * *}$ & $-2.733(1.205)^{* *}$ \\
\hline GP per 100,000 & $2.085(0.758)^{* * *}$ & $2.078(0.765)^{* * *}$ & $2.020(0.786)^{* *}$ & $1.938(0.758)^{* *}$ & $1.933(0.765)^{* *}$ & $1.857(0.783)^{* *}$ \\
\hline \multicolumn{7}{|l|}{ Patient } \\
\hline Prop. Emergency & $-1.226(0.463)^{* * *}$ & $-1.295(0.489)^{* * *}$ & $-1.232(0.489)^{* *}$ & $-1.440(0.463)^{* * *}$ & $-1.473(0.489)^{* * *}$ & $-1.418(0.507)^{* * *}$ \\
\hline Prop. Female & $1.314(1.589)$ & $1.118(1.666)$ & $1.175(1.670)$ & $0.522(1.589)$ & $0.337(1.666)$ & $0.354(1.680)$ \\
\hline Patients aged $0-14$ & $3.220(1.506)^{* *}$ & $3.049(1.504)^{* *}$ & $3.257(1.548)^{* *}$ & $2.480(1.506)$ & $2.295(1.504)$ & $2.389(1.576)$ \\
\hline Patients aged $45-59$ & $1.392(2.362)$ & $0.957(2.418)$ & $1.465(2.381)$ & $1.253(2.362)$ & $0.725(2.418)$ & $1.193(2.448)$ \\
\hline Patients aged over 60 & $2.864(0.861)^{* * *}$ & $2.700(0.883)^{* * *}$ & $2.753(0.911)^{* * *}$ & $2.380(0.861)^{* * *}$ & $2.231(0.883)^{* *}$ & $2.207(0.914)^{* *}$ \\
\hline \multicolumn{7}{|l|}{ Skill-Mix } \\
\hline Prop. Medical & $-0.313(1.421)$ & $-0.122(1.456)$ & $-0.369(1.447)$ & $2.196(1.421)$ & $2.342(1.456)$ & $2.132(1.634)$ \\
\hline Prop. Nurse & $0.621(0.741)$ & $0.773(0.746)$ & $0.540(0.764)$ & $0.218(0.741)$ & $0.345(0.746)$ & $0.119(0.781)$ \\
\hline \multicolumn{7}{|l|}{$H R M$} \\
\hline Decisions & $0.708(0.221)^{* * *}$ & & & $0.718(0.221)^{* * *}$ & & \\
\hline Communication & & $0.420(0.180)^{* *}$ & & & $0.360(0.180)^{* *}$ & \\
\hline Feedback & & & $0.541(0.196)^{* * *}$ & & & $0.499(0.205)^{* *}$ \\
\hline Flexible & $-0.746(0.198)^{* * *}$ & $-0.668(0.199)^{* * *}$ & $-0.693(0.192)^{* * *}$ & $-0.608(0.198)^{* * *}$ & $-0.519(0.199)^{* * *}$ & $-0.546(0.207)^{* * *}$ \\
\hline Training & $-0.032(0.184)$ & $-0.002(0.187)$ & $-0.024(0.189)$ & $-0.082(0.184)$ & $-0.039(0.187)$ & $-0.066(0.191)$ \\
\hline \multicolumn{7}{|l|}{ Average } \\
\hline Decisions & $0.211(0.440)$ & & & $0.056(0.440)$ & & \\
\hline Communication & & $0.307(0.441)$ & & & $0.301(0.441)$ & \\
\hline Feedback & & & $-0.103(0.486)$ & & & $-0.180(0.519)$ \\
\hline Flexible & $0.349(0.454)$ & $0.298(0.451)$ & $0.413(0.466)$ & $0.436(0.454)$ & $0.361(0.451)$ & $0.489(0.473)$ \\
\hline Training & $0.461(0.398)$ & $0.423(0.414)$ & $0.469(0.428)$ & $0.610(0.398)$ & $0.560(0.414)$ & $0.621(0.419)$ \\
\hline \multicolumn{7}{|l|}{ Year Dummies } \\
\hline $2011 / 12$ & $-16.04(4.885)^{* * *}$ & $-13.81(4.997)^{* * *}$ & $-15.28(4.739)^{* * *}$ & $-15.23(4.885)^{* * *}$ & $-12.64(4.997)^{* *}$ & $-14.13(5.082)^{* * *}$ \\
\hline $2012 / 13$ & $-22.21(6.114)^{* * *}$ & $-19.70(6.178)^{* * *}$ & $-20.65(5.950)^{* * *}$ & $-21.18(6.114)^{* * *}$ & $-18.23(6.178)^{* * *}$ & $-19.24(6.324)^{* * *}$ \\
\hline$R^{2}$ & 0.393 & 0.372 & 0.329 & 0.359 & 0.336 & 0.329 \\
\hline Adj. $R^{2}$ & 0.357 & 0.337 & 0.298 & 0.325 & 0.305 & 0.298 \\
\hline$N$ & 224 & 224 & 224 & 224 & 224 & 224 \\
\hline
\end{tabular}


Table S7: Total Factor Productivity: Incentives \& Workplace Flexibility

\begin{tabular}{|c|c|c|c|c|}
\hline & (1) & (2) & (3) & (4) \\
\hline Intercept & $-27.94(175.4)$ & $-64.06(184.1)$ & $-60.83(182.9)$ & $-63.21(183.8)$ \\
\hline \multicolumn{5}{|l|}{ Structural } \\
\hline Teaching Trust & $-0.512(7.447)$ & $5.029(8.084)$ & $3.924(8.163)$ & $4.054(8.043)$ \\
\hline Foundation Trust & $9.893(4.805)^{* *}$ & $12.364(5.342)^{* *}$ & $11.951(5.343)^{* *}$ & $10.657(5.155)^{* *}$ \\
\hline Hospital Beds & $0.001(0.009)$ & $-0.003(0.010)$ & $-0.003(0.010)$ & $-0.002(0.009)$ \\
\hline \multicolumn{5}{|l|}{ Regional } \\
\hline MFF & $-2.255(0.559)^{* * *}$ & $-2.255(0.615)^{* * *}$ & $-2.306(0.619)^{* * *}$ & $-2.095(0.586)^{* * *}$ \\
\hline GP per 100,000 & $2.254(0.543)^{* * *}$ & $2.219(0.577)^{* * *}$ & $2.234(0.574)^{* * *}$ & $2.268(0.561)^{* * *}$ \\
\hline \multicolumn{5}{|l|}{ Patients } \\
\hline Prop. Emergency & $-0.961(0.456)^{* *}$ & $-0.980(0.483)^{* *}$ & $-0.944(0.484)^{*}$ & $-1.028(0.478)^{* *}$ \\
\hline Prop. Female & $0.041(1.217)$ & $0.125(1.291)$ & $0.140(1.282)$ & $-0.028(1.272)$ \\
\hline Patients aged $0-14$ & $1.797(1.114)$ & $2.092(1.156)^{*}$ & $2.007(1.157)^{*}$ & $2.150(1.150)^{*}$ \\
\hline Patients aged $45-59$ & $1.358(1.885)$ & $1.794(1.982)$ & $1.931(1.947)$ & $1.656(2.024)$ \\
\hline Patients aged over 60 & $1.735(0.714)^{* *}$ & $2.203(0.753)^{* * *}$ & $2.129(0.749)^{* * *}$ & $2.164(0.756)^{* * *}$ \\
\hline \multicolumn{5}{|l|}{ Skill-Mix } \\
\hline Prop. Medical & $-0.299(0.817)$ & $-0.283(0.871)$ & $-0.266(0.881)$ & $-0.355(0.852)$ \\
\hline Prop. Nurse & $0.313(0.531)$ & $0.191(0.566)$ & $0.260(0.565)$ & $0.207(0.558)$ \\
\hline \multicolumn{5}{|c|}{ HRM Variables \& Interactions } \\
\hline Flexible & $-0.399(0.144)^{* * *}$ & $-0.349(0.146)^{* *}$ & $-0.294(0.144)^{* *}$ & $-0.296(0.140)^{* *}$ \\
\hline Avg. Flexible & $0.643(0.328)^{*}$ & $0.924(0.375)^{* *}$ & $0.873(0.364)^{* *}$ & $0.775(0.366)^{* *}$ \\
\hline milFlex & $0.443(0.112)^{* * * *}$ & $-0.001(0.095)$ & $-0.131(0.095)$ & $-0.307(0.086)^{* * *}$ \\
\hline \multicolumn{5}{|l|}{ Year Dummies } \\
\hline $2011 / 12$ & $-6.347(3.501)^{*}$ & $-8.017(3.476)^{* *}$ & $-7.468(3.483)^{* *}$ & $-8.329(3.466)^{* *}$ \\
\hline $2012 / 13$ & $-7.633(4.252)^{*}$ & $-9.852(4.363)^{* *}$ & $-9.256(4.308)^{* *}$ & $-10.022(4.342)^{* *}$ \\
\hline$R^{2}$ & 0.328 & 0.282 & 0.282 & 0.299 \\
\hline $\operatorname{Adj} . R^{2}$ & 0.314 & 0.270 & 0.270 & 0.286 \\
\hline$N$ & 421 & 421 & 421 & 421 \\
\hline
\end{tabular}

Table S7 segments the data according to the four quartiles of the within-group mean of the variable Intention-to-Leave to investigate the interaction between incentives and workplace flexibility (Flexible). Column 1 reports the results for hospitals where within-group mean of Intention-to-leave is below or equal to the first quartile. Columns 2 through 4 respectively reports the results for the remaining quartiles. The dependent variable in all the models is the quality-adjusted total factor productivity measure. In addition to the interaction term miFlex, Flexible appears in each column twice: once in its original form and once as a within-hospital mean. The coefficient of the original-form variable reports the fixed effects estimate and the coefficient of the within-group mean reports the random effects estimate. All the models include year dummies. Robust standard errors are given in parentheses. ${ }^{* * *} p<0.01,{ }^{* *} p<0.05,{ }^{*} p<0.1$. 
Table S8: Total Factor Productivity: Incentives \& Workforce Training

\begin{tabular}{|c|c|c|c|c|}
\hline & (1) & (2) & (3) & (4) \\
\hline Intercept & $-61.19(176.2)$ & $-120.46(186.9)$ & $-131.1(187.6)$ & $-106.8(187.7)$ \\
\hline \multicolumn{5}{|l|}{ Structural } \\
\hline Teaching Trust & $-0.274(7.642)$ & $4.842(7.969)$ & $4.262(8.305)$ & $4.476(8.122)$ \\
\hline Foundation Trust & $9.731(4.895)^{* *}$ & $12.352(5.437)^{* *}$ & $12.109(5.412)^{* *}$ & $10.812(5.285)^{* *}$ \\
\hline Hospital Beds & $0.001(0.009)$ & $-0.003(0.009)$ & $-0.003(0.009)$ & $-0.003(0.009)$ \\
\hline \multicolumn{5}{|l|}{ Regional } \\
\hline MFF & $-2.311(0.535)^{* * *}$ & $-2.261(0.591)^{* * *}$ & $-2.230(0.594)^{* * *}$ & $-2.068(0.563)^{* * *}$ \\
\hline GP per 100,000 & $2.358(0.535)^{* * *}$ & $2.345(0.559)^{* * *}$ & $2.349(0.555)^{* * *}$ & $2.421(0.539)^{* * *}$ \\
\hline \multicolumn{5}{|l|}{ Patients } \\
\hline Prop. Emergency & $-0.917(0.465)^{* *}$ & $-0.935(0.492)^{*}$ & $-0.907(0.496)^{*}$ & $-0.940(0.484)^{*}$ \\
\hline Prop. Female & $0.488(1.242)$ & $0.840(1.322)$ & $0.839(1.326)$ & $0.348(1.345)$ \\
\hline Patients aged $0-14$ & $1.870(1.122)^{*}$ & $2.164(1.149)^{*}$ & $2.162(1.161)^{*}$ & $2.131(1.163)^{*}$ \\
\hline Patients aged $45-59$ & $1.166(1.862)$ & $1.819(1.971)$ & $2.033(1.967)$ & $1.499(2.033)$ \\
\hline Patients aged over 60 & $1.884(0.733)^{* *}$ & $2.344(0.775)^{* * *}$ & $2.363(0.779)^{* * *}$ & $2.280(0.789)^{* * *}$ \\
\hline \multicolumn{5}{|l|}{ Skill-Mix } \\
\hline Prop. Medical & $-0.037(0.847)$ & $-0.180(0.880)$ & $-0.131(0.888)$ & $-0.112(0.878)$ \\
\hline Prop. Nurse & $0.277(0.498)$ & $0.182(0.520)$ & $0.213(0.520)$ & $0.205(0.512)$ \\
\hline \multicolumn{5}{|c|}{ HRM Variables $\mathcal{E}$ Interactions } \\
\hline Training & $-0.265(0.128)^{* *}$ & $-0.117(0.136)$ & $-0.136(0.126)$ & $-0.043(0.136)$ \\
\hline Avg. Training & $0.389(0.291)$ & $0.606(0.282)^{* *}$ & $0.627(0.288)^{* *}$ & $0.468(0.281)^{*}$ \\
\hline milTrain & $0.524(0.145)^{* * *}$ & $-0.125(0.125)$ & $-0.069(0.143)$ & $-0.415(0.109)^{* * *}$ \\
\hline \multicolumn{5}{|l|}{ Year Dummies } \\
\hline 2011/12 & $-1.484(2.539)$ & $-2.241(2.495)$ & $-2.102(2.533)$ & $-2.200(2.487)$ \\
\hline $2012 / 13$ & $-1.765(2.838)$ & $-2.894(2.909)$ & $-2.974(2.899)$ & $-2.886(2.902)$ \\
\hline$R^{2}$ & 0.318 & 0.280 & 0.275 & 0.294 \\
\hline Adj. $R^{2}$ & 0.304 & 0.268 & 0.263 & 0.282 \\
\hline$N$ & 421 & 421 & 421 & 421 \\
\hline
\end{tabular}

Table S8 segments the data using the within-group mean of the Intention-to-leave variable to investigate the interaction between incentives and workforce training (Training). Column 1 reports the results for hospitals where within-group mean of Intention-to-leave is below or equal to the first quartile. Columns 2 through 4 respectively report the results for the remaining quartiles. The dependent variable in all the models is the quality-adjusted total factor productivity measure. In addition to the interaction term miTrain, Training appears in each column twice: once in its original form and once as a within-hospital mean. The coefficient of the original-form variable reports the fixed effects estimate and the coefficient of the within-group mean reports the random effects estimate. All the models include year dummies. Robust standard errors are given in parentheses. ${ }^{* * *} p<0.01,{ }^{* *} p<0.05,{ }^{*} p<0.1$. 
Table S9: Interaction Models: Human Capital Measures

\begin{tabular}{|c|c|c|c|c|c|c|}
\hline & (1) & (2) & (3) & (4) & (5) & (6) \\
\hline Intercept & $-20.54(178.7)$ & $-6.780(177.3)$ & $-6.683(176.0)$ & $-27.91(187.5)$ & $-20.38(185.6)$ & $-15.82(184.0)$ \\
\hline \multicolumn{7}{|l|}{ Structural } \\
\hline Teaching Trust & $1.030(7.786)$ & $0.360(7.723)$ & $0.781(7.708)$ & $4.771(8.202)$ & $4.521(8.272)$ & $4.419(8.245)$ \\
\hline Foundation Trust & $10.22(5.239)^{*}$ & $10.06(5.194)^{*}$ & $10.42(5.181)^{* *}$ & $10.24(5.114)^{* *}$ & $9.870(5.062)^{* *}$ & $10.36(5.046)^{* * *}$ \\
\hline Hospital Beds & $0.003(0.009)$ & $0.004(0.009)$ & $0.004(0.009)$ & $0.001(0.010)$ & $0.002(0.0)$ & $0.002(0.010)$ \\
\hline \multicolumn{7}{|l|}{ Regional } \\
\hline MFF & $-2.929(0.661)^{* * *}$ & $-2.987(0.645)^{* * *}$ & $-2.837(0.639)^{* * *}$ & $-2.550(0.637)^{* * *}$ & $-2.589(0.623)^{* * *}$ & $-2.517(0.625)^{* * *}$ \\
\hline GP per 100,000 & $2.492(0.586)^{* * *}$ & $2.415(0.588)^{* * *}$ & $2.431(0.596)^{* * *}$ & $2.121(0.597)^{* * *}$ & $2.009(0.599)^{* * *}$ & $2.055(0.602)^{* * *}$ \\
\hline \multicolumn{7}{|l|}{ Patient } \\
\hline Prop. Emergency & $-0.371(0.638)$ & $-0.382(0.624)$ & $-0.788(0.629)$ & $-0.283(0.642)$ & $-0.264(0.625)$ & $-0.517(0.620)$ \\
\hline Prop. Female & $0.449(1.292)$ & $0.410(1.288)$ & $0.313(1.282)$ & $0.597(1.317)$ & $0.645(1.292)$ & $0.505(1.289)$ \\
\hline Patients aged 0-14 & $2.864(1.166)^{* *}$ & $2.890(1.147)^{* *}$ & $2.777(1.151)^{* *}$ & $2.165(1.192)^{*}$ & $2.232(1.202)^{*}$ & $2.132(1.192)^{*}$ \\
\hline Patients aged 45-59 & $1.797(2.038)$ & $1.869(2.034)$ & $1.528(2.021)$ & $1.667(2.067)$ & $1.790(2.059)$ & $1.754(2.074)$ \\
\hline Patients aged over 60 & $2.392(0.740)^{* * *}$ & $2.375(0.732)^{* * *}$ & $2.339(0.729)^{* * *}$ & $2.344(0.790)^{* * *}$ & $2.351(0.787)^{* * *}$ & $2.283(0.782)^{* * *}$ \\
\hline \multicolumn{7}{|l|}{ Skill-Mix (lagged) } \\
\hline Prop. Medical & $-0.948(1.326)$ & $0.095(1.313)$ & $0.162(1.277)$ & $-0.164(1.185)$ & $0.134(1.170)$ & $0.121(1.210)$ \\
\hline Prop. Nurse & $0.096(0.557)$ & $-0.155(0.573)$ & $0.133(0.556)$ & $0.137(0.531)$ & $-0.038(0.534)$ & $0.116(0.534)$ \\
\hline \multicolumn{7}{|l|}{ Averages } \\
\hline Prop. Medical & $-0.460(2.282)$ & $-0.578(2.275)$ & $-0.708(2.277)$ & $-0.720(2.192)$ & $-0.583(2.176)$ & $-0.574(2.193)$ \\
\hline Prop. Nurse & $0.337(1.200)$ & $0.265(1.223)$ & $0.223(1.208)$ & $-.239(1.203)$ & $-.334(1.222)$ & $-0.350(1.215)$ \\
\hline Prop. Emergency & $-1.008(0.754)$ & $-1.050(0.747)$ & $-0.924(0.758)$ & $-.774(0.761)$ & $-.786(0.747)$ & $-.710(0.765)$ \\
\hline \multicolumn{7}{|l|}{ Interactions } \\
\hline dMPropmed & $1.613(0.467)^{* * *}$ & & & $1.334(0.581)^{* *}$ & & \\
\hline dMPropnurse & & $0.641(0.172)^{* * *}$ & & & $0.609(0.215)^{* * *}$ & \\
\hline dMEmer & & & $0.520(0.150)^{* * *}$ & & & $0.518(0.206)^{* *}$ \\
\hline \multicolumn{7}{|l|}{ Year Dummies } \\
\hline $2011 / 12$ & $-1.384(2.199)$ & $-1.336(2.197)$ & $-1.455(2.196)$ & $-1.332(2.205)$ & $-1.297(2.202)$ & $-1.383(2.208)$ \\
\hline $2012 / 13$ & $-1.156(3.046)$ & $-1.135(3.011)$ & $-1.298(3.022)$ & $-1.788(3.072)$ & $-1.627(3.072)$ & $-1.747(3.086)$ \\
\hline$R^{2}$ & 0.298 & 0.303 & 0.303 & 0.285 & 0.291 & 0.294 \\
\hline Adj. $R^{2}$ & 0.285 & 0.290 & 0.289 & 0.272 & 0.278 & 0.281 \\
\hline$N$ & 417 & 417 & 417 & 417 & 417 & 417 \\
\hline
\end{tabular}

Table S8 tests the idea that human capital inputs, e.g., medical staff, are more productive and variables such as proportion of emergency patients has lower adverse impact in effectively managed hospitals. We create two indicator variables. The first binary variable takes one when the within-hospital mean of the composite management index exceeds its median and zero otherwise. The second indicator variable takes one when the within-hospital means of Job satisfaction, Team quality and Job design exceed their medians and otherwise zero. Columns 1 through 3 report the results for when we interact the first binary variable with the measures of human capital and proportion of emergency patients in the sample. Columns 4 through 6 reports the results for the second binary variable. The complementarity hypothesis implies that the coefficients of the interacted terms will be statistically significant and positive. The variables of interest appear twice: once in their original form and once as within-hospital means. The coefficients of the original-form variable reports fixed effects estimates and the coefficients of the within-group mean reports random effects estimates. All the models include year dummies. Robust standard errors are given in parentheses. The dependent variable is quality-adjusted total factor productivity ${ }^{* * *} p<0.01,{ }^{* *} p<0.05,{ }^{*} p<0.1$. 


\section{Labour Productivity Results}

This section replicates the results for our quality-adjusted labour productivity measure. Interpretations of the results are similar to those given in the text for the total factor productivity measure. The comments on the individual tables further shed light on the variables entering the models. 


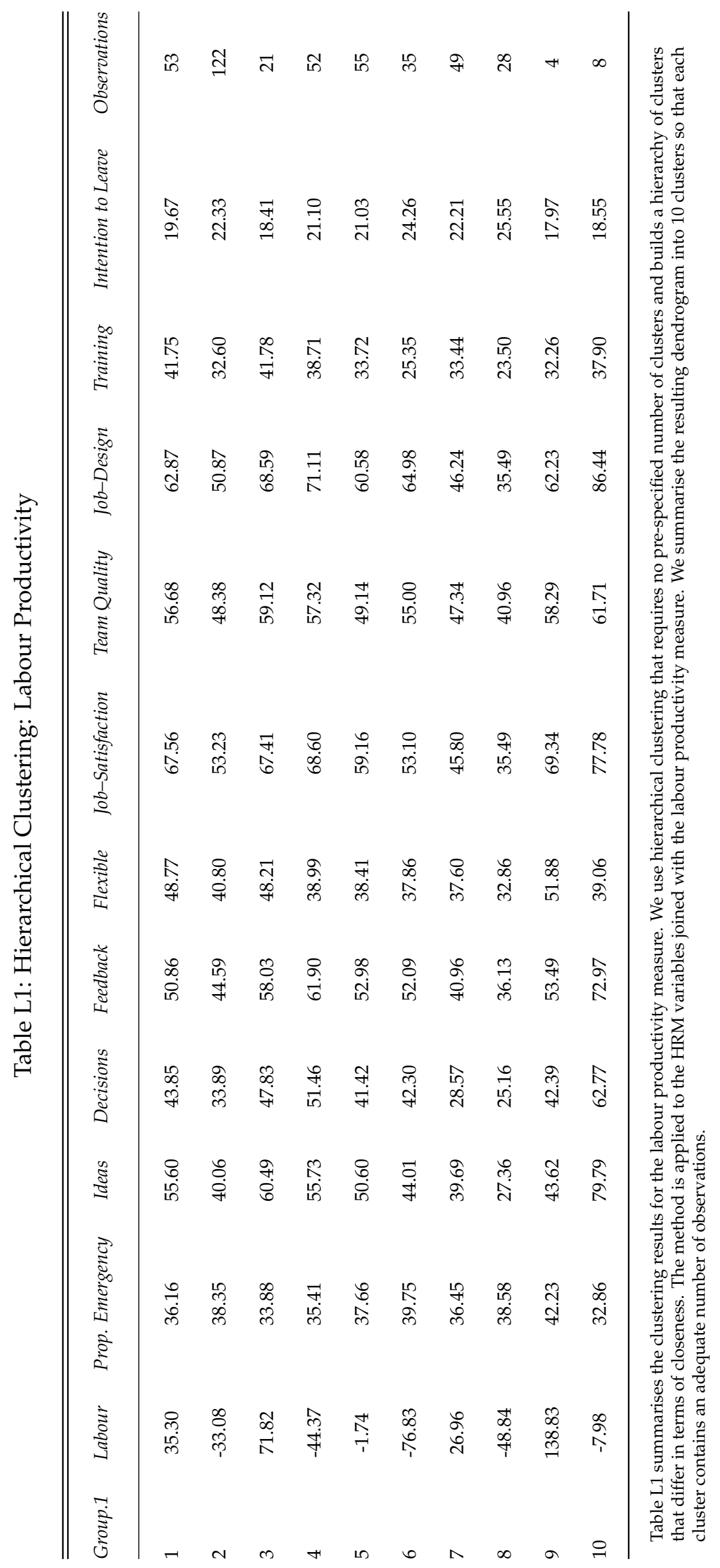


Table L2: Base Model: Labour Productivity

\begin{tabular}{|c|c|c|c|c|}
\hline & (1) & (2) & (3) & (4) \\
\hline Intercept & $-60.53(174.2)$ & $-61.47(171.8)$ & $-48.02(172.3)$ & $-98.51(174.5)$ \\
\hline \multicolumn{5}{|l|}{ Structural } \\
\hline Teaching Trust & $-4.090(8.203)$ & $0.984(8.365)$ & $1.560(8.323)$ & $3.118(8.478)$ \\
\hline Foundation Trust & $6.647(4.765)$ & $10.01(4.877)^{* *}$ & $8.975(4.782)^{*}$ & $9.495(4.993)^{*}$ \\
\hline Hospital Beds & $0.014(0.010)$ & $0.008(0.010)$ & $0.006(0.010)$ & $0.005(0.010)$ \\
\hline \multicolumn{5}{|l|}{ Regional } \\
\hline MFF & $-2.488(0.573)^{* * *}$ & $-2.767(0.585)^{* * *}$ & $-2.821(0.582)^{* * *}$ & $-2.476(0.623)^{* * *}$ \\
\hline GP per 100,000 & $2.046(0.547)^{* * *}$ & $2.203(0.515)^{* * *}$ & $2.205(0.550)^{* * *}$ & $2.225(0.560)^{* * *}$ \\
\hline \multicolumn{5}{|l|}{ Patient } \\
\hline Prop. Emergency & $-1.414(0.465)^{* * *}$ & $-1.366(0.445)^{* * *}$ & $-1.387(0.435)^{* * *}$ & $-1.352(0.446)^{* * *}$ \\
\hline Prop. Female & $-0.219(1.220)$ & $0.057(1.218)$ & $-0.010(1.230)$ & $0.079(1.241)$ \\
\hline Patients aged 0-14 & $2.186(1.021)^{* *}$ & $2.487(1.107)^{* *}$ & $2.395(1.102)^{* *}$ & $2.472(1.074)^{* *}$ \\
\hline Patients aged $45-59$ & $2.416(1.853)$ & $2.124(1.933)$ & $1.677(1.922)$ & $2.007(1.875)$ \\
\hline Patients aged over 60 & $1.917(0.689)^{* * *}$ & $2.349(0.744)^{* * *}$ & $2.327(0.759)^{* * *}$ & $2.385(0.740)^{* * *}$ \\
\hline \multicolumn{5}{|l|}{ Skill-Mix } \\
\hline Prop. Medical & $1.394(0.895)$ & $1.677(0.950)^{*}$ & $1.682(0.965)^{*}$ & $1.677(0.981)^{*}$ \\
\hline Prop. Nurse & $-0.218(0.533)$ & $-0.083(0.537)$ & $-0.009(0.529)$ & $-0.105(0.545)$ \\
\hline \multicolumn{5}{|l|}{ HRM } \\
\hline Ideas & $0.212(0.120)^{*}$ & & & \\
\hline Decisions & & $0.321(0.169)^{*}$ & & \\
\hline Communication & & & $0.119(0.164)$ & \\
\hline Feedback & & & & $0.309(0.167)^{*}$ \\
\hline Flexible & $-0.302(0.136)^{* *}$ & $-0.332(0.139)^{* *}$ & $-0.303(0.137)^{* *}$ & $-0.318(0.137)^{* *}$ \\
\hline Training & $-0.215(0.115)^{*}$ & $-0.226(0.117)^{*}$ & $-0.198(0.120)^{*}$ & $-0.231(0.118)^{*}$ \\
\hline \multicolumn{5}{|l|}{ Average } \\
\hline Idea & $0.766(0.238)^{* * *}$ & & & \\
\hline Decisions & & $0.617(0.352)^{*}$ & & \\
\hline Communication & & & $0.719(0.332)^{* *}$ & \\
\hline Feedback & & & & $0.335(0.354)$ \\
\hline Flexible & $0.755(0.352)^{* *}$ & $0.756(0.338)^{* *}$ & $0.726(0.326)^{* *}$ & $0.817(0.342)^{* *}$ \\
\hline Training & $0.386(0.247)$ & $0.514(0.285)^{*}$ & $0.472(0.299)$ & $0.556(0.301)^{*}$ \\
\hline \multicolumn{5}{|l|}{ Year Dummies } \\
\hline $2011 / 12$ & $-10.30(3.666)^{* * *}$ & $-9.980(3.538)^{* * *}$ & $-9.153(3.547)^{* *}$ & $-10.07(3.528)^{* * *}$ \\
\hline 2012/13 & $-13.52(4.815)^{* * *}$ & $-13.62(4.735)^{* * *}$ & $-12.44(4.723)^{* * *}$ & $-13.49(4.607)^{* * *}$ \\
\hline$R^{2}$ & 0.336 & 0.319 & 0.313 & 0.300 \\
\hline $\operatorname{Adj} . R^{2}$ & 0.319 & 0.303 & 0.298 & 0.285 \\
\hline$N$ & 421 & 421 & 421 & 421 \\
\hline
\end{tabular}


Table L3: Labour Productivity: Above Individual HRM Medians

\begin{tabular}{|c|c|c|c|c|}
\hline & (1) & (2) & (3) & (4) \\
\hline Intercept & $-55.13(214.9)$ & $-328.3(220.3)$ & $-176.6(213.4)$ & $-361.4(254.4)$ \\
\hline \multicolumn{5}{|l|}{ Structural } \\
\hline Teaching Trust & $-1.674(12.05)$ & $-3.937(11.58)$ & $-0.829(10.61)$ & $-3.801(12.35)$ \\
\hline Foundation Trust & $6.043(6.376)$ & $5.400(7.226)$ & $5.849(6.970)$ & $4.935(6.970)$ \\
\hline Hospital Beds & $0.001(0.014)$ & $0.027(0.023)$ & $0.039(0.020)^{*}$ & $0.038(0.023)^{*}$ \\
\hline \multicolumn{5}{|l|}{ Regional } \\
\hline MFF & $-2.600(1.017)^{* *}$ & $-1.814(0.896)^{* *}$ & $-2.167(0.696)^{* * *}$ & $-1.516(0.923)$ \\
\hline GP per 100,000 & $2.074(0.710)^{* * *}$ & $2.060(0.859)^{* *}$ & $2.239(0.910)^{* *}$ & $2.563(0.984)^{* * *}$ \\
\hline \multicolumn{5}{|l|}{ Patient } \\
\hline Prop. Emergency & $-1.584(0.477)^{* * *}$ & $-0.827(0.626)$ & $-0.672(0.570)$ & $-0.862(0.646)$ \\
\hline Prop. Female & $0.466(1.607)$ & $0.946(1.337)$ & $-0.350(1.392)$ & $0.363(1.539)$ \\
\hline Patients aged $0-14$ & $2.078(1.489)$ & $3.134(1.519)^{* *}$ & $1.920(1.395)$ & $3.610(1.483)^{* *}$ \\
\hline Patients aged $45-59$ & $1.392(2.245)$ & $3.502(2.333)$ & $0.517(2.391)$ & $2.668(2.334)$ \\
\hline Patients aged over 60 & $1.933(0.845)^{* *}$ & $3.103(0.877)^{* * *}$ & $2.476(0.857)^{* * *}$ & $3.008(0.944)^{* * *}$ \\
\hline \multicolumn{5}{|l|}{ Skill-Mix } \\
\hline Prop. Medical & $1.595(1.455)$ & $1.565(1.202)$ & $1.358(1.194)$ & $0.744(1.190)$ \\
\hline Prop. Nurse & $-0.136(0.737)$ & $-0.662(0.761)$ & $-0.338(0.747)$ & $-0.467(0.761)$ \\
\hline \multicolumn{5}{|l|}{ HRM } \\
\hline Ideas & $0.425(0.162)^{* * *}$ & & & \\
\hline Decisions & & $0.464(0.215)^{* *}$ & & \\
\hline Communication & & & $0.104(0.219)$ & \\
\hline Feedback & & & & $0.347(0.267)$ \\
\hline Flexible & $-0.480(0.203)^{* *}$ & $-0.353(0.194)^{*}$ & $-0.307(0.224)$ & $-0.275(0.184)$ \\
\hline Training & $-0.033(0.176)$ & $-0.047(0.198)$ & $-0.032(0.188)$ & $-0.170(0.184)$ \\
\hline \multicolumn{5}{|l|}{ Average } \\
\hline Ideas & $0.832(0.510)$ & & & \\
\hline Decisions & & $1.098(0.584)^{*}$ & & \\
\hline Communication & & & $1.542(0.585)^{* * *}$ & \\
\hline Feedback & & & & $1.070(0.738)$ \\
\hline Flexible & $0.514(0.452)$ & $1.062(0.548)^{*}$ & $1.350(0.509)^{* * *}$ & $1.120(0.578)^{*}$ \\
\hline Training & $0.431(0.369)$ & $0.393(0.404)$ & $-0.069(0.374)$ & $0.236(0.408)$ \\
\hline \multicolumn{5}{|l|}{ Year Dummies } \\
\hline $2011 / 12$ & $-15.39(5.133)^{* * *}$ & $-9.584(4.691)^{* *}$ & $-8.183(5.012)$ & $-8.292(4.758)^{*}$ \\
\hline $2012 / 13$ & $-20.32(6.367)^{* * *}$ & $-14.86(6.501)^{* *}$ & $-12.68(6.628)^{*}$ & $-13.34(6.098)^{* *}$ \\
\hline$R^{2}$ & 0.376 & 0.363 & 0.391 & 0.320 \\
\hline Adj. $R^{2}$ & 0.341 & 0.328 & 0.353 & 0.288 \\
\hline$N$ & 224 & 218 & 217 & 209 \\
\hline
\end{tabular}

Table L3 reports the results for the quality-adjusted labour productivity measure for the sub-samples where the within-hospital means of the senior management variables exceed their medians. Column 1 through 4 each includes a set of not highly correlated management variables. Management variables are lagged by one year. The coefficients of the original-form variables report FE estimates and the coefficients of the within-group means report RE estimates. The columns include time dummies and other controls. Robust standard errors are in parentheses. ${ }^{* * *} p<0.01,{ }^{* *} p<0.05,{ }^{*} p<0.1$. 
Table L4: Labour Productivity: Incentives \& Workplace Flexibility

\begin{tabular}{|c|c|c|c|c|}
\hline & (1) & (2) & (3) & (4) \\
\hline Intercept & $41.17(172.5)$ & $11.84(180.72)$ & $15.01(179.56)$ & $11.30(180.4)$ \\
\hline \multicolumn{5}{|l|}{ Structural } \\
\hline Teaching Trust & $1.127(7.725)$ & $6.396(8.170)$ & $5.436(8.283)$ & $5.487(8.176)$ \\
\hline Foundation Trust & $12.31(4.78)^{* *}$ & $14.56(5.322)^{* * *}$ & $14.17(5.319)^{* * *}$ & $12.94(5.137)^{* *}$ \\
\hline Hospital Beds & $0.004(0.009)$ & $-0.000(0.010)$ & $-0.000(0.010)$ & $0.000(0.009)$ \\
\hline \multicolumn{5}{|l|}{ Regional } \\
\hline MFF & $-2.272(0.575)^{* * *}$ & $-2.277(0.634)^{* * *}$ & $-2.321(0.635)^{* * *}$ & $-2.125(0.607)^{* * *}$ \\
\hline GP per 100,000 & $2.060(0.526)^{* * *}$ & $2.021(0.562)^{* * *}$ & $2.036(0.558)^{* * *}$ & $2.068(0.548)^{* * *}$ \\
\hline \multicolumn{5}{|l|}{ Patients } \\
\hline Prop. Emergency & $-1.227(0.449)^{* * *}$ & $-1.240(0.474)^{* * *}$ & $-1.208(0.475)^{* *}$ & $-1.285(0.470)^{* * *}$ \\
\hline Prop. Female & $-0.715(1.219)$ & $-0.650(1.288)$ & $-0.642(1.281)$ & $-0.791(1.271)$ \\
\hline Patients aged $0-14$ & $1.400(1.075)$ & $1.645(1.120)$ & $1.564(1.118)$ & $1.712(1.118)$ \\
\hline Patients aged $45-59$ & $0.999(1.879)$ & $1.329(1.962)$ & $1.448(1.928)$ & $1.231(2.000)$ \\
\hline Patients aged over 60 & $1.397(0.699)^{* *}$ & $1.817(0.736)^{* *}$ & $1.751(0.732)^{* *}$ & $1.788(0.741)^{* *}$ \\
\hline \multicolumn{5}{|l|}{ Skill-Mix } \\
\hline Prop. Medical & $1.436(0.931)$ & $1.461(0.991)$ & $1.477(0.997)$ & $1.389(0.968)$ \\
\hline Prop. Nurse & $0.073(0.514)$ & $-0.070(0.549)$ & $-0.010(0.549)$ & $-0.045(0.538)$ \\
\hline \multicolumn{5}{|c|}{ HRM Variables $\mathcal{E}$ Interactions } \\
\hline Flexible & $-0.336(0.140)^{* *}$ & $-0.286(0.141)^{* *}$ & $-0.240(0.140)^{*}$ & $-0.239(0.138)^{*}$ \\
\hline Avg. Flex & $0.717(0.323)^{* *}$ & $0.986(0.370)^{* * *}$ & $0.939(0.360)^{* * *}$ & $0.844(0.362)^{* *}$ \\
\hline milFlex & $0.418(0.116)^{* * *}$ & $-0.009(0.092)$ & $-0.115(0.093)$ & $-0.288(0.083)^{* * *}$ \\
\hline \multicolumn{5}{|l|}{ Year Dummies } \\
\hline $2011 / 12$ & $-6.243(3.426)^{*}$ & $-7.829(3.414)^{* *}$ & $-7.355(3.429)^{* *}$ & $-8.117(3.405)^{* *}$ \\
\hline $2012 / 13$ & $-8.109(4.253)^{*}$ & $-10.192(4.353)^{* *}$ & $-9.676(4.315)^{* *}$ & $-10.357(4.339)^{* *}$ \\
\hline$R^{2}$ & 0.318 & 0.275 & 0.274 & 0.289 \\
\hline Adj. $R^{2}$ & 0.304 & 0.263 & 0.263 & 0.277 \\
\hline$N$ & 421 & 421 & 421 & 421 \\
\hline
\end{tabular}

Table L4 segments the data according to the four quartiles of the within-group mean of the variable Intention-to-Leave to investigate the interaction between incentives and workplace flexibility. Column 1 reports the results for hospitals where within-group mean of Intention-to-leave is below or equal to the first quantile. Columns 2 through 4 respectively reports the results for the remaining quartiles. The dependent variable in all the models is the quality-adjusted labour productivity measure. In addition to the interaction term miFlex, Flexible appears in each column twice: once in its original form and once as a within-hospital mean. The coefficient of the original-form variable reports the fixed effects estimate and the coefficient of the within-group mean reports the random effects estimate. All the models include year dummies. Robust standard errors are given in parentheses. ${ }^{* * *} p<0.01,{ }^{* *} p<0.05,{ }^{*} p<0.1$. 
Table L5: Labour Productivity: Incentives \& Workforce Training

\begin{tabular}{|c|c|c|c|c|}
\hline & (1) & (2) & (3) & (4) \\
\hline Intercept & $-3.035(172.3)$ & $-59.09(183.0)$ & $-67.70(183.1)$ & $-45.34(183.2)$ \\
\hline \multicolumn{5}{|l|}{ Structural } \\
\hline Teaching Trust & $1.236(7.879)$ & $6.289(8.086)$ & $5.633(8.475)$ & $5.937(8.243)$ \\
\hline Foundation TRust & $11.83(4.832)^{* *}$ & $14.34(5.403)^{* * *}$ & $14.07(5.376)^{* * *}$ & $12.819(5.241)^{* *}$ \\
\hline Hospital Beds & $0.003(0.009)$ & $-0.000(0.009)$ & $-0.000(0.009)$ & $-0.000(0.009)$ \\
\hline \multicolumn{5}{|l|}{ Regional } \\
\hline MFF & $-2.310(0.542)^{* * *}$ & $-2.260(0.603)^{* * *}$ & $-2.236(0.604)^{* * *}$ & $-2.075(0.575)^{* * * *}$ \\
\hline GP per 100,000 & $2.188(0.513)^{* * *}$ & $2.173(0.542)^{* * *}$ & $2.174(0.536)^{* * *}$ & $2.245(0.522)^{* * *}$ \\
\hline \multicolumn{5}{|l|}{ Patients } \\
\hline PropEmergency & $-1.172(0.455)^{* *}$ & $-1.184(0.482)^{* *}$ & $-1.155(0.485)^{* *}$ & $-1.190(0.474)^{* *}$ \\
\hline PropFemale & $-0.114(1.236)$ & $0.218(1.320)$ & $0.218(1.321)$ & $-0.261(1.333)$ \\
\hline Patients aged $0-14$ & $1.501(1.075)$ & $1.770(1.110)$ & $1.756(1.120)$ & $1.742(1.124)$ \\
\hline Patients aged $45-59$ & $0.880(1.873)$ & $1.491(1.971)$ & $1.682(1.956)$ & $1.174(2.017)$ \\
\hline Patients aged over 60 & $1.568(0.717)^{* *}$ & $2.011(0.761)^{* * *}$ & $2.018(0.764)^{* * *}$ & $1.947(0.774)^{* *}$ \\
\hline \multicolumn{5}{|l|}{ Skill-Mix } \\
\hline Prop. Medical & $1.606(0.957)^{*}$ & $1.476(0.996)$ & $1.527(1.000)$ & $1.539(0.989)$ \\
\hline Prop. Nurse & $0.039(0.488)$ & $-0.071(0.505)$ & $-0.044(0.506)$ & $-0.043(0.500)$ \\
\hline \multicolumn{5}{|c|}{ HRM Variables \& Interactions } \\
\hline Training & $-0.274(0.123)^{* *}$ & $-0.131(0.129)$ & $-0.145(0.121)$ & $-0.055(0.128)$ \\
\hline Avg. Training & $0.496(0.276)^{*}$ & $0.713(0.268)^{* * *}$ & $0.733(0.274)^{* * *}$ & $0.576(0.269)^{* *}$ \\
\hline milTrain & $0.516(0.148)^{* * *}$ & $-0.112(0.119)$ & $-0.078(0.136)$ & $-0.408(0.106)^{* * *}$ \\
\hline \multicolumn{5}{|l|}{ Year Dummies } \\
\hline $2011 / 12$ & $-2.429(2.499)$ & $-3.191(2.476)$ & $-3.047(2.511)$ & $-3.147(2.465)$ \\
\hline $2012 / 13$ & $-3.585(2.857)$ & $-4.718(2.923)$ & $-4.778(2.922)$ & $-4.698(2.922)$ \\
\hline$R^{2}$ & 0.314 & 0.275 & 0.271 & 0.289 \\
\hline Adj. $R^{2}$ & 0.300 & 0.264 & 0.259 & 0.277 \\
\hline Num. obs. & 421 & 421 & 421 & 421 \\
\hline
\end{tabular}

Table L5 segments the data using the within-group mean of the Intention-to-leave variable to investigate the interaction between incentives and workforce training (Training). Column 1 reports the results for hospitals where within-group mean of Intention-to-leave is below or equal to the first quantile. Columns 2 through 4 respectively report the results for the remaining quartiles. The dependent variable in all the models is the quality adjusted labour productivity measure. In addition to the interaction term miTrain, Training appears in each column twice: once in its original form and once as a within-hospital mean. The coefficient of the original-form variable reports fixed effects estimates and the coefficient of the within-group mean reports random effects estimates. All the models include year dummies. Robust standard errors are given in parentheses. ${ }^{* * *} p<0.01,{ }^{* *} p<0.05,{ }^{*} p<0.1$. 
Table L6: Interaction Models : Human Capital Measures (Labour)

\begin{tabular}{|c|c|c|c|c|c|c|}
\hline & (1) & (2) & (3) & (4) & (5) & (6) \\
\hline Intercept & $53.37(177.9)$ & $65.49(176.3)$ & $65.47(175.05)$ & $45.89(183.4)$ & $53.26(181.3)$ & $57.27(179.0)$ \\
\hline \multicolumn{7}{|l|}{ Structural } \\
\hline Teaching Trust & $3.278(7.996)$ & $2.597(7.934)$ & $2.874(7.909)$ & $6.449(8.245)$ & $6.208(8.318)$ & $6.070(8.342)$ \\
\hline Foundation Trust & $13.19(5.204)^{* *}$ & $13.03(5.160)^{* *}$ & $13.29(5.135)^{* * *}$ & $12.89(4.992)^{* *}$ & $12.63(4.945)^{* *}$ & $12.99(4.913)^{* * *}$ \\
\hline Hospital Beds & $0.003(0.009)$ & $0.003(0.009)$ & $0.004(0.009)$ & $0.002(0.010)$ & $0.003(0.010)$ & $0.003(0.010)$ \\
\hline \multicolumn{7}{|l|}{ Regional } \\
\hline MFF & $-2.953(0.684)^{* * *}$ & $-3.014(0.668)^{* * *}$ & $-2.889(0.658)^{* * *}$ & $-2.646(0.649)^{* * *}$ & $-2.680(0.633)^{* * *}$ & $-2.612(0.632)^{* * *}$ \\
\hline GP per 100,000 & $2.348(0.568)^{* * *}$ & $2.282(0.571)^{* * *}$ & $2.299(0.578)^{* * *}$ & $1.999(0.581)^{* * *}$ & $1.894(0.582)^{* * *}$ & $1.929(0.585)^{* * *}$ \\
\hline \multicolumn{7}{|l|}{ Patient } \\
\hline Prop. Emergency & $-0.437(0.603)$ & $-0.447(0.592)$ & $-0.821(0.596)$ & $-0.350(0.605)$ & $-0.332(0.591)$ & $-0.590(0.585)$ \\
\hline Prop. Female & $-0.368(1.309)$ & $-0.399(1.305)$ & $-0.481(1.299)$ & $-0.188(1.311)$ & $-0.147(1.285)$ & $-0.272(1.279)$ \\
\hline Patients aged 0-14 & $2.166(1.147)^{*}$ & $2.202(1.124)^{*}$ & $2.120(1.128)^{*}$ & $1.562(1.168)$ & $1.619(1.175)$ & $1.534(1.166)$ \\
\hline Patients aged $45-59$ & $1.349(2.040)$ & $1.421(2.033)$ & $1.125(2.021)$ & $1.274(2.050)$ & $1.380(2.036)$ & $1.377(2.048)$ \\
\hline Patients aged over 60 & $1.945(0.737)^{* * *}$ & $1.934(0.728)^{* * *}$ & $1.907(0.725)^{* * *}$ & $1.923(0.778)^{* *}$ & $1.926(0.775)^{* *}$ & $1.866(0.770)^{* *}$ \\
\hline \multicolumn{7}{|l|}{ Skill-Mix (lagged) } \\
\hline Prop. Medical & $-0.589(1.222)$ & $0.332(1.219)$ & $0.393(1.189)$ & $0.071(1.107)$ & $0.375(1.090)$ & $0.363(1.126)$ \\
\hline Prop. Nurse & $0.165(0.547)$ & $-0.389(0.570)$ & $0.128(0.550)$ & $-0.120(0.525)$ & $-0.297(0.537)$ & $-0.139(0.530)$ \\
\hline \multicolumn{7}{|l|}{ Averages } \\
\hline Prop. Medical & $0.343(2.250)$ & $0.244(2.245)$ & $0.131(2.251)$ & $0.140(2.159)$ & $0.274(2.138)$ & $0.292(2.144)$ \\
\hline Prop. Nurse & $1.086(1.190)$ & $1.026(1.214)$ & $0.990(1.200)$ & $0.538(1.186)$ & $0.455(1.207)$ & $0.417(1.198)$ \\
\hline Prop. Emergency & $-1.265(0.707)^{*}$ & $-1.304(0.702)^{*}$ & $-1.192(0.710)^{*}$ & $-1.043(0.713)$ & $-1.056(0.701)$ & $-0.975(0.715)$ \\
\hline \multicolumn{7}{|l|}{ Interactions } \\
\hline dMPropmed & $1.422(0.459)^{* * *}$ & & & $1.353(0.590)^{* *}$ & & \\
\hline dMPropnurse & & $0.575(0.169)^{* * *}$ & & & $0.605(0.216)^{* * *}$ & \\
\hline dMEmer & & & $0.478(0.147)^{* * *}$ & & & $0.534(0.208)^{* *}$ \\
\hline \multicolumn{7}{|l|}{ Year Dummies } \\
\hline $2011 / 12$ & $-0.824(2.137)$ & $-0.780(2.136)$ & $-0.886(2.135)$ & $-0.760(2.145)$ & $-0.730(2.145)$ & $-0.812(2.150)$ \\
\hline $2012 / 13$ & $-2.184(2.983)$ & $-2.160(2.954)$ & $-2.300(2.965)$ & $-2.764(3.036)$ & $-2.602(3.027)$ & $-2.727(3.042)$ \\
\hline$R^{2}$ & 0.285 & 0.290 & 0.291 & 0.278 & 0.286 & 0.290 \\
\hline Adj. $R^{2}$ & 0.272 & 0.277 & 0.277 & 0.266 & 0.273 & 0.276 \\
\hline$N$ & 417 & 417 & 417 & 417 & 417 & 417 \\
\hline \multicolumn{7}{|c|}{$\begin{array}{l}\text { This table tests the idea that human capital inputs, e.g., medical staff, are more productive and variables such as proportion of emergency patients has lower adverse impact } \\
\text { in effectively managed hospitals. We create two indicator variables. The first binary variable takes one when the within-hospital mean of the composite management index } \\
\text { exceeds its median and zero otherwise. The second indicator variable takes one when the within-hospital means of Job satisfaction, Team quality and Job design exceed } \\
\text { their medians and otherwise zero. Columns } 1 \text { through } 3 \text { report the results for when we interact the first binary variable with the measures of human capital and proportion } \\
\text { of emergency patients in the sample. Columns } 4 \text { through } 6 \text { reports the results for the second binary variable. The complementarity hypothesis implies that the coefficients } \\
\text { of the interacted terms will be statistically significant and positive. The variables of interest appear twice: once in their original form and once as within-hospital means. } \\
\text { The coefficients of the original-form variable reports fixed effects estimates and the coefficients of the within-group mean reports random effects estimates. All the models } \\
\text { include year dummies. Robust standard errors are given in parentheses. The dependent variable is quality-adjusted labour productivity }{ }^{* * *} p<0.01,{ }^{* *} p<0.05,{ }^{*} p<0.1 \text {. }\end{array}$} \\
\hline
\end{tabular}




\section{Additional Robustness Analysis Results}

The following tables provide the results that arise from our alternative measures of qualityadjusted total factor productivity and labour productivity. The order of the tables mirrors the order in the main sections in the text that report our data analysis. In general, the same interpretation applies to the tables except that the dependent variables are adjusted using different quality measures. The comments on individual tables are expected to be self-explanatory. 
Table R1: Base Model: Total Factor Productivity

\begin{tabular}{|c|c|c|c|c|}
\hline & (1) & (2) & (3) & (4) \\
\hline Intercept & $-572.3(264.8)^{* *}$ & $-544.3(269.1)^{* *}$ & $-524.1(275.3)^{*}$ & $-619.9(269.2)^{* *}$ \\
\hline \multicolumn{5}{|l|}{ Structural } \\
\hline Teaching Trust & $12.20(12.90)$ & $19.35(12.45)$ & $21.36(12.44)^{*}$ & $22.90(12.23)^{*}$ \\
\hline Foundation Trust & $7.397(6.891)$ & $11.28(7.089)$ & $10.43(7.049)$ & $10.55(7.222)$ \\
\hline Hospital Beds & $0.009(0.015)$ & $0.001(0.014)$ & $-0.004(0.013)$ & $-0.004(0.013)$ \\
\hline \multicolumn{5}{|l|}{ Regional } \\
\hline MFF & $-1.589(1.020)$ & $-2.376(1.006)^{* *}$ & $-2.242(1.009)^{* *}$ & $-1.941(1.060)^{*}$ \\
\hline GP per 100,000 & $2.347(0.881)^{* * *}$ & $2.205(0.931)^{* *}$ & $2.336(0.947)^{* *}$ & $2.451(0.946)^{* * * *}$ \\
\hline \multicolumn{5}{|l|}{ Patients } \\
\hline Prop. Emergency & $-1.351(0.745)^{*}$ & $-1.369(0.727)^{*}$ & $-1.373(0.735)^{*}$ & $-1.372(0.751)^{*}$ \\
\hline Prop. Female & $3.783(2.308)$ & $4.208(2.253)^{*}$ & $4.011(2.271)^{*}$ & $4.284(2.295)^{*}$ \\
\hline Patients aged 0-14 & $4.833(1.907)^{* *}$ & $5.507(2.054)^{* * *}$ & $5.130(2.060)^{* *}$ & $5.529(2.007)^{* * *}$ \\
\hline Patients aged 45-59 & $9.441(3.324)^{* * *}$ & $8.824(3.471)^{* *}$ & $7.882(3.500)^{* *}$ & $8.370(3.457)^{* *}$ \\
\hline Patients aged over 60 & $3.397(1.182)^{* * *}$ & $4.203(1.264)^{* * *}$ & $4.063(1.284)^{* * *}$ & $4.382(1.230)^{* * *}$ \\
\hline \multicolumn{5}{|l|}{ Skill-Mix } \\
\hline Prop. Medical & $-0.159(1.786)$ & $0.361(1.792)$ & $0.126(1.762)$ & $0.448(1.773)$ \\
\hline Prop. Nurse & $0.087(0.910)$ & $0.338(0.891)$ & $0.389(0.892)$ & $0.397(0.898)$ \\
\hline \multicolumn{5}{|l|}{$H R M$} \\
\hline Ideas & $0.012(0.201)$ & & & \\
\hline Decisions & & $0.383(0.301)$ & & \\
\hline Communication & & & $-0.198(0.317)$ & \\
\hline Feedback & & & & $0.246(0.306)$ \\
\hline Flexible & $-0.685(0.246)^{* * *}$ & $-0.716(0.253)^{* * *}$ & $-0.657(0.245)^{* * *}$ & $-0.686(0.248)^{* * *}$ \\
\hline Training & $0.021(0.221)$ & $-0.010(0.220)$ & $0.093(0.228)$ & $0.005(0.230)$ \\
\hline \multicolumn{5}{|l|}{ Averages } \\
\hline Ideas & $1.564(0.414)^{* * *}$ & & & \\
\hline Decisions & & $1.500(0.491)^{* * *}$ & & \\
\hline Communication & & & $1.663(0.528)^{* * *}$ & \\
\hline Feedback & & & & $1.218(0.472)^{* *}$ \\
\hline Flexible & $0.355(0.559)$ & $0.258(0.559)$ & $0.229(0.558)$ & $0.331(0.562)$ \\
\hline Training & $0.050(0.370)$ & $0.195(0.419)$ & $0.112(0.440)$ & $0.214(0.440)$ \\
\hline \multicolumn{5}{|l|}{ Year Dummies } \\
\hline $2011 / 12$ & $-15.520(6.537)^{* *}$ & $-16.573(6.424)^{* *}$ & $-15.070(6.322)^{* *}$ & $-16.268(6.423)^{* *}$ \\
\hline $2012 / 13$ & $-19.991(8.207)^{* *}$ & $-21.994(8.092)^{* * *}$ & $-19.366(7.937)^{* *}$ & $-21.126(8.056)^{* * *}$ \\
\hline$R^{2}$ & 0.170 & 0.163 & 0.156 & 0.148 \\
\hline Adj. $R^{2}$ & 0.162 & 0.155 & 0.148 & 0.140 \\
\hline$N$ & 420 & 420 & 420 & 420 \\
\hline
\end{tabular}

Table R1 reports the initial results for quality-adjusted total factor productivity. Column 1 through 4 each includes a set of not highly correlated management variables. Management variables are lagged by one year. They appear in each model twice: once in their original form and once as within-hospital means. The coefficients of the original-form variables report FE estimates and the coefficients of the within-group means report RE estimates. The columns also include time dummies, with the period 2010/11 being taken as the base period.Robust standard errors are in parentheses. ${ }^{* * *} p<0.01,{ }^{* *} p<0.05,{ }^{*} p<0.1$. 
Table R2: Base Model: Labour Productivity

\begin{tabular}{|c|c|c|c|c|}
\hline & (1) & $(2)$ & (3) & $(4)$ \\
\hline Intercept & $-551.7(274.9)^{* *}$ & $-531.1(281.1)^{*}$ & $-508.1(286.6)^{*}$ & $-601.5(281.2)^{* *}$ \\
\hline \multicolumn{5}{|l|}{ Structural } \\
\hline Teaching Trust & $14.62(13.70)$ & $22.63(13.45)^{*}$ & $24.54(13.51)^{*}$ & $26.19(13.26)^{* *}$ \\
\hline Foundation Trust & $10.74(6.922)$ & $15.20(7.230)^{* *}$ & $14.28(7.109)^{* *}$ & $14.60(7.324)^{* *}$ \\
\hline Hospital Beds & $0.013(0.015)$ & $0.003(0.014)$ & $-0.001(0.013)$ & $-0.001(0.013)$ \\
\hline \multicolumn{5}{|l|}{ Regional } \\
\hline MFF & $-1.486(1.066)$ & $-2.193(1.049)^{* *}$ & $-2.080(1.028)^{* *}$ & $-1.745(1.106)$ \\
\hline GP per 100,000 & $2.195(0.901)^{* *}$ & $2.037(0.955)^{* *}$ & $2.172(0.969)^{* *}$ & $2.270(0.969)^{* *}$ \\
\hline \multicolumn{5}{|l|}{ Patient } \\
\hline Prop. Emergency & $-1.742(0.758)^{* *}$ & $-1.735(0.748)^{* *}$ & $-1.727(0.753)^{* *}$ & $-1.711(0.768)^{* *}$ \\
\hline Prop. Female & $3.178(2.444)$ & $3.650(2.400)$ & $3.431(2.415)$ & $3.693(2.442)$ \\
\hline Patients aged $0-14$ & $4.863(2.023)^{* *}$ & $5.504(2.173)^{* *}$ & $5.119(2.174)^{* *}$ & $5.453(2.119)^{* *}$ \\
\hline Patients aged $45-59$ & $10.043(3.482)^{* * *}$ & $9.500(3.655)^{* * *}$ & $8.487(3.682)^{* *}$ & $8.969(3.644)^{* *}$ \\
\hline Patients aged over 60 & $3.198(1.248)^{* *}$ & $4.001(1.336)^{* * *}$ & $3.860(1.357)^{* * *}$ & $4.139(1.299)^{* * *}$ \\
\hline \multicolumn{5}{|l|}{ Skill-Mix } \\
\hline Prop. Medical & $1.805(1.874)$ & $2.332(1.885)$ & $2.077(1.856)$ & $2.372(1.887)$ \\
\hline Prop. Nurse & $-0.313(0.911)$ & $-0.077(0.889)$ & $-0.026(0.890)$ & $-0.033(0.895)$ \\
\hline \multicolumn{5}{|l|}{$H R M$} \\
\hline Ideas & $0.046(0.198)$ & & & \\
\hline Decisions & & $0.456(0.306)$ & & \\
\hline Communication & & & $-0.189(0.326)$ & \\
\hline Feedback & & & & $0.220(0.302)$ \\
\hline Flexible & $-0.580(0.244)^{* *}$ & $-0.619(0.248)^{* *}$ & $-0.553(0.241)^{* *}$ & $-0.579(0.244)^{* *}$ \\
\hline Training & $-0.014(0.215)$ & $-0.056(0.216)$ & $0.059(0.227)$ & $-0.023(0.225)$ \\
\hline \multicolumn{5}{|l|}{ Averages } \\
\hline Ideas & $1.608(0.424)^{* * *}$ & & & \\
\hline Decisions & & $1.375(0.520)^{* * *}$ & & \\
\hline Communication & & & $1.644(0.569)^{* * *}$ & \\
\hline Feedback & & & & $1.184(0.495)^{* *}$ \\
\hline Flexible & $0.386(0.561)$ & $0.323(0.560)$ & $0.280(0.556)$ & $0.389(0.566)$ \\
\hline Training & $0.160(0.362)$ & $0.354(0.419)$ & $0.253(0.438)$ & $0.363(0.438)$ \\
\hline \multicolumn{5}{|l|}{ Year Dummies } \\
\hline $2011 / 12$ & $-16.022(6.590)^{* *}$ & $-17.124(6.489)^{* * *}$ & $-15.412(6.396)^{* *}$ & $-16.522(6.492)^{* *}$ \\
\hline $2012 / 13$ & $-20.233(8.382)^{* *}$ & $-22.392(8.276)^{* * *}$ & $-19.456(8.134)^{* *}$ & $-21.101(8.262)^{* *}$ \\
\hline$R^{2}$ & 0.183 & 0.170 & 0.164 & 0.154 \\
\hline Adj. $R^{2}$ & 0.173 & 0.161 & 0.156 & 0.146 \\
\hline$N$ & 420 & 420 & 420 & 420 \\
\hline
\end{tabular}


Table R3: Above Individual HRM Medians: Total Factor Productivity

\begin{tabular}{|c|c|c|c|c|}
\hline & (1) & (2) & (3) & (4) \\
\hline Intercept & $-418.4(374.4)$ & $-759.7(378.5)^{* *}$ & $-654.0(344.9)^{*}$ & $-775.8(377.345)^{* *}$ \\
\hline \multicolumn{5}{|l|}{ Structural } \\
\hline Teaching Trust & $11.42(15.96)$ & $23.83(17.32)$ & $19.45(14.83)$ & $25.96(17.75)$ \\
\hline Foundation Trust & $5.409(10.99)$ & $8.432(10.031)$ & $10.71(9.015)$ & $10.92(9.289)$ \\
\hline Hospital Beds & $-0.023(0.024)$ & $0.005(0.028)$ & $0.034(0.024)$ & $0.026(0.026)$ \\
\hline \multicolumn{5}{|l|}{ Regional } \\
\hline MFF & $-1.233(2.159)$ & $-0.489(1.726)$ & $-0.790(1.213)$ & $-0.249(1.571)$ \\
\hline GP & $1.297(1.206)$ & $-0.176(1.607)$ & $0.772(1.533)$ & $0.293(1.475)$ \\
\hline \multicolumn{5}{|l|}{ Patient } \\
\hline Prop. Emergency & $-2.286(1.029)^{* *}$ & $-0.675(1.104)$ & $-0.466(0.784)$ & $-0.463(0.967)$ \\
\hline Prop. Female & $2.255(2.870)$ & $3.962(2.776)$ & $3.007(2.994)$ & $3.072(3.159)$ \\
\hline Patients aged $0-14$ & $4.460(2.542)^{*}$ & $6.411(2.889)^{* *}$ & $4.877(2.771)^{*}$ & $7.194(2.859)^{* *}$ \\
\hline Patients aged $45-59$ & $9.382(3.889)^{* *}$ & $10.48(4.592)^{* *}$ & $7.268(4.820)$ & $8.360(4.924)^{*}$ \\
\hline Patients aged over 60 & $2.982(1.457)^{* *}$ & $5.370(1.625)^{* * *}$ & $4.196(1.569)^{* * *}$ & $5.016(1.578)^{* * *}$ \\
\hline \multicolumn{5}{|l|}{ Skill-Mix } \\
\hline Prop. Medical & $-1.452(2.653)$ & $-0.381(2.474)$ & $-0.333(2.152)$ & $-1.327(2.170)$ \\
\hline Prop. Nurse & $0.603(1.249)$ & $-0.254(1.310)$ & $-0.258(1.223)$ & $-0.169(1.205)$ \\
\hline \multicolumn{5}{|l|}{$H R M$} \\
\hline Ideas & $0.256(0.275)$ & & & \\
\hline Decisions & & $0.401(0.374)$ & & \\
\hline Communication & & & $-0.238(0.454)$ & \\
\hline Feedback & & & & $0.005(0.395)$ \\
\hline Flexible & $-0.720(0.373)^{*}$ & $-0.503(0.419)$ & $-0.490(0.342)$ & $-0.325(0.336)$ \\
\hline Training & $0.636(0.362)^{*}$ & $0.852(0.374)^{* *}$ & $0.889(0.385)^{* *}$ & $0.591(0.367)$ \\
\hline \multicolumn{5}{|l|}{ Averages } \\
\hline Ideas & $1.788(0.932)^{*}$ & & & \\
\hline Decisions & & $2.427(1.062)^{* *}$ & & \\
\hline Communication & & & $2.690(1.258)^{* *}$ & \\
\hline Feedback & & & & $2.749(1.343)^{* *}$ \\
\hline Flexible & $0.756(0.944)$ & $1.084(0.990)$ & $1.485(0.731)^{* *}$ & $1.176(0.870)$ \\
\hline Training & $-0.492(0.540)$ & $-0.692(0.673)$ & $-1.023(0.631)$ & $-0.747(0.669)$ \\
\hline \multicolumn{5}{|l|}{ Year Dummies } \\
\hline 2011/12 & $-18.125(9.435)^{*}$ & $-14.309(9.772)$ & $-12.937(8.673)$ & $-9.550(9.152)$ \\
\hline 2012/13 & $-26.550(10.319)^{* *}$ & $-22.110(11.889)^{*}$ & $-18.869(10.545)^{*}$ & $-17.740(11.005)$ \\
\hline$R^{2}$ & 0.187 & 0.193 & 0.220 & 0.172 \\
\hline Adj. $R^{2}$ & 0.169 & 0.174 & 0.199 & 0.155 \\
\hline$N$ & 223 & 217 & 216 & 208 \\
\hline
\end{tabular}


Table R4: Above Individual HRM Medians: Labour Productivity

\begin{tabular}{|c|c|c|c|c|}
\hline & (1) & (2) & (3) & (4) \\
\hline Intercept & $-446.2(387.3)$ & $-773.6(395.0)^{*}$ & $-679.8(367.9)^{*}$ & $-780.4(393.2)^{* *}$ \\
\hline \multicolumn{5}{|l|}{ Structural } \\
\hline Teaching Trust & $12.85(17.63)$ & $28.100(19.02)$ & $24.55(16.46)$ & $31.22(19.72)$ \\
\hline Foundation Trust & $9.546(11.13)$ & $13.09(10.29)$ & $15.05(9.224)$ & $15.51(9.484)$ \\
\hline Hospital Beds & $-0.013(0.025)$ & $0.011(0.028)$ & $0.040(0.025)$ & $0.031(0.026)$ \\
\hline \multicolumn{5}{|l|}{ Regional } \\
\hline MFF & $-0.928(2.302)$ & $-0.074(1.805)$ & $-0.299(1.243)$ & $0.116(1.624)$ \\
\hline GP per 100,000 & $1.183(1.235)$ & $-0.423(1.707)$ & $0.564(1.628)$ & $-0.120(1.589)$ \\
\hline \multicolumn{5}{|l|}{ Patient } \\
\hline Prop. Emergency & $-2.575(1.033)^{* *}$ & $-0.934(1.119)$ & $-0.755(0.840)$ & $-0.735(1.001)$ \\
\hline Prop. Female & $1.669(3.062)$ & $3.654(3.006)$ & $2.581(3.266)$ & $2.762(3.412)$ \\
\hline Patients aged $0-14$ & $4.192(2.802)$ & $6.198(3.151)^{*}$ & $4.759(2.971)$ & $7.023(3.016)^{\text {** }}$ \\
\hline Patients aged $45-59$ & $10.24(4.232)^{* *}$ & $11.173(4.911)^{* *}$ & $7.789(5.180)$ & $9.108(5.192)^{*}$ \\
\hline Patients aged over 60 & $2.760(1.563)^{*}$ & $5.116(1.743)^{* * *}$ & $4.041(1.719)^{* *}$ & $4.758(1.681)^{* * *}$ \\
\hline \multicolumn{5}{|l|}{ Skill-Mix } \\
\hline Prop. Medical & $1.300(2.938)$ & $1.530(2.624)$ & $1.183(2.195)$ & $0.287(2.223)$ \\
\hline Prop. Nurse & $-0.100(1.324)$ & $-1.097(1.309)$ & $-1.108(1.258)$ & $-0.909(1.222)$ \\
\hline \multicolumn{5}{|l|}{ HRM } \\
\hline Ideas & $0.238(0.274)$ & & & \\
\hline Decisions & & $0.418(0.391)$ & & \\
\hline Communication & & & $-0.355(0.482)$ & \\
\hline Feedback & & & & $-0.122(0.404)$ \\
\hline Flexible & $-0.502(0.395)$ & $-0.370(0.391)$ & $-0.341(0.350)$ & $-0.215(0.320)$ \\
\hline Training & $0.549(0.364)$ & $0.765(0.376)^{* *}$ & $0.807(0.379)^{* *}$ & $0.545(0.358)$ \\
\hline \multicolumn{5}{|l|}{ Averages } \\
\hline Ideas & $1.982(0.990)^{* *}$ & & & \\
\hline Decisions & & $2.365(1.195)^{* *}$ & & \\
\hline Communication & & & $2.951(1.417)^{* *}$ & \\
\hline Feedback & & & & $2.984(1.522)^{*}$ \\
\hline Flexible & $0.862(1.006)$ & $1.162(1.012)$ & $1.500(0.777)^{*}$ & $1.278(0.895)$ \\
\hline Training & $-0.307(0.561)$ & $-0.434(0.694)$ & $-0.775(0.647)$ & $-0.580(0.666)$ \\
\hline \multicolumn{5}{|l|}{ Year Dummies } \\
\hline $2011 / 12$ & $-16.974(10.065)^{*}$ & $-14.645(9.605)$ & $-12.626(8.996)$ & $-9.288(9.077)$ \\
\hline $2012 / 13$ & $-24.185(11.085)^{* *}$ & $-21.887(11.847)^{*}$ & $-18.092(10.935)^{*}$ & $-17.047(11.115)$ \\
\hline$R^{2}$ & 0.185 & 0.189 & 0.222 & 0.178 \\
\hline $\operatorname{Adj} . R^{2}$ & 0.168 & 0.170 & 0.200 & 0.160 \\
\hline$N$ & 223 & 217 & 216 & 208 \\
\hline
\end{tabular}

Table R4 reports the results for the quality-adjusted labour productivity measure for the sub-samples where the within-hospital means of the senior management variables exceed their medians. Column 1 through 4 each includes a set of not highly correlated management variables. Management variables are lagged by one year. The coefficients of the original-form variables report FE estimates and the coefficients of the within-group means report RE estimates. The columns include time dummies and other controls. Robust standard errors are in parentheses. ${ }^{* * *} p<0.01,{ }^{* *} p<0.05,{ }^{*} p<0.1$. 
Table R5: Total Factor Productivity: Incentives \& Workplace Flexibility

\begin{tabular}{|c|c|c|c|c|}
\hline & (1) & (2) & (3) & (4) \\
\hline Intercept & $-458.4(281.5)$ & $-519.3(286.1)^{*}$ & $-517.2(287.7)^{*}$ & $-505.0(282.1)^{*}$ \\
\hline \multicolumn{5}{|l|}{ Structural } \\
\hline Teaching Trust & $21.16(12.32)^{*}$ & $29.03(11.99)^{* *}$ & $27.60(12.27)^{* *}$ & $27.15(11.89)^{* *}$ \\
\hline Foundation Trust & $15.77(7.179)^{* *}$ & $20.33(7.870)^{* *}$ & $19.96(7.886)^{* *}$ & $17.03(7.403)^{* *}$ \\
\hline Hospital Beds & $-0.008(0.013)$ & $-0.014(0.013)$ & $-0.013(0.013)$ & $-0.012(0.013)$ \\
\hline \multicolumn{5}{|l|}{ Regional } \\
\hline MFF & $-1.180(1.058)$ & $-1.157(1.119)$ & $-1.227(1.125)$ & $-0.880(1.074)$ \\
\hline GP per 100,000 & $2.045(0.974)^{* *}$ & $2.029(0.976)^{* *}$ & $2.050(0.975)^{* *}$ & $2.116(0.929)^{* *}$ \\
\hline \multicolumn{5}{|l|}{ Patient } \\
\hline Prop. Emergency & $-1.022(0.736)$ & $-1.045(0.770)$ & $-0.994(0.770)$ & $-1.154(0.754)$ \\
\hline Prop. Female & $3.460(2.485)$ & $3.625(2.554)$ & $3.672(2.558)$ & $3.273(2.525)$ \\
\hline Patients aged $0-14$ & $3.804(2.122)^{*}$ & $4.183(2.092)^{* *}$ & $4.075(2.095)^{*}$ & $4.197(2.124)^{* *}$ \\
\hline Patients aged $45-59$ & $7.879(3.355)^{* *}$ & $8.503(3.571)^{* *}$ & $8.690(3.504)^{* *}$ & $8.063(3.622)^{* *}$ \\
\hline Patients aged over 60 & $2.729(1.287)^{* *}$ & $3.425(1.266)^{* * *}$ & $3.330(1.274)^{* * *}$ & $3.318(1.280)^{* * *}$ \\
\hline \multicolumn{5}{|l|}{ Skill-Mix } \\
\hline Prop. Medical & $-0.109(1.819)$ & $-0.069(1.884)$ & $-0.047(1.901)$ & $-0.171(1.836)$ \\
\hline Prop. Nurse & $0.486(0.862)$ & $0.321(0.941)$ & $0.421(0.936)$ & $0.283(0.919)$ \\
\hline \multicolumn{5}{|c|}{ HRM Variables $\mathcal{E}$ Interactions } \\
\hline Flexible & $-0.753(0.243)^{* * *}$ & $-0.684(0.246)^{* * *}$ & $-0.606(0.246)^{* *}$ & $-0.596(0.243)^{* *}$ \\
\hline Avg. Flex & $0.295(0.580)$ & $0.686(0.624)$ & $0.616(0.603)$ & $0.454(0.616)$ \\
\hline milFlex & $0.639(0.217)^{* * *}$ & $0.010(0.142)$ & $-0.177(0.159)$ & $-0.516(0.144)^{* * *}$ \\
\hline \multicolumn{5}{|l|}{ Year Dummies } \\
\hline $2011 / 12$ & $-13.323(6.181)^{* *}$ & $-15.776(6.218)^{* *}$ & $-14.993(6.207)^{* *}$ & $-16.437(6.229)^{* * *}$ \\
\hline $2012 / 13$ & $-17.791(7.627)^{* *}$ & $-21.010(7.911)^{* * *}$ & $-20.160(7.841)^{* *}$ & $-21.383(7.931)^{* * *}$ \\
\hline$R^{2}$ & 0.144 & 0.117 & 0.118 & 0.135 \\
\hline Adj. $R^{2}$ & 0.138 & 0.112 & 0.113 & 0.129 \\
\hline$N$ & 420 & 420 & 420 & 420 \\
\hline
\end{tabular}

Table R5 segments the data according to the four quartiles of the within-group mean of the variable Intention-to-Leave to investigate the interaction between incentives and workplace flexibility (Flexible). Column 1 reports the results for hospitals where within-group mean of Intention-to-leave is below or equal to the first quartile. Columns 2 through 4 respectively reports the results for the remaining quartiles. The dependent variable in all the models is the quality-adjusted total factor productivity measure. In addition to the interaction term miFlex, Flexible appears in each column twice: once in its original form and once as a within-hospital mean. The coefficient of the original-form variable reports the fixed effects estimate and the coefficient of the within-group mean reports the random effects estimate. All the models include year dummies. Robust standard errors are given in parentheses. ${ }^{* * *} p<0.01,{ }^{* *} p<0.05,{ }^{*} p<0.1$. 
Table R6: Labour Productivity: Incentives \& Workplace Flexibility

\begin{tabular}{|c|c|c|c|c|}
\hline & (1) & (2) & (3) & (4) \\
\hline Intercept & $-416.9(292.3)$ & $-476.0(296.3)$ & $-473.5(297.8)$ & $-466.6(292.8)$ \\
\hline \multicolumn{5}{|l|}{ Structural } \\
\hline Teaching Trust & $24.39(13.24)^{*}$ & $32.59(12.83)^{* *}$ & $31.16(13.10)^{* *}$ & $30.69(12.78)^{* *}$ \\
\hline Foundation Trust & $19.70(7.366)^{* * *}$ & $24.19(8.172)^{* * *}$ & $23.77(8.176)^{* * *}$ & $21.06(7.661)^{* * *}$ \\
\hline Hospital Beds & $-0.005(0.013)$ & $-0.011(0.013)$ & $-0.011(0.013)$ & $-0.010(0.013)$ \\
\hline \multicolumn{5}{|l|}{ Regional } \\
\hline MFF & $-1.097(1.127)$ & $-1.084(1.193)$ & $-1.152(1.200)$ & $-0.803(1.152)$ \\
\hline GP per 100,000 & $1.864(1.001)^{*}$ & $1.845(1.008)^{*}$ & $1.867(1.005)^{*}$ & $1.937(0.962)^{* *}$ \\
\hline \multicolumn{5}{|l|}{ Patient } \\
\hline Prop. Emergency & $-1.394(0.754)^{*}$ & $-1.415(0.789)^{*}$ & $-1.364(0.791)^{*}$ & $-1.528(0.772)^{* *}$ \\
\hline Prop. Female & $2.749(2.627)$ & $2.922(2.691)$ & $2.962(2.698)$ & $2.585(2.665)$ \\
\hline Patients aged 0-14 & $3.753(2.239)^{*}$ & $4.125(2.204)^{*}$ & $4.010(2.210)^{*}$ & $4.178(2.238)^{*}$ \\
\hline Patients aged 45-59 & $8.301(3.526)^{* *}$ & $8.883(3.726)^{* *}$ & $9.072(3.663)^{* *}$ & $8.520(3.777)^{* *}$ \\
\hline Patients aged over 60 & $2.466(1.346)^{*}$ & $3.164(1.321)^{* *}$ & $3.068(1.331)^{* *}$ & $3.080(1.338)^{* *}$ \\
\hline \multicolumn{5}{|l|}{ Skill-Mix } \\
\hline Prop. Medical & $1.866(1.913)$ & $1.908(1.987)$ & $1.931(1.999)$ & $1.791(1.937)$ \\
\hline Prop. Nurse & $0.088(0.863)$ & $-0.097(0.950)$ & $-0.000(0.941)$ & $-0.100(0.922)$ \\
\hline \multicolumn{5}{|c|}{ HRM Variables E Interactions } \\
\hline Flexible & $-0.648(0.241)^{* * *}$ & $-0.573(0.244)^{* *}$ & $-0.498(0.243)^{* *}$ & $-0.487(0.243)^{* *}$ \\
\hline mFlex & $0.346(0.583)$ & $0.750(0.636)$ & $0.678(0.614)$ & $0.508(0.623)$ \\
\hline milFlex & $0.657(0.228)^{* * *}$ & $0.000(0.143)$ & $-0.177(0.159)$ & $-0.519(0.142)^{* * * *}$ \\
\hline \multicolumn{5}{|l|}{ Year Dummies } \\
\hline $2011 / 12$ & $-13.369(6.296)^{* *}$ & $-15.870(6.362)^{* *}$ & $-15.111(6.334)^{* *}$ & $-16.483(6.363)^{* * *}$ \\
\hline 2012/13 & $-17.387(7.911)^{* *}$ & $-20.651(8.190)^{* *}$ & $-19.826(8.121)^{* *}$ & $-20.998(8.206)^{* *}$ \\
\hline$R^{2}$ & 0.153 & 0.124 & 0.126 & 0.142 \\
\hline Adj. $R^{2}$ & 0.146 & 0.119 & 0.120 & 0.136 \\
\hline$N$ & 420 & 420 & 420 & 420 \\
\hline
\end{tabular}

Table R6 segments the data according to the four quartiles of the within-group mean of the variable Intention-to-Leave to investigate the interaction between incentives and workplace flexibility. Column I reports the results for hospitals where within-group mean of Intention-to-leave is below or equal to the first quartile. Columns 2 through 4 respectively reports the results for the remaining quartiles. The dependent variable in all the models is the quality-adjusted labour productivity measure. In addition to the interaction term milFlex, Flexible appears in each column twice: once in its original form and once as a within-hospital mean. The coefficient of the original-form variable reports the fixed effects estimate and the coefficient of the within-group mean reports the random effects estimate. All the models include year dummies. Robust standard errors are given in parentheses. ${ }^{* * *} p<0.01,{ }^{* *} p<0.05,{ }^{*} p<0.1$. 
Table R7: Total Factor Productivity: Incentives \& Workforce Training

\begin{tabular}{|c|c|c|c|c|}
\hline & (1) & (2) & (3) & (4) \\
\hline Intercept & $-520.4(287.7)^{*}$ & $-610.4(290.1)^{* *}$ & $-631.9(293.8)^{* *}$ & $-586.9(291.7)^{* *}$ \\
\hline \multicolumn{5}{|l|}{ Structural } \\
\hline Teaching Trust & $18.35(12.62)$ & $26.05(11.75)^{* *}$ & $25.38(12.37)^{* *}$ & $25.25(11.98)^{* *}$ \\
\hline Foundation Trust & $13.59(6.752)^{* *}$ & $18.30(7.532)^{* *}$ & $18.18(7.482)^{* *}$ & $15.78(7.252)^{* *}$ \\
\hline Hospital Beds & $-0.006(0.013)$ & $-0.011(0.012)$ & $-0.011(0.013)$ & $-0.011(0.012)$ \\
\hline \multicolumn{5}{|l|}{ Regional } \\
\hline MFF & $-0.989(1.034)$ & $-0.907(1.123)$ & $-0.829(1.132)$ & $-0.601(1.103)$ \\
\hline GP per 100,000 & $2.088(0.950)^{* *}$ & $2.099(0.929)^{* *}$ & $2.124(0.920)^{* *}$ & $2.216(0.876)^{* *}$ \\
\hline \multicolumn{5}{|l|}{ Patient } \\
\hline Prop. Emergency & $-0.953(0.754)$ & $-0.995(0.777)$ & $-0.953(0.784)$ & $-1.016(0.761)$ \\
\hline Prop. Female & $3.520(2.405)$ & $4.079(2.420)^{*}$ & $4.066(2.436)^{*}$ & $3.279(2.466)$ \\
\hline Patients aged $0-14$ & $3.675(2.232)$ & $4.054(2.143)^{*}$ & $4.045(2.172)^{*}$ & $4.003(2.210)^{*}$ \\
\hline Patients aged $45-59$ & $7.646(3.442)^{* *}$ & $8.482(3.556)^{* *}$ & $8.829(3.571)^{* *}$ & $8.021(3.659)^{* *}$ \\
\hline Patients aged over 60 & $2.754(1.323)^{* *}$ & $3.440(1.297)^{* * *}$ & $3.495(1.315)^{* * *}$ & $3.344(1.332)^{* *}$ \\
\hline \multicolumn{5}{|l|}{ Skill-Mix } \\
\hline Prop. Medical & $0.650(1.806)$ & $0.411(1.886)$ & $0.488(1.901)$ & $0.540(1.856)$ \\
\hline Prop. Nurse & $0.290(0.811)$ & $0.140(0.873)$ & $0.182(0.872)$ & $0.126(0.851)$ \\
\hline \multicolumn{5}{|c|}{ HRM Variables \& Interactions } \\
\hline Training & $-0.106(0.190)$ & $0.138(0.244)$ & $0.088(0.241)$ & $0.234(0.241)$ \\
\hline Avg. Training & $0.198(0.442)$ & $0.510(0.449)$ & $0.544(0.458)$ & $0.313(0.437)$ \\
\hline milTrain & $0.796(0.300)^{* * *}$ & $-0.241(0.190)$ & $-0.077(0.231)$ & $-0.617(0.187)^{* * *}$ \\
\hline \multicolumn{5}{|l|}{ Year Dummies } \\
\hline $2011 / 12$ & $-1.702(4.139)$ & $-2.849(4.127)$ & $-2.673(4.210)$ & $-2.871(4.103)$ \\
\hline $2012 / 13$ & $-2.647(4.701)$ & $-4.232(4.838)$ & $-4.420(4.903)$ & $-4.323(4.877)$ \\
\hline$R^{2}$ & 0.134 & 0.109 & 0.106 & 0.121 \\
\hline Adj. $R^{2}$ & 0.129 & 0.104 & 0.101 & 0.116 \\
\hline$N$ & 420 & 420 & 420 & 420 \\
\hline
\end{tabular}

Table R7 segments the data using the within-group mean of the Intention-to-leave variable to investigate the interaction between incentives and workforce training (Training). Column 1 reports the results for hospitals where within-group mean of Intention-to-leave is below or equal to the first quartile. Columns 2 through 4 respectively report the results for the remaining quartiles. The dependent variable in all the models is the quality-adjusted total factor productivity measure. In addition to the interaction term milTrain, Training appears in each column twice: once in its original form and once as a within-hospital mean. The coefficient of the original-form variable reports the fixed effects estimate and the coefficient of the within-group mean reports the random effects estimate. All the models include year dummies. Robust standard errors are given in parentheses. ${ }^{* * *} p<0.01,{ }^{* *} p<0.05,{ }^{*} p<0.1$. 
Table R8: Labour Productivity: Incentives \& Workforce Training

\begin{tabular}{|c|c|c|c|c|}
\hline & (1) & (2) & (3) & (4) \\
\hline Intercept & $-488.6(297.1)$ & $-581.8(298.8)^{*}$ & $-602.9(302.1)^{* *}$ & $-558.9(299.7)^{*}$ \\
\hline \multicolumn{5}{|l|}{ Structural } \\
\hline Teaching Trust & $21.73(13.55)$ & $29.76(12.61)^{* *}$ & $29.08(13.24)^{* *}$ & $28.98(12.88)^{* *}$ \\
\hline Foundation Trust & $17.28(6.868)^{* *}$ & $22.00(7.758)^{* * *}$ & $21.87(7.713)^{* * *}$ & $19.46(7.444)^{* * * *}$ \\
\hline Hospital Beds & $-0.003(0.013)$ & $-0.008(0.012)$ & $-0.008(0.012)$ & $-0.008(0.012)$ \\
\hline \multicolumn{5}{|l|}{ Regional } \\
\hline MFF & $-0.897(1.095)$ & $-0.817(1.191)$ & $-0.741(1.201)$ & $-0.499(1.171)$ \\
\hline GP per 100,000 & $1.936(0.967)^{* *}$ & $1.947(0.950)^{* *}$ & $1.971(0.942)^{* *}$ & $2.070(0.899)^{* *}$ \\
\hline \multicolumn{5}{|l|}{ Patient } \\
\hline Prop. Emergency & $-1.316(0.768)^{*}$ & $-1.354(0.791)^{*}$ & $-1.312(0.799)$ & $-1.375(0.770)^{*}$ \\
\hline Prop. Female & $2.987(2.533)$ & $3.572(2.549)$ & $3.561(2.563)$ & $2.749(2.584)$ \\
\hline Patients aged $0-14$ & $3.659(2.348)$ & $4.055(2.257)^{*}$ & $4.043(2.286)^{*}$ & $4.003(2.324)^{*}$ \\
\hline Patients aged $45-59$ & $8.103(3.621)^{* *}$ & $8.987(3.727)^{* *}$ & $9.325(3.737)^{* *}$ & $8.500(3.817)^{* *}$ \\
\hline Patients aged over 60 & $2.536(1.382)^{*}$ & $3.242(1.351)^{* *}$ & $3.294(1.372)^{* *}$ & $3.146(1.388)^{* *}$ \\
\hline \multicolumn{5}{|l|}{ Skill-Mix } \\
\hline Prop. Medical & $2.501(1.923)$ & $2.259(2.011)$ & $2.335(2.020)$ & $2.378(1.977)$ \\
\hline Prop. Nurse & $-0.110(0.815)$ & $-0.265(0.878)$ & $-0.221(0.875)$ & $-0.251(0.856)$ \\
\hline \multicolumn{5}{|c|}{ HRM Variables E Interactions } \\
\hline Training & $-0.148(0.186)$ & $0.101(0.237)$ & $0.053(0.234)$ & $0.205(0.234)$ \\
\hline Avg. Training & $0.339(0.441)$ & $0.665(0.451)$ & $0.699(0.461)$ & $0.456(0.439)$ \\
\hline milTrain & $0.823(0.312)^{* * *}$ & $-0.239(0.188)$ & $-0.080(0.230)$ & $-0.648(0.190)^{* * *}$ \\
\hline \multicolumn{5}{|l|}{ Year Dummies } \\
\hline $2011 / 12$ & $-3.919(4.129)$ & $-5.095(4.162)$ & $-4.911(4.223)$ & $-5.080(4.131)$ \\
\hline $2012 / 13$ & $-5.044(4.820)$ & $-6.687(4.987)$ & $-6.863(5.050)$ & $-6.740(5.026)$ \\
\hline$R^{2}$ & 0.149 & 0.122 & 0.119 & 0.135 \\
\hline Adj. $R^{2}$ & 0.142 & 0.117 & 0.114 & 0.129 \\
\hline$N$ & 420 & 420 & 420 & 420 \\
\hline
\end{tabular}

Table R8 segments the data using the within-group mean of the Intention-to-leave variable to investigate the interaction between incentives and workforce training (Training). Column 1 reports the results for hospitals where within-group mean of Intention-to-leave is below or equal to the first quartile. Column 2 through 4 respectively report the results for the remaining quartiles. The dependent variable in all the models is the quality adjusted labour productivity measure. In addition to the interaction term milTrain, Training appears in each column twice: once in its original form and once as a within-hospital mean. The coefficient of the original-form variable reports fixed effects estimates and the coefficient of the within-group mean reports random effects estimates. All the models include year dummies. Robust standard errors are given in parentheses. ${ }^{* * *} p<0.01,{ }^{* *} p<0.05,{ }^{*} p<0.1$. 
Table R9: Interaction Models: Human Capital Measures

\begin{tabular}{|c|c|c|c|c|c|c|}
\hline & (1) & (2) & (3) & (4) & (5) & (6) \\
\hline Intercept & $-435.9(267.0)$ & $-419.9(265.5)$ & $-417.3(267.2)$ & $-390.6(280.0)$ & $-375.0(278.3)$ & $-374.3(279.7)$ \\
\hline \multicolumn{7}{|l|}{ Structural } \\
\hline Teaching Trust & $16.14(10.62)$ & $14.73(10.68)$ & $15.62(10.81)$ & $20.35(11.503)^{*}$ & $18.86(11.604)$ & $19.76(11.74)^{*}$ \\
\hline Foundation Trust & $15.39(7.648)^{* *}$ & $14.707(7.536)^{*}$ & $15.47(7.543)^{* *}$ & $19.86(7.837)^{* *}$ & $19.18(7.714)^{* *}$ & $19.87(7.727)^{* *}$ \\
\hline Hospital Beds & $0.000(0.012)$ & $0.002(0.012)$ & $0.001(0.012)$ & $-0.000(0.012)$ & $0.002(0.012)$ & $0.001(0.012)$ \\
\hline \multicolumn{7}{|l|}{ Regional } \\
\hline MFF & $-1.744(1.206)$ & $-1.892(1.170)$ & $-1.662(1.170)$ & $-1.692(1.336)$ & $-1.848(1.300)$ & $-1.627(1.297)$ \\
\hline GP per 100,000 & $2.257(0.923)^{* *}$ & $2.190(0.930)^{* *}$ & $2.195(0.933)^{* *}$ & $2.151(0.949)^{* *}$ & $2.091(0.956)^{* *}$ & $2.097(0.960)^{* *}$ \\
\hline \multicolumn{7}{|l|}{ Patient } \\
\hline Prop. Emergency & $0.807(1.412)$ & $0.790(1.394)$ & $0.324(1.391)$ & $0.724(1.402)$ & $0.707(1.388)$ & $0.270(1.381)$ \\
\hline Prop. Female & $3.162(2.458)$ & $3.153(2.443)$ & $2.988(2.451)$ & $2.478(2.622)$ & $2.471(2.609)$ & $2.330(2.613)$ \\
\hline Patients aged 0-14 & $4.991(2.206)^{* *}$ & $5.153(2.168)^{* *}$ & $4.921(2.166)^{* *}$ & $4.647(2.318)^{* *}$ & $4.818(2.278)^{* *}$ & $4.606(2.274)^{* *}$ \\
\hline Patients aged $45-59$ & $8.565(3.747)^{* *}$ & $8.744(3.729)^{* *}$ & $8.244(3.718)^{* *}$ & $8.987(3.917)^{* *}$ & $9.158(3.895)^{* *}$ & $8.710(3.887)^{* *}$ \\
\hline Patients aged over 60 & $3.440(1.256)^{* * *}$ & $3.451(1.245)^{* * *}$ & $3.380(1.247)^{* * *}$ & $3.106(1.327)^{* *}$ & $3.121(1.316)^{* *}$ & $3.060(1.318)^{* * *}$ \\
\hline \multicolumn{7}{|l|}{ Skill-Mix } \\
\hline Prop. Medical & $-1.878(1.846)$ & $-0.738(1.811)$ & $-0.646(1.795)$ & $-1.581(1.773)$ & $-0.529(1.738)$ & $-0.447(1.726)$ \\
\hline Prop. Nurse & $-0.331(0.936)$ & $-0.638(0.882)$ & $-0.289(0.922)$ & $-0.744(0.919)$ & $-1.033(0.882)$ & $-0.701(0.911)$ \\
\hline \multicolumn{7}{|l|}{ Averages } \\
\hline Prop. Medical & $2.988(3.700)$ & $2.906(3.686)$ & $2.714(3.697)$ & $3.798(3.915)$ & $3.730(3.902)$ & $3.550(3.915)$ \\
\hline Prop. Nurse & $-0.459(1.744)$ & $-0.522(1.730)$ & $-0.580(1.744)$ & $0.419(1.766)$ & $0.368(1.758)$ & $0.309(1.767)$ \\
\hline Prop. Emergency & $-2.584(1.401)^{*}$ & $-2.653(1.396)^{*}$ & $-2.493(1.408)^{*}$ & $-3.058(1.381)^{* *}$ & $-3.126(1.380)^{* *}$ & $-2.974(1.386)^{* *}$ \\
\hline \multicolumn{7}{|l|}{ Interactions } \\
\hline dMPropmed & $1.792(0.628)^{* * * *}$ & & & $1.645(0.639)^{* *}$ & & \\
\hline dMPropnurse & & $0.798(0.234)^{* * *}$ & & & $0.754(0.237)^{* * *}$ & \\
\hline dMEmer & & & $0.599(0.194)^{* * *}$ & & & $0.563(0.195)^{* * * *}$ \\
\hline \multicolumn{7}{|l|}{ Year Dummies } \\
\hline $2011 / 12$ & $-2.517(3.830)$ & $-2.433(3.826)$ & $-2.593(3.829)$ & $-2.664(3.826)$ & $-2.584(3.822)$ & $-2.735(3.826)$ \\
\hline $2012 / 13$ & $-3.982(5.196)$ & $-3.872(5.143)$ & $-4.116(5.168)$ & $-5.240(5.317)$ & $-5.130(5.270)$ & $-5.359(5.293)$ \\
\hline$R^{2}$ & 0.128 & 0.135 & 0.132 & 0.137 & 0.144 & 0.141 \\
\hline $\operatorname{Adj} \cdot R^{2}$ & 0.122 & 0.129 & 0.126 & 0.131 & 0.137 & 0.135 \\
\hline$N$ & 416 & 416 & 416 & 416 & 416 & 416 \\
\hline
\end{tabular}




\section{References}

Aragon, M. J. A., Castelli, A., Gaughan, J., et al. (2015). Hospital Trusts Productivity in the English NHS: Uncovering Possible Drivers of Productivity Variations. CHE Research Paper 117. University of York.

Castelli, A., Street, A., Verzulli, R., and Ward, P. (2015). Examining Variations in Hospital Productivity in the English NHS. The European Journal of Health Economics, 16(3):243-254.

Dunleavey, P. and Carrera, L. N. (2010). Why Does Productivity Vary Across NHS Hospital Trusts in England? Untangling How Management Competence and the Use of ICTs Shape Hospitals' Performance. Political Studies Association Conference, Edinburgh. 